\title{
E1 segundo sistema de funciones como marco definitorio de la escala psicológica
}

Juan Bautista Fuentes*

Universidad Complutense

\section{○. INTRODUCCION}

Me parece que debo comenzar esta charla señalando una advertencia: voy a presentar aquí un trabajo de naturaleza filosófica y no psicológico-científica; además, apenas mencionaré la psicología del procesamiento de información, que es el tema que ocupa estas jornadas. Mis intereses, en esta ocasión al menos, son de naturaleza filosófica muy general, aunque, por descontado, de filosofía de là ciencia o epistemología, y en particular de epistemología de la psicología. Con todo, me apresuro a decir inmediatamente, ante una audiencia que supongo compuesta principalmente de psicólogos y de personas interesadas en psicología, que no me gustaría que estas palabras de advertencia suscitasen en ustedes ciertas reservas o espectativas negativas, que todos conocemos frente a la filosofía. Todo lo contrario, mis propios planteamientos filosóficos, que van en la línea de una filosofía de la praxis, conciben a la propia filosofía como algo que no puede, ni debe, imponer, legislar, prescribir, ni justificar, normativa alguna con respecto a cualquier práctica humana - tampoco, en consecuencia, a las prácticas científicas--, antes bien, desde mi perspectiva prag- mática todas las prácticas se justifican por sí mismas, y las cientificas de manera eminente, por lo que a lo más a lo que puede, y debe, aspirar la filosofía es a entender lo que podriamos llamar la estructura interna de esa propia autojustificación práctica. Así pues, voy a intentar esbozar aquí algunas reflexiones epistemológicas conducentes a esclarecer ciertas características a mi juicio esenciales del campo de la psicología científica, precisamente como un campo ya dado a la reflexión epistemológica - si bien dado-baciéndose, desde luego- en cuanto que construido por las propias prácticas científicas, y en ningún caso por la reflexión filosófica. En este sentido, mis reflexiones habrán de ser más bien generales y podrán por esto parecer alejadas de muchos problemas específicos que los psicólogos se traen entre manos; con todo, lo cierto es que sólo en el contexto de tales problemas puede ser contrastado el valor que las ideas que expondré puedan tener.

Para llevar a cabo este objetivo me parece conveniente comenzar por poner en tela de juicio el concepto kuhniano de paradigma, así como el uso que de él viene haciéndose en buena parte de la comunidad psicológica misma.

* Dirección del autor: Departamento de Psicología y Antropología. Facultad de Filosofia y C. C. E. E. Universidad Complutense 
I. EL CONCEPTO

DE PARADIGMA

Y SU RELEVANCIA EPISTEMOLOGICA:

LA CUESTION

DE SU APLICABILIDAD A LA PSICOLOGIA

I. Dos son las razones principales por las que considero digno de ser cuestionado críticamente el concepto kuhniano de paradigma. En primer lugar, porque considero que, a pesar del amplio uso que del mismo se viene haciendo, se trata de un concepto que carece de la suficiente potencia epistemológica para clarificar $y$, en ocasiones, para siquiera centrar o enfocar los problemas que con él se pretenden resolver. En segundo lugar, porque la propia comunidad psicológica viene haciendo, a mi juicio, un uso tan amplio y a veces tan indiscriminado de este concepto que ha tendido a potenciar aún más sus propias oscuridades tal y como salió de las manos de Kuhn. En verdad, mi idea es que este concepto presenta, en Kuhn, algunos aspectos notablemente interesantes, así como no pocas ambigüedades y oscuridades, pero creo que el uso que buena parte de la bibliografía psicológica está haciendo de él ha tendido más bien a recoger los aspectos más cuestionables del concepto y a dejar de lado aquellos otros que podrían resultar más fecundos. Como es sabido, el concepto de paradigma ha alcanzado eco en psicología en el seno, principalmente, de los representantes de la llamada psicología cognitiva del procesamiento de información, los cuales se han servido de él para explicarse la transición entre el conductismo y la nueva psicología cognitiva. Al entender al conductismo y al cognitivismo en términos de, respectivamente, paradigma obsoleto y paradigma emergente, la estrategia que estos cognitivistas siguen consiste en mostrar que toda la actividad científica psicológica que actualmente pueda desarrollarse - si quiere, al menos, formar parte de la "ciencia normal" en curso, y no ser considerada como una reliquia histórica- habrá de ser, de un modo u otro, paradigmáticamente cognitiva. Por supuesto, caben también otras posiciones más liberales, que aceptan la mutua convivencia relativamente pacífica de varios paradigmas en la actual psicologia (así, el cognitivismo y el conductismo podrian de este modo compartir el nicho ecológico académico). Basta ahora con decretar el carácter multiparadigmático de la psico- logía, como su supuesto estado de madurez - esto es, basta con introducir esta pequeña modificación ad boc en el pensamiento kuhniano- para sosegar las disputas y resolver, en apariencia al menos, el problema. Lo malo, a mi juicio, de todos estos planteamientos es que fallan por la base, precisamente en cuanto que asumen de un modo $u$ otro la perspectiva impuesta por el concepto de paradigma.

Por decirlo, de momento, en dos palabras: lo radicalmente cuestionable, según lo veo, del uso que en la comunidad psicológica se viene haciendo de este concepto, es que se tiende sistemáticamente a tomat a los contenidos científicos como si fueran sistemas, teorías o representaciones filosóficas del campo, en conjunción con las supuestas metodologias más adecuadas a aquellas teorías filosóficas para investigar dicho campo. De este modo, no es infrecuente el caso en el que lo que los psicólogos nos ofrecen cuando polemizan sobre sus supuestos respectivos paradigmas -en discusiones en las que se contrastan, por ejemplo, el paradigma cognitivo y el conductista - no son sino polémicas puramente filosóficas, y ya no sólo en el sentido - que parece aceptable - de que todo científico se instala, lo quiera o no, en un plano filosófico, o epistemológico, cuando se representa su propia empresa científica, sino en el sentido, que parece ya menos aceptable, de que semejantes representaciones epistemológicas perciben a la empresa científica como si no consistiese ella misma más que en modelos filosóficos del campo. En este sentido, algunas polémicas, planteadas de este modo, corren el riesgo de derivar en una discusión entre lo que podríamos llamar ontologías regionales distintas, o, acaso mejor, entre distintas antropologias filosóficas relativas a la naturaleza del hombre y de la acción humana, asi como de las respectivas metodologías más idóneas para enfocar el conocimiento de aquellos campos ontológicamente predelimitados. Dicho crudamente, de lo que se trata es de saber si los psicólogos, al margen de sus relaciones socioacadémicas, son simplemente filósofos propagandistas del método y de la temática científicos, o si son algo más y/o algo distinto -en algún sentido efectivo: si son cientificos--. Mi posición al respecto es que la psicología, además de la compleja red de instituciones socioculturales en las que se asienta en las que, como parece natural, hay de todo- si contiene algo más y/o distinto que propaganda del método 
y del objeto supuestamente científicos, esto es, que si es una forma de práctica científica; mas sostengo que para percatarnos de esto es menester, precisamente, abandonar la perspectiva epistemológica impuesta por el concepto kuhniano de paradigma, y situarnos en otras coordenadas.

2. Como es sabido, la obra de Kuhn es considerada por muchos como constituyendo, dentro del panorama de lo que suele llamarse la nueva filosofía de la ciencia, una alternativa netamente distinta y crítica a la "concepción heredadan, esto es, ai positivismo lógico. $\dot{A} \mathrm{mi}$ juicio, sin embargo, aunque es cierto que la obra de Kuhn contiene algunos componentes notablemente distintos y valiosamente críticos del positivismo lógico, no es menos cierto que en otros aspectos igualmente importantes no se despega de él, y que incluso en algunos otros respectos queda a la zaga de la propia concepción heredada.

Para explicarles lo que quiero decir, me es imprescindible exponer mi propio diagnóstico de las características filosóficas esenciales del positivismo lógico. A mi juicio, las dos coordenadas más radicalmente esenciales que constituyen la concepción de la racionalidad científica en el positivismo lógico son, en primer lugar, la tajante separación entre contexto de justificación y el contexto de descubrimiento, y en segundo lugar, la concepción de la autonomía significativa del lenguaje observacional en relación con el teórico (a fin de cuentas, como se ve, los dos dogmas señalados por Quine). Pero esto debe ser precisado con cuidado: en realidad, de los dos tópicos, es él primero el que determina y dota de sentido al segundo, esto es, es la concepción logicista o formalista de la racionalidad la que confiere su figura epistemológica a la concepción empirista de la experiencia, en la medida en que, en rigor, la experiencia empírica figura en el positivismo lógico como reducida o pre-contenida en el espacio lógico-formal proposicional, y es sólo en esta medida por lo que es tenida epistemológicamente en cuenta. La cuestión es que la separación entre ambos contextos no implica, desde luego, el rechazo de la evidencia empírica de las cosas que acontecen en el seno del contexto de descubrimiento - los factores psicológicos, sociológicos, históricos, etćetera, que dicho contexto comprende-, sino que consiste en no conceder relevancia epistemológica a semejantes factores. Lo que se supone que es epistemoló- gicamente relevante son las razones que validan, legitiman o justifican nuestras pretensiones de conocimiento, las que lo fundamentan racionalmente, y éstas se resuelven enteramente en el interior de las relaciones lógico-formales de alguna construcción proposicional, de suerte que los procesos o causas empírico-genéticos que involucra la práctica de las ciencias, procesos cuya existencia sin duda no es negada, no tendrían aspecto epistemológico alguno de relevancia que exhibir en relación con aquellas razones lógico-formales justificativas. En este sentido, la experiencia, en cuanto que actividad sensorial, perceptiva, en cuanto que de algún modo acto práctico, no forma parte interna de la racionalidad en el positivismo lógico. Naturalmente, los positivistas lógicos tuvieron que habérselas de algún modo con la experiencia, esto es, tuvieron que recoger la presencia de contenidos empíricos en los lenguajes lógico-formalmente bien hechos, si querían retener alguna distinción válida entre lo que, al margen de su interpretación empírica, sólo sería un cálculo axiomático, y lo que sería un sistema hipotético-deductivo, con contenido empírico, es decir, entre los discursos puramente lógico-formales y los discursos de las ciencias empíricas. Pues bien, aquello que de la experiencia es epistemológicamente recogido como componente interno a la racionalidad, no es sino su - supuesta, naturalmente- estructura lógico-formal. Es, en efecto, la estructura lógico-formal de los enunciados de observación -los enunciados atómicos, protocolarios, básicos o como se les quiera llamar-, lo que constituye las condiciones lógicas de posibilidad del lenguaje empíricamente significativo, esto es, si vale decir, de que el acto de experiencia aporte su información al metabolismo de la racionalidad. Recuérdese cómo el Wittgenstein del Tractatus habló del mundo como el espacio lógico de los hechos posibles, y de los hechos como de los acontecimientos que, diriamos, da la casualidad que acaecen de hecho dentro de ese espacio lógico. O recuérdese los esfuerzos de un Popper por evadir todo atisbo de psicologismo en su concepción de los enunciados básicos, a los cuales concibe estrictamente como consecuencias lógicas deductivas de enunciados teóricos, y de cuya contrastación directa con la experiencia ha pretendido incluso dar cuenta en términos de nuevas relaciones lógicas deductivas, lo que, como es sabido, le lleva a un regreso lógico infinito irresoluble. 


\section{Estudios}

Así pues, la tesis de la neutralidad o independencia significativa de la experiencia, la concepción empirista de la experiencia es en el positivismo lógico una tesis lógica que resulta de la conjunción de estas dos presuposiciones: la que asume que una estructura lógico-proposicional es, de suyo, significativamente vacía, y la que asume que todo el contenido semántico que pueda recibir dicha estructura le viene ya reducido o asimilado a través de esta estructura lógica. Es, por tanto, la separación epistemológica entre lenguaje como espacio lógico de la racionalidad y experiencia como acto práctico, lo que implica que todo lo que la experiencia aporte a dicha racionalidad ha de venir, por así decirlo, despiezado en unidades de información que tengan la estructura lógica misma del lenguaje. Además, en la medida en que se supone que la estructura lógica es de suyo semánticamente vacía y que todo lo que hace con las unidades empíricas de información es someterlas a un metabolismo puramente lógico, esto es, a transformaciones tautológicas que para nada afectarian a sus significados, éstos, de hecho - el aspecto semántico, digamos- quedan expulsados fuera del lenguaje, depositándoselos, por así decir, en los referentes mismos. Por lo demás, en la medida en que se supone que la experiencia viene reducida por su espacio lógico, se asume una concepción atómica de esta experiencia en donde cada unidad de información sería de este modo semánticamente inmodificable, poseyendo un significado completo y cerrado en si mismo, impenetrable, al modo de átomos de información. En resumidas cuentas, ambas suposiciones, la de que la experiencia nos informa en términos de unidades discretas o atómicas, y en términos de significados neutrales o independientes - en realidad, independientes de todo lenguaje-, son en rigor, como he pretendido hacer ver, dos tesis lógicas.

Merece la pena ahora que consideremos ciertas características filosóficas que se desprenden de esta concepción formalista (o logicista) - proposicionalista - de la racionalidad, para poder contrastar con ellas otros rasgos de la concepción kuhniana.

En primer lugar, cabría destacar la concepción teoreticista de la ciencia y de la razón, o acaso mejor, de las relaciones entre teoría. y práctica en las ciencias, que de aquella coordenada formalista se desprende. Podemos considerar, según propongo, como teoreticista, en un sentido suficientemente amplio, a la posición que mantiene que existe algo así como un espacio teórico, o cognoscitivo, de suyo independiente (previo o aislado) del resto de la práctica o acción humana, y en cuyo seno independiente cabría detectar, a su vez, los fundamentos, los criterios de justificación, del conocimiento. El positivismo lógico ha desarrollado de un modo extremadamente consecuente la posición teoreticista, precisamente al deslindar tajantemente el contexto racional o cognoscitivo lógico-proposicional del contexto de actividades prácticas cuya realidad, como he dicho, no tiene que ser negada, sino tan sólo epistemológicamente obviada como no relevante con respecto al contexto de racionalidad. En este sentido, la posición crítica del teoreticismo es la que podemos denominar pragmatismo, el cual ya no consistiría simplemente en dirigir la mirada al contexto práctico de descubrimiento, sino en hacerlo desde la concepción de que al menos importantes fragmentos de semejante contexto práctico si constituyen componentes internos y relevantes de la propia racionalidad. Por supuesto, en esto va a residir lo más sugerente de la aportación de Kuhn a la epistemología, así como la de otros autores, como Hanson y Feyerabend.

Pero, antes de pasar a Kuhn, me interesa señalar que aquel teoreticismo de la concepción heredada, acarrea, a su vez, una doble concepción idealista, un idealismo objetivo y un idealismo subjetivo. En efecto, la ubicación de la racionalidad, o el conocimiento, en un espacio lógico-proposicional, implica que ni tan siquiera podamos hablar, en rigor, del conocimiento como representaciones cognitivas, en cuanto que éstas dicen inevitable relación con algún sujeto empírico, psicológico, con algún sujeto pragmático que posea, ejecute o realice el conocimiento de algún modo. El conocimiento, como entidad epistémica, seria por tanto algo ajeno a los sujetos pragmáticos -diríamos, de carne y hueso-, en cuanto que se trata de una estructura objetiva, que no subjetiva, y su objetividad, naturalmente, no es físico-empírica, sino objetivo-ideal (lógicoobjetivo-ideal): trátase de una objetividad ciertamente trascendental, que a lo que más se parece, más aún que al sujeto trascendental kantiano, es al mundo platónico de las ideas, o sea, al tercer mundo de Popper. Por supuesto, Popper no ha descubierto nada nuevo con su tercer mundo: no ha hecho sino explicar 


\section{Estudios}

abiertamente el lugar ontológico que desde siempre ocupó la racionalidad en la concepción lógico-positivista.

Pues bien, la cuestión es, ahora, que semejante idealismo objetivo sólo puede desarrollarse consecuentemente, cuando pretende hacerse de algún modo cargo de las relaciones entre aquel mundo platónico y el mundo pragmático en donde también parece tener lugar el conocimiento, como idealismo subjetivo, o, como prefiero llamarlo, como idealismo de la praxis.

Me interesa destacar ahora un par de cuestiones derivadas de dicho idealismo de la praxis, las que tienen que ver con el sujeto agente de la ciencia, con los científicos y con la historia de la ciencia; pues en estos puntos, como luego veremos, van a aparecérsenos ciertas coincidencias esenciales entre Kuhn y el positivismo lógico. Significativamente, la historiografia de corte positivista se ve sumida en una suerte de peculiar tensión esquizoide: por un lado, aquello que debería ser historiado, según nos pide el modelo de ciencia del que partimos, sería una serie de secuencias lógicas deductivas que irian encajando unas con otras según el modelo de la explicación reductiva (como clásicamente señalaron $\mathrm{Hem}$ pel y Nagel), y que irían dejando como resultado un acúmulo cada vez más amplio de dominios observacionales - una acumulación de hechos empíricos que irian rellenando, no se olvide, el espacio lógico de todos los hechos posibles. Ocurre, sin embargo, que los cielos platónicos siempre han sido muy reacios a dejarse historiar, y cuando es el historiador el que se enfrenta a la tarea de hacer historia de una ciencia, le resulta sumamente difícil encontrar entre los materiales de este mundo con los que trabaja algo que se parezca a aquel modelo ideal. La consecuencia práctica de esto es que aquéllo que de hecho nos ofrece la historiografía de factura positivista no es más que lo que bien podríamos llamar un conjunto de "historietas» más bien ajenas a cualquier control racional, externas a cualquier criterio epistemológico mínimamente sólido. Ciertamente, desde el momento en que el historiador no encuentra en la historia del contexto de descubrimiento algo que se parezca al modelo ofrecido por el contexto de justificación, cualquier registro histórico viene a ser válido; en cierto modo, todo es posible, diríamos, todo vale porque nada vale. Desde luego, de entre las más significativas historietas que la historiografia positivista nos ofrece, ocupan un lugar notable las biografias: la historia de la ciencia aparece cuajada de personalidades relevantes, ingeniosas, llenas de talento y sagacidad o, en resumidas cuentas, plagada de cualquier tipo de invenciones psicológicas que actúan como pseudoexplicaciones ad boc, para cubrir la laguna entre el contexto de justificación y el contexto de descubrimiento. Ahora bien, de entre estas explicaciones imaginarias hay una que tiene un eminente significado filosófico: se trata de concebir al sujeto científico como un sujeto individual, libre y racional. El sujeto aparece aquí como un individuo también atómico, desconectado de las condiciones sociales (como pide, por cierto, la ideología liberal), de manera que, en la medida en que se le piensa como individuo libre de toda condición social, se le puede pensar libre para doblegarse, entregarse captar la racionalidad dada en el tercer mundo. Del mismo modo a como Platón recurrió al mito de Demiurgo para hacer participar a la materia amorfa preexistente del mundo de las formas de igual modo previamente dado, nos encontramos ahora con otro Demiurgo científico pensado ad boc para que pueda poner en práctica, o realizar en este mundo, el modelo ideal de ciencia, dado en el tercer mundo. Se trata, pues, de una peculiar explicación circular que diseña ad boc al sujeto a partir de unos resultados previamente dados -el contexto mismo de justificación-. En este sentido, esta concepción del sujeto no es sino un componente que funciona dentro de una de las más singulares mitologías producidas por la historiografia positivista: el mito del árbol de las ciencias, como metáfora explicativa del origen y constitución históricos de las mismas. Se trata, en verdad, de una metáfora tan oscura y engañosa como aparente es su claridad, y cuya implantación cultural es tan fuerte que son muchos, cientificos y filósofos de las más diversas disciplinas y credos, quienes la asumen acríticamente con extraordinaria frecuencia y facilidad. Según esta imagen, como se recordará, las ciencias resultan al desprenderse del tronco-madre, que es la filosofia, como consecuencia de la aplicación del método de la ciencia a los temas, áreas u objetos que ofrece dicho tronco, la filosofia. A resultas de la aplicación del supuesto método de la ciencia a los campos ofrecidos por la filosofía, estos últimos quedan ya - como quien diceajustados o recortados por su rasante científi- 
co, y ya tenemos con esto, al parecer, una ciencia en marcha. Aunque la imagen del árbol de las ciencias es un producto cultural más amplio que el positivismo lógico, lo cierto es que éste se aviene perfectamente a aquélla. Repárese, en este sentido, en lo que consiste el método en la concepción positivista lógica: el método no es sino el contexto mismo de justificación pensado abora en su versión normativa. En efecto, el método es ahora un conjunto de condiciones normativas, para hacer ciencia, de tipo lógico-formal, para la correcta construcción lógica de los enunciados y para el establecimiento de las condiciones, asimismo, lógicas de la contratabilidad empirica. De este modo, tal parece como si, una vez en posesión del método como una especie de artefacto previo y/o separado podemos ponernos a hacer ciencias de forma inmediata, simplemente mediante su aplicación. Las ciencias serian entonces el resultado de ponerse a hacer la ciencia. Naturalmente, el sujeto libre y racional puede ocupar ahora una buena función dentro del semejante mecanismo: él es quien, poseyendo previamente el método, lo aplica y hace la ciencia. Por lo demás, repárese en que la única diferencia que habria entre las características universales de la cientificidad, esto es, el modelo ideal de ciencia, que es modelo tanto de los resultados como del método que lleva a ellos, y las ciencias particulares producidas históricamente, no residiria sino en los distintos temas o materias empíricas de las que cada ciencia se ocupa, o sea, a las que se aplica el método universal. Sin duda, esto nos recuerda a la concepción hilemórfica de la tradición escolástico-aristotélica, pues aquí también la materia actuaba como principio de individuación y la forma como principio de especificación. Lo peor de esta manera de ver las cosas es que al estarse sustituyendo el proceso práctico-histórico-real y concreto de constitución y desarrollo de las ciencias por semejante modelo ideal, nos estamos privando de percibir la posible relevancia epistemológica que pudiera tener aquel proceso. Por último, hay un aspecto esencial de la práctica científica que la concepción heredada margina afuera de la racionalidad: se trata del contexto experimental; pero no hablaré ahora de él, sino que volveré a considerarle una vez que hayamos tenido en cuenta a Kuhn, pues, como se verá, la epistemología de este autor nos pone en las puertas mismas del problema del contexto experimental.
3. Desde las coordenadas que he diseñado, puede apreciarse ahora, me parece, con alguna precisión la aportación de la epistemología de Kuhn. Para empezar, Kuhn dirige la atención al interior del contexto de descubrimiento para comprender la empresa científica. De este modo, nuestro autor se sitúa en una perspectiva pragmática frente a la perspectiva teoreticista de la concepción heredada $\mathrm{y}$, en este sentido, se acerca notablemente a desvelar algunos rasgos esenciales de lo que, a mi juicio, constituye el mecanismo interno de la racionalidad cientifica como práctica. Con todo, me parece que Kuhn no acaba por analizar la estructura interna de la práctica científica y es, en esta medida, en la que la explicación sociológica actúa como una cobertura o coartada de la insatisfactoria explicación epistemológica. Intentaré explicarlo.

Como es sabido, en respuesta a las críticas que sufriera su inicial trabajo de i962 La Estructura de las Revoluciones Cientificas, Kuhn escribió algunos artículos posteriores sumamente interesantes: me refiero a su Postdata, de 1969; a su Respuesta a mis criticos, de 1970; y a sus Segundos Pensamientos sobre Paradigmas, asimismo, de 1970. Estos trabajos son, como digo, muy relevantes porque en ellos Kuhn aquilata y clarifica su inicial concepción de paradigma, precisamente al desglosar su en un principio confuso, abigarrado y polisémico sentido en distintos componentes, lo cual nos permite ya saber mejor a qué atenernos a la hora de hacer una evaluación crítica del concepto en cuestión. Como se sabe, en estos trabajos, Kuhn distinguió entre un sentido global del concepto de paradigma, y otros cuatro sentidos relativos a componentes particulares diferenciables dentro de aquel sentido global. En su sentido general, o en palabras del propio Kuhn, en cuanto que «formando una función total o reunida» ${ }^{1}$, el paradigma es denominado ahora matriz disciplinar. "Disciplinar -según Kuhn- porque se refiere a la posesión común de los practicantes de una disciplina individual» ${ }^{2}$ y «matriz - también según sus palabras - porque está compuesta de elementos ordenados de varios tipos, cada uno de los cuales sugiere una especificación posteriors ${ }^{3}$. Como se ve, pues, la matriz disciplinar, en cuanto que disciplinar, tiene que ver con. el aspecto sociológico $o$ de acuerdo de grupo en torno a esos elementos ordenados de la matriz que «requieren especificación ulterior». Estos otros elementos son, 
como se sabe, estos cuatro: «modelos», «valores», "generalizaciones simbólicas» y "ejemplares». Con ellos, Kuhn ya se aproxima al entramado interno de la empresa científica, a los elementos que son compartidos por el grupo; esto es, además de decirnos algo tan obvio y tan simple como que el grupo comparte un paradigma en el sentido de que comparte una disciplina, ahora nos desglosará qué es lo que comparten de esa disciplina los miembros del grupo. Pues bien: los modelos son para Kuhn, como se sabe, aquellos componentes que proporcionan al grupo las añalogias preferidas sobre un objeto de estudio, analogías que pueden tener un valor beurístico y/o ontológico 4. Se trata, pues, del marco de presuposiciones que delinean o diseñan las características generales del campo u objeto de conocimiento, las cuales determinan, por tanto, como Kuhn señala ${ }^{5}$, lo que constituye un problema relevante o no, dentro de la investigación $y$, en consecuencia, lo que es aceptable como explicación del mismo. Los valores, por su parte, según Kuhn nos sugiere, vienen a consistir en ciertos modos de enjuiciar el tipo y alcance de cosas tales como - según los propios ejemplos que Kuhn nos pone-: las predicciones que se consideran aceptables, la compatibilidad entre teorías, su consistencia interna ${ }^{6} \mathrm{y}$, según la propia expresión de Kuhn, «elementos de esta índoles ${ }^{7}$. Aunque Kuhn no haya sido muy explícito en torno a esta cuestión, sí parece, no obstante, bastante claro a qué se está refiriendo: los valores serían, según lo entiendo, algo así como las estrategias metodológicas que se corresponden con aquellos presupuestos que delimitan la naturaleza del campo y que, por tanto, mejor se avendrían para enfocar la investigación.

Las generalizaciones simbólicas nos ponen en presencia de aquellos componentes formales de la teoría, o fácilmente formalizables que, merced a su interpretación empírica o factual, constituyen las leyes de la misma. Según los propios ejemplos de Kuhn, fórmulas tales como $\mathrm{f}=\mathrm{m} . \mathrm{a}, \mathrm{o} I=\mathrm{v} / \mathrm{r}$, pueden adoptar significaciones empíricas cuando se las acopla a la naturaleza en algún contexto experimental determinado, así como pueden recibir diversas reformulaciones a través de contextos experimentales distintos ${ }^{8}$. Estos contextos experimentales concretos son, precisamente, los ejemplares, el cuarto componente en el que Kuhn ha desglosado la matriz disciplinar, y el que constituye, a mi juicio y como ahora veremos, a juicio dèl propio Kuhn, el aspecto epistemológicamente más importante del concepto de paradigma. En efecto, se ha de señalar que ha sido Kuhn quien ha llamado la atención sobre el carácter epistemológicamente prominente del concepto de ejemplar. Según Kuhn, la primera vez que optó por utilizar el término paradigma aquello a lo que queria referirse era a este componente que ulteriormente llamó «ejemplar». En su Postdata, de 1969, por ejemplo, nos dice: "vayamos ahora a la cuarta clase de elemento de la matriz disciplinar... Para el!o, e! término paradigma sería enteramente apropiado, tanto filológica como autobiográficamente; este es el componente de los acuerdos de grupo compartido que primero me guió en la elección de esta palabra. Sin embargo, aquí la sustituiré por ejemplar porque el término paradigma ha tomado una vida que le es propia» ${ }^{9} \mathrm{y}$, poco más adelante, dice: «Más que otros grupos de la matriz disciplinar, las diferencias entre los conjuntos de ejemplares proporcionan la admirable estructura de la comunidad científica» ${ }^{10} \mathrm{y}$, añade, líneas después: «El paradigma como ejemplar compartido es el elemento central de lo que ahora considero el aspecto más original y el menos comprometido de este libro. Por consiguiente, los ejemplares necesitan más atención que otras clases de componentes de la matriz disciplinar" ${ }^{11}$. Se comprende, ciertamente esta importancia que Kuhn concede a los ejemplares en cuanto que éstos son, en efecto, para él, soluciones concretas a problemas concretos que tienen carácter paradigmático (entendido ahora en el sentido usual ordinatio del término, o sea, que tienen carácter ejemplar) precisamente porque dichas soluciones han sido aprendi. das en el contexto práctico de cada situación experimental concreta, de suerte que es a través de dicho aprendizaje en la práctica experimental como los científicos aprenden, asumen o incorporan tácitamente el resto de los componentes del paradigma, o sea, el conjunto de la matriz disciplinar ${ }^{12}$. Ahora bien: una vez que Kuhn nos ha acercado hasta aquí, hasta esta situación práctica concreta y experimental que denomina ejemplar, se le abren, por asi decirlo, dos posibilidades ulteriores: una sería profundizar en la estructura epistemológica interna del ejemplar, precisamente en cuanto que situación eminentemente práctica; la otra, por el contrario, consistiría en limitarse a constatar dicha situación como una especie de situación pragmática de hecho, opaca en último término al análisis epistemológico. El camino que si- 
gue Kuhn es ambiguo: porque, por un lado, adelanta ciertos barruntos sugerentes sobre la posible estructura interna de los ejemplares, que no acaban, sin embargo, por establecer ningún análisis definitivo. En esta medida, los ejemplares acaban siendo en Kuhn una especie de punto ciego al análisis y, por esto mismo, siguen prevaleciendo, a la postre, los modelos y los valores como características más comprensibles o determinantes de lo que sea un paradigma y, es también, por este motivo por el que el factor sociológico -o psicosocialsigue perfilado en primer plano, como la instancia que viene a servir de cobertura aparentemente explicativa a la oscuridad última del concepto de ejemplar.

Para explicar lo que quiero decir, podemos acudir, me parece, a los tres sentidos del término paradigma que Masterman acuñó para agrupar los veintiún sentidos distintos que su crítica textual encontró en el libro Estructura de las Revoluciones Cientificas, e interpretar, a través de estos tres conceptos los distintos sentidos en los que, como acabamos de ver, Kuhn descompusiera la idea de paradigma en los artículos que antes mencionamos. En efecto, estos tres componentes esenciales del concepto de paradigma que Masterman nos ofrece en su artículo de $1970 \mathrm{La}$ Naturaleza de los paradigmas son: los paradigmas metafísicos u ontológicos, los paradigmas sociológicos y los paradigmas artefactos o construcciones ${ }^{13}$. Podemos, ahora, me parece, poner a los modelos y los valores de Kuhn como constituyendo to que Masterman llama los paradigmas metafísicos u ontológicos; ubicar, asimismo, a los ejemplares y a las generalizaciones simbólicas en los artefactos o construcciones $y$, por último, entender el carácter disciplinar o sociológico como el paradigma sociológico de Masterman. En definitiva, lo que Kuhn nos estaria ofreciendo sería esto: entender que un paradigma es un acuerdo de grupo, psicosocial, cuyo contenido vendria dado por un paradigma ontológico, esto es, una Weltanschaung y alguna metodología adecuada a la misma, y un artefacto o construcción experimental, esto es, un conjunto de ejemplares en los que se obtiene ciertas leyes o generalizaciones simbólicas. El problema, entonces, consiste en comprender cuál puede ser el entramado interno de la matriz, el entramado epistemológico entre los paradigmas ontológicos y los artefectos, así como, cuál seria el papel que en relación con este entramado juega el paradig- ma sociológico, esto es, la circunstancia de que la matriz es algo psicosocialmente aprendido y/o compartido por el grupo.

Pues bien: Kuhn ha puesto, en sus últimas obras, todo el peso del conjunto de la matriz en el ejemplar y, más en particular, ha insistido en que las propias leyes sólo llegan a serlo en cuanto que producidas en el seno del ejemplar, del contexto experimental. Son interesantes, a este respecto, por ejemplo, las siguientes palabras suyas: "Generalmente -nos dice en sus Respuesta a mis criticos (1970)-, a estas soluciones de problemas se las considera meras aplicaciones de una teoría que ya se ha aprendido. El estudiante las hace para practicar, para adquirir facilidad en el uso de lo que ya conoce. Es indudable que esta descripción es correcta después de que se hayan hecho bastante problemas, pero no creo que valga nunca para los comienzos. Antes bien, hacer problemas es aprender el lenguaje de una teoría y adquirir el conocimiento de la naturaleza inmerso en ese lenguaje» ${ }^{14}$. En el mismo sentido, se expresa nuestro autor, por ejemplo, en su Postdata, de 1969 , cuando dice: «En general los filósofos de la ciencia no han discutido los problemas con que tropieza el estudiante en los laboratorios o en los textos científicos, porque éstos son pensados para proporcionar sólo práctica en la aplicación de lo que el estudiante ya sabe. El no puede, se dice, resolver problemas, a menos que primero aprenda la teoria y algunas reglas para aplicarla. El conocimiento científico está enclavado dentro de las teorías y reglas; los problemas son proporcionados para lograr destreza en su aplicación. Sin embargo, yo he tratado de demostrar que esta localización del contenido cognoscitivo de la ciencia es errónea. Después de que el estudiante ha resuelto muchos problemas, sólo entonces gana mayor destreza para resolver más. Pero al principio, y después de algún tiempo, el resolver problemas es saber cosas consecuentes sobre la naturaleza. En ausencia de tales ejemplares, las leyes y teoria que con anterioridad ha aprendido podrian tener poco de contenido empíricon" ${ }^{15}$.

Como se ve, al llamar la atención nuestro autor de este modo sobre la circunstancia de que las leyes y teorias no son algo que se posea previamente y que ulteriormente se aplique en la práctica, sino que son más bien el resultado de un aprendizaje implícito que 
tiene lugar manejando ejemplares, está situando a la empresa científica en un contexto claramente práctico, aproximándose, por decirlo asi, al lugar donde, de hecho, ocurriría la construcción científica. Sin embargo, como antes señalé, en este punto podemos o bien retrotraernos hacia una mera constatación del hecho pragmático del aprendizaje psicosocial del manejo de ejemplares o bien avanzar hacia la comprensión de la estructura epistemológica puesta en práctica en aquellos ejemplares. En este sentido, todavía Kuhn nos ofrece algunas sugerencias valiosas, pern que $n n$ acaban, sin embargo, de asaltar el interior del artefacto, del constructo experimental al que nos remite. Como se sabe, lo que Khun viene a decirnos es que los ejemplares son los lugares en donde se ejemplifican experimentalmente las leyes y teorías, esto es, en donde el científico aprende a «ver las cosas» de una determinada manera, o, como el propio Khun nos dice, a percibir las «analogías», "similaridades» o «parecidos» entre los diversos problemas concretos, es decir, a hacerse con una "gestalt conceptual» 16 . Ahora bien: esta referencia al proceso psicológico (o psicosocial) de aprendizaje de "gestalten conceptuales", a la que se añade la referencia al contexto experimental en el que aquéllas serían aprendidas, se aproxima, pero deja, a la postre, sin resolver precisamente el problema esencial: cuál puede ser la relación interna entre el artefacto experimental y dichos enclasamientos conceptuales de la experiencia que, al parecer, tienen lugar en él. Como es sabido, tanto Kuhn como Hanson y el propio Feyerabend han utilizado la, sin duda, interesante idea de gestalt conceptual, o semántica, para fundir de este modo la experiencia perceptual con el lenguaje y en particular con sus contenidos semánticos. Así como en el positivismo lógico no había propiamente contenidos semánticos, sino que los significados residian en los referentes empíricos mismos, ahora el lenguaje aparece cargado semánticamente, de manera que mientras que la experiencia aparecía en el positivismo lógico reducida tan sólo a su supuesta estructura lógico-formal, ahora aparece aqui preconcebida por semejantes gestalten semánticas. Mas la cuestión es si dichas gestalten deben ser entendidas como una suerte de factum lingüístico ya dado, inanalizable en último término, con el que hay que contar como una especie de estructura "a priori» semejante a la estructura lógico-formal en el positivismo lógico, o si por el contrario cabe ponerlo de algún modo en relación intema con el artefacto experimental. La primera alternativa, me parece, es la que cabría denominar proposicionalista, partidaria de un constructivismo o contextualismo puramente proposicional de la experiencia; a la segunda podemos denominar, según propongo, constructivismo práctico-experimental. Según la primera, las entidades lingüisticas se construirian, tanto si son puras estructuras lógicas como si son contenidos semánticos, por medios, por asi decirlo, puramente proposicionales; en la segunda perspectiva, el artefacto experimcntal constituiría un componente interno de la propia construcción proposicional. Pues bien, aunque Kuhn ha sido con toda seguridad quien más se ha aproximado a la segunda perspectiva, al insistir en el contexto experimental como lugar de aprendizaje de estas gestalten, lo cierto es que no nos ha explicitado nunca cuál pudiera ser la relación interna entre ambos aspectos, el experimento y la gestalt conceptual. Todo lo más, se pueden rastrear en su obra algunas sugerencias interesantes. Por ejemplo, en su Postdata, de 1969, Kuhn llega a decirnos que las leyes se aprenden cuando previamente hemos aprendido ya algo sobre las situaciones manejadas en un ejemplar, y apunta que: «esta clase de erudición no es adquirida por medios verbales exclusivamente. Más bien llega como si se dieran a uno, a la par, las palabras y los ejemplos concretos de cómo funcionan en cada caso. Naturaleza y palabras son aprendidas simultáneamente» 17 . He aquí, como se ve, un atisbo que señala la posibilidad de un aprendizaje simultáneo de cosas y palabras en el contexto de ejemplares concretos. Sin embargo, Kuhn sigue sin aclararnos de qué modo el contexto experimental puede constituir un componente interno de semejante aprendizaje simultáneo.

En definitiva, en la medida en que Khun no llega a pronunciarse sobre este punto, su inicial perspectiva pragmática se acaba resolviendo en lo que podemos llamar un pragmatismo proposicionalista, esto es, en la mera constatación de que los científicos cuentan, de hecho, con gestalten conceptuales. $Y$ es ahora, me parece, cuando esta constatación pragmática de un aprendizaje psicosocial se hace indiscriminadamente extensiva a los paradigmas ontológicos, de modo que ejemplares o artefactos y paradigmas ontológicos pueden aparecer, de nuevo, como confundidamente referidos a una posesión pragmática, en defi- 


\section{Estudios}

nitiva inanalizable, que los científicos tendrian. En esta situación, el paradigma sociológico no viene sino a repetir lo que ya tenemos: la constatación de un aprendizaje psicosocial, que sigue sin explicar lo que antes tampoco estaba explicado. En definitiva, identificar un paradigma en primer lugar por medios sociológicos, apelando al grupo que lo comparte y/o a la circunstancia de que ha sido psicosocialmente aprendido, y especificar después el contenido de ese paradigma remitiéndonos de nuevo a la circunstancia de dicho aprendizaje psicosocial, constituye el circulo vicioso que caracteriza a la postre a la obra de Kuhn, cuya más importante característica epistemológica es que elude precisamente el análisis epistemológico de la práctica científico-experimental a la que alude ${ }^{18}$.

4. Se comprende ahora, me parece, la facilidad con la que en el seno de las ciencias humanas, y en la psicología entre ellas, se tiende a centrar más bien la atención en los paradigmas sociológicos y en los ontológicos, obviándose los paradigmas ejemplares o experimentales. En la psicología, en particular, esta situación se recoge muy significativamente en el seno de la atmósfera intelectual desarrollada por la nueva historiografía de corte kuhniano. Como es sabido, en los últimos tiempos viene produciéndose en el ámbito cultural anglosajón una historiografía de la psicología inspirada por la obra de Kuhn que se presenta con visos de novedad en relación con la tradicional historiografia de factura positivista. Sin embargo, me parece que esta historiografía no avanza gran cosa su perspectiva epistemológica de fondo por lo que respecta al enfoque positivista de la historiografía más tradicional. A fin de cuentas, esta nueva historiografia nos viene a presentar cada paradigma psicológico caracterizándolo en términos de la composición entre los presupuestos teóricos -ontológicos - que delinean el campo psicológico de conocimiento y la estrategia metodológica más adecuada, en razón de aquellos presupuestos para acceder a dicho campo, poniéndose a su vez mucho hincapié -eso sí- en los factores sociológicos que involucra la empresa científica. Los ejemplares experimentales suelen ser sistemáticamente eludidos $o$, en todo caso, obviados, aludiéndose a ellos como si fueran el resultado obtenible de la ulterior aplicación, ya en el terreno experimental, de aquel marco de presupuestos teóricos y de su correspondierite método. Cada paradigma aparece, de este modo, como un marco o perspectiva filosófica previa - como una Weltanscbauzng-, de las cuales perspectivas se supone que son susceptibles de desarrollar cada una su propia aplicación experimental - la cual por esto mismo suele ser obviada-, subrayándose - acaso, como toda novedad - la por lo demás trivial circunstancia de que cada paradigma, o la empresa científica en general, es una actividad social (o psicosocial). Mas de este modo esta escolástica kuhniana viene a retroceder en relación con lo más sugerente de lo que el propio Kuhn ya había esbozado en su obra - la importancia decisiva del ejemplar experimental--, neutralizando, e incluso invirtiendo lo más potente de dicha sugerencia, que, como hemos visto, nos dice que es en el seno de los contextos experimentales concretos donde los científicos aprenden sus modelos y valores, y no a la inversa. Por lo demás, la insistencia en los factores sociológicos de la ciencia, sin prejuicio de los análisis, sin duda, pertinentes que en ocasiones produce en un plano genéricamente sociológico, no acaba de superar la propia perspectiva epistemológica de fondo del positivismo lógico, sino que más bien se instala dentro de ella reproduciéndola acríticamente. Intento explicarme en dos palabras.

Por lo que respecta a la cuestión de la relación de predominancia entre el contexto experimental y los modelos ontológicos, quiero subrayar que las dos posibles alternativas que se nos abren a partir de la propia obra kuhniana no constituyen una cuestión secundaria o accidental, sino decisiva -epistemológicamente decisiva. Y no se trata, por cierto, de una cuestión puramente empirica psicológicotemporal- de saber, diriamos, qué ocurre antes y qué después, si el experimento o el marco teórico (como queda planteado, en definitiva, en el propio Kuhn), sino de una cuestión filosófico-epistemológica de fondo insoslayable. Pues si tendemos a concebir el experimento como posible lugar de aplicación de - los distintos- presupuestos ontológicos y metodológicos previos $\mathrm{y} / \mathrm{o}$ independientes, implicamos con ello inevitablemente la idea -filosófica- de que el experimento es algo así como un campo abierto de múltiples posibilidades ontológicas, susceptible de adquirir diversas realizaciones en virtud de la ontología desde la que el experimento se diseña, o de que cualquier ontología es susceptible de realizarse o ser asimilada experimentalmente, como si cada ontología llevase internamente 


\section{Estudios}

acoplada la posibilidad de contener su propio desarrollo experimental. Significativamente, quienes así se representan la ciencia tienden a obviar, de hecho, las construcciones experimentales concretas (ignoran el análisis de la estructura interna de las construcciones experimentales), sujetos, a la postre, a la concepción proposicionalista de la ciencia que entiende que el interior del metabolismo científico se resuelve enteramente en el seno de los lenguajes. Se comprende, entonces, que al caracterizar las diversas realizaciones científicas de las ciencias, el énfasis se ponga en el marco de presupuestos ontológicos y metodológicos, como si éstos fueran los caracteres distintivos de cada realización científica (de cada paradigma, según se nos dice), y se obvie el contexto experimental, como si éste fuese el lugar secundario que, simplemente, bubiese de resultar, según se supone, de la aplicación de aquel marco de presupuestos (como si, diríamos, el lector de estas historias de la ciencia, no tuviese sino que explicitar por su cuenta lo que al parecer vendría ya presupuesto con la mera exposición del paradigma ontológico como anteproyecto teórico y metodológico). Por tomar un ejemplo de la bibliografia reciente 'en este tipo de historiografia psicológica, Thomas Leahey, en su reciente Historia de la Psicologia, de 1980, nos ofrece una paradigmática muestra de esta trivial caracterización de los paradigmas psicológicos en términos de anteproyecto teórico-ontológico y su correspondiente metodología adecuada (el propio término de "anteproyecto", usado para caracterizar al paradigma ontológico es de este autor) ${ }^{19}$. Por cierto que una muestra significativa de la manera como desde esta perspectiva se obvia el contexto experimental la ofrece este autor cuando llega a confundir el ejemplar kuhniano con la metodología, como si la construcción experimental toda se redujese - o quedase contenida en- la metodología mediante la que aplicamos el anteproyecto o modelo teórico previo (como si el metabolismo interno de la construcción experimental quedase reducida al método como artefacto separado). Así, cuando este autor pasa a exhibirnos las características o el entramado interno de cada paradigma psicológico se limita (como es usual en este tipo de historiografia) a ofrecernos una lista de «ismos», de notas que caracterizarían el modelo filosófico teórico, así como su correspondiente "ejemplar", esto es una lista de aproximaciones metodológicas que serian adecuadas para tratar aquel objeto recortado por el anterior modelo teórico. Significativamente, cuando este autor se adentra un ápice en el análisis de las realizaciones psicológicas concretas, sus esquemas kuhnianos estallan irremediablemente. La psicología Ganzheit de Wundt, por ejemplo, es tratada como la conjuncion de ciertos postulados de la matriz disciplinar - del modelo previo--, tales como el dotar de atención preferencial al estudio de la mente y la experiencia consciente y de ciertos «ejemplares» o metodologías, tal como, en lógica adecuación con el modelo, la aceptación $y$ el uso de la introspcceión ${ }^{2 n}$. Llegado el análisis del conductismo, sin embargo, nuestro autor, una vez que nos of rece una típica lista de "ismos" como características del paradigma o modelo teórico conductista ${ }^{21}$, señala, no obstante, como ejemplares compartidos por el conductismo al "condicionamiento clásico de Paulov» y al "método del condicionamiento operante utilizado por Skinner» 22 . Sin duda que ambos condicionamientos si constituyen sendas realizaciones experimentales que poseen todas las trazas de los ejemplares experimentales kuhnianos. Mas dichas realizaciones no pueden ser, precisamente, entendidas como simples metodologías más o menos derivadas de ciertos presupuestos teóricos generales, como si fuesen una especie de artefactos previos consistentes en ciertas «reglas de procedimiento» derivables de algún marco de presupuestos teóricos y susceptibles de encontrar una realización experimental. Mas bien al contrario, si aquellas realizaciones experimentales involucran efectivamente cierta metodología, la involucran por la via de su ejercicio experimental, en cuanto que ciertos procedimientos de intervención quedan efectivamente ejercitados en el seno de cierta realización práctica. Si cabe hablar con algún sentido de "reglas de procedimiento", de un cierto catálogo, pues, de reglas, en abstracto, esto es posible sólo en cuanto que abstraibles, del contexto experimental en el que no ya tanto se "aplican» cuanto se producen internamente, desde dentro, diríamos, de la propia estructura interna de una actividad práctica, la científico-experimental, desde dentro de la estructura relacional resultante del "contacto" entre la intervención experimental y el material mismo empírico circundante intervenido constructivamente (como tendré ocasión de detallar algo más, poco más adelante). Naturalmente, Leahey no se entretiene en analizar el entramado interno de estas realizaciones experimentales, sino que se conforma con la 
tarea de hacer encajar cada uno de los más importantes conductistas dentro del catálogo de ismos que previamente ha endorsado al paradigma conductista como definidores suyos. No es de extrañar, entonces, que ninguno de los psicólogos conductistas que considera (que son Watson, Hull, Tolman y Skinner) acabe de encajar del todo en el marco de «ismos» que previamente ha ofrecido, sino que a todos les falte o les sobre alguna que otra característica. Se llega, de esta suerte, a tan peculiares y significativas situaciones como la de reconocer por un lado que el «análisis experimental de la conducta representa, sin lugar a dudas, lo más parecido a un programa de investigación propio de una ciencia normal que ha producido la Psicología” 23 y apuntar, no obstante, por otro del "conductismo radical de Skinner» que "su adhesión al paradigma es más compleja” 24: pues ya es curioso que de la realización experimental conductista que ha producido «lo más parecido a un programa de investigación propio de una ciencia normal» (esto es, ese tipo de realizaciones que caracterizan, según Kuhn, a los paradigmas) se diga que "su adhesión al paradigma es más compleja». Al parecer, algo falla: pues ocurre que el paradigma conductista no ha acabado de producir una "ciencia normal", y el apartado suyo que sí la produce resulta que es dificil de avenirse al catálogo de características de aquel paradigma conductista. Falla, en definitivia, por la propia base, el instrumental epistemológico e historiográfico adoptado por la escolástica kuhniana. Pues reaparece aqui, de nuevo, el mismo tipo de idealismo de la praxis que, según vimos, caracterizaba a la historiografia y epistemología positivista. Para esta última, como dije, las ciencias resultaban - directa, automáticamente- de la aplicación del método universal de la ciencia, como artefacto ya previamente poseído, a los campos temáticos ofrecidos por el tronco-madre, la filosofía. Ahora, en la "nueva» historiografía lo que aparece poseído de antemano es el modelo filosófico del campo; es un marco semántico de presupuestos cuya realización experimental viene a ser cosa de uponerse a realizarlo experimentalmentem. Cada paradigma (realización experimental) viene a ser el resultado de la realización del propio paradigma (teóricoontológico), como en la perspectiva positivista cada ciencia era el resultado de ponerse a «hacer la ciencia».

Adviértase de qué modo en ambos casos se trata de una "realización» (de una "puesta en práctica») puramente proposicional-externa, por tanto, ya no sólo al material empírico envolvente, sino también a la intervención experimental misma con él ejecutada. En un caso se trata de la realización de un esquema proposional lógico-formal, cuyo metabolismo excluye tanto al medio material empírico como a la experiencia misma como acto práctico - según dijimos-, esto es, al propio experimento, pues es la estructura de la construcción experimental aquello en donde, como veremos, podemos hacer residir la experiencia científica como acto práctico. En el caso de la perspectiva kuhniana, ya hemos visto de qué modo el contexto experimental, aunque rodeado por el propio Kuhn, no ha acabado de ser asaltado en su interior - $y$ menos aún por la escolástica kuhniana-: aquí también la "puesta en práctica) de una realización científica acaba consistiendo en la (supuesta) re-producción de un modelo semántico-proposicional, como si (platónicamente, diriamos) la práctica experimental fuese el "reflejo», la re-producción, de su modelo ideal, como si el ejemplar experimental fuese el caso concreto donde se ejemplifica el paradigma, modelo ontológico. (Como si, en definitiva, el propio contexto experimental, como acto práctico - subjetivo- no impusiese sus propios limites objetivos a la asimilación de cualquier ontología.) No es de extrañar que la historiografia sujeta a semejantes herramientas epistemológicas se acabe por encontrar en una situación de tensión muy parecida a la que señalábamos en relación con la historiografia positivista. Aquello que el modelo epistemológico pide historiar, es una serie de distintos puntos de vista filosóficos, poco más, en realidad, que una bistoria tradicional de la filosofia, si bien acotada regionalmente, una historia en donde, llegado cierto momento de su desarrollo, se acopla al diseño experimental para poner a prueba sus presupuestos, y en donde -a diferencia de la perspectiva positivista en esto- cualquier tipo de presupuestos filosóficos contiene su posible realización experimental (con lo que resulta que el experimento ya no demarca, a la postre, en modo alguno a la ciencia de la filosofía). Ciertamente, en la historia de las ciencias - y de las humanas más en particular-- si se pueden encontrar una multitud de presupuestos filosóficos, pero precisamente en el plano de las autorrepresentaciones que los científicos tienen de su propia práctica, de modo que la historiografía que derive su atención hacia este plano acaba por 


\section{Estudios}

exhibirnos la sucesión de los puntos de vista filosóficos como si fuera la historia de las realizaciones científicas de esa ciencia. En la medida, entonces, en que el contexto experimental queda de este modo trivialmente aludido (como una supuesta obviedad), y por lo mismo realmente eludido, cuando quiera que el historiador se encuentra con las realizaciones experimentales que le ofrece su material histórico, todo lo que de pertinente pueda decir al respecto, será, por fuerza independiente del arsenal epistemológico con el que trabaja. Naturalmente, no se me ocurre negar que esta reciente historiografía no esté arrojando análisis interesantes, sino que subrayo el hecho de que es difícil que éstos provengan de su arsenal epistemológico. También Boring, por citar un clásico sin duda ejemplar, nos ofreció resultados históricos admirables (y está por ver cuánto se ha avanzado realmente en relación con su trabajo), resultados éstos, asimismo, independientes del marco positivista de su trabajo de historiador.

Por lo demás, el énfasis en la naturaleza sociológica de la ciencia que pone la nueva escolástica kuhniana, sin prejuicio de que, como digo, alcance a producir algunos trabajos de interés sociológico, no acaba de romper el punto de vista filosófico de la «concepción heredadas, sino que lo reproduce internamente - a veces muy ingenuamente-. En efecto, el riesgo que corre el concepto kuhniano de paradigma es que, aun cuando pueda constituir un buen acicate para el estudio sociológico (o psicosociológico) de las ciencias, no modifica, sino que reproduce internamente, la tajante compartimentación epistemológica entre el contexto de justificación y el contexto de descubrimiento que puso en juego el positivismo lógico. Pues como ya he señalado, la superación de la epistemología lógico-positivista no se cifra simplemente en dirigir la atención hacia el contexto de descubrimiento -y en propiciar por ende más finos análisis de lo que aquí ocurra-, sino, esencialmente, en buscar en dicho interior el propio ejercicio de la racionalidad científica. Los análisis que se mueven en un plano meramente sociológicos cultural o psicológico de las ciencias, son sin duda pertinentes, pero de una manera sólo genérica y no específica, pues de lo que habría de tratarse es de alcanzar la perspectiva especifica (específicamente epistemológica) capaz de percibir la forma particular de racionalidad en que consiste un tipo determinado (pero no cualquiera) de praxis social, psicológica e histórica: la científica. Sólo de este modo el registro de ciertos fragmentos de práctica social e histórica puede resultar internamente relevante desde el punto de vista epistemológico: esto es, justamente lo que quedaba excluido por la epistemología lógico-positivista. $Y$ también es, me parece, lo que queda excluido por esta historiografia de corte kuhniano, la cual viene a limitarse a ofrecer, de hecho, una ingenua y acrítica yuxtaposición entre el desarrollo racional por un lado y los acontecimientos -sociales del contento de descubrimientó por otro. Asi, por ejemplo, Leahey, en su trabajo ya citado, nos dice, con no poca candidez, que «al igual que hemos distinguido entre Grandes Hombres y Zeitgeists, debemos también distinguir entre razones y causas en las explicaciones históricas" y que "... en consecuencia, debemos indagar tanto las causas personales e históricas de un acontecimiento, como las razones justificativas en términos racionales de dicho acontecimiento", bien entendido que «estos factores (se refiere a las causas históricas) no añaden ni quitan nada al valor científico racional de una idea» ${ }^{25}$. Ya se ve de qué modo el historiador acaba por conformarse con esta yuxtaposición - diríamos, componenda: "prudente combinación» llega a decir Leahey 26 - entre las causas (o contexto de descubrimiento) y las razones (o contexto de justificación), mera yuxtaposición que no anula, sino que reproduce la misma duplicación o compartimentación epistemológica entre ambos contextos de factura lógicopositivista. Semejante situación se hace particularmente aguda, y significativa, cuando este autor nos ofrece su versión del cambio cientifico: nos dice Leahey que mientras que el modelo de cambio evolutivo de Toulmin puede aplicarse para entener el transcurso de la ciencia normal (la evolución de un paradigma, en efecto) es menester explicarse el cambio de un paradigma a otro (cuando, al parecer, irrumpe la crisis) en términos del modelo revolucionario de Kuhn ${ }^{27}$. Naturalmente, esta posibilidad estaba ya contenida en la perspectiva de Kuhn, y ella es una excelente muestra de la incapacidad del aparato kuhniano para explicar precisamente aquello que, al parecer, debería más adecuadamente explicar -el cambio científico-, así como de la reproducción de la compartimentación epistemológica entre los dos contextos que la perspectiva kuhniana hereda, como digo, del positivismo lógico. Pues el modelo evolutivo de Toulmin vendría 
a explicar el desarrollo de la ciencia normal precisamente en la medida en que durante tales supuestos periodos tendria lugar un desarrollo más bien racional (y semejante racionalidad no sería otra, a la postre, que la racionalidad lógico-deductiva del neopositivismo mediante la cual van resolviéndose los «rompecabezas» o anomalías que no ponen en peligro, debido a su ausencia de excesiva proliferación, el paradigma), y sólo cuando la crisis amenaza es entonces cuando habría que recurrir al modelo revolucionario, esto es, a la apelación a las causas (a los crudos acontecimientos del contexto de descubrimiento). Pues, ¿en qué otra cosa consiste la explicación kuhniana de la estructura del cambio científico en términos de "revolución" si no es en la apelación a la brusca irrupción del contexto de descubrimiento como contexto de causas sociales de hecho exentas de toda racionalidad? Significativamente, el reparto epistemológico de papeles dentro del contexto de descubrimiento - de las causas - y el de justificación - el de las razones - se aviene perfectamente (como Leahey ha tenido acaso la ingenuidad de explicitarnos) con la distinción kuhniana entre ciencia normal y ciencia revolucionaria, acoplándose - por así decirlo- la razón tradicional de la concepción heredada con el curso normal de la ciencia, y las crudas causas socioinstitucionales con los supuestos momentos revolucionarios. Con lo cual, a fin de cuentas, el arsenal epistemológico kuhniano nos deja sin dar una explicación -al menos, racional- de aquello para lo que al parecer iba dirigido su primer y ya clásico libro (y en general toda su obra): el devenir científico.

Pues bien, por poner ahora un ejemplo próximo y creo que también significativo, así fue, me parece, como los profesores españoles Ruiz Vargas y Zaccagnini plantearon, en el II Congreso de Teoria y Metodología de las Ciencias, de Oviedo, el año pasado, su defensa del paradigma cognitivo frente al paradigma conductista. Según nos dijeron, la diferencia esencial entre ambos paradigmas vendría a radicar en los diferentes modelos de acción (de conducta) que cada uno de ellos postulaba. Mientras que el conductismo postularía un modelo de acción fisicalista, "ferozmente antimentalista», como nos dijo Ruiz Vargas, el cognitivismo propondría un modelo de sujeto activo que posee representaciones $o$ «modelos de mundo" que dicho sujeto construye a través de su actividad conductual en el mun- do. Como se ve, en el conductismo, seria el método empirista el que diese como resultado un modelo del campo de factura fisicalista, y, por tanto, antimentalista. Sin duda que si el método pide ceñirse al plano de los datos empíricos directamente observables, el campo recortado a resultas de la aplicación de dicho método ha de ser fisicalista, y por eso antimentalista, pues ciertamente la mente no se ofrece entre los datos empíricos (ni directamente observables, ni observables empíricamente en modo alguno, por descontado). El cognitivismo, por su parte, partiría de un modelo o enfoque (palabra de estos autores) racionalista del campo, al cual cabría acoplar el método empírico general de la ciencia convenientemente flexibilizado, esto es, no empirista, sino simplemente empírico, que diese cabida a términos teóricos no observacionales, los cuales recogerían las hipótesis relativas a la actividad mental racional del sujeto de conducta ${ }^{28}$. Como se ve, cada paradigma resulta ser, según esta presentación, el resultado de componer un método y una teoria. Repátese en que el conductismo es pensado como resultado de aplicar (de "realizarse», diriamos) el modelo mismo positivista lógico de ciencia para hacer ciencia. Se parte del método y, como consecuencia, se diseña el campo para hacer ciencia. En el caso del cognitivismo, entonces, sin embargo, de lo que se parte es del modelo teórico $y$, a partir de éste, se desarrolla ya el método más adecuado: repárese, asimismo, en que ahora se trata del modelo epistemológico kuhniano de ciencia para hacer ciencia. En ambos casos, pues, trátese de concebir a la realización científica como el resultado de un modelo filosófico de ciencia.

Ahora bien, como ya entonces señalé y luego he dejado escrito ${ }^{29}$, los profesores Ruiz Vargas y Zaccagnini podian haber sido un poco más misericordes con los conductistas. Pues șí, como la psicología cognitiva nos ha enseñado, todo conocimiento es una construcción (y lo es, para empezar, el conocimiento sensorial perceptivo), no se ve por qué se ha de hacer una excepción con esos organismos filogenéticamente desarrollados que, después de todo, son. los psicólogos conductistas, y pensar que ellos conocen, de becho, datos o perceptos empíricos brutos como pide el modelo epistemológico empirista. ¿Qué es lo que se está aquí sobreentendiendo?: ¿acaso que los conductistas se comportan, de hecho, cuando conocen, como pide la epistemología positivis- 
ta lógica que deberian conocer? ¿No es, acaso, más razonable suponer $-y$ acorde, precisamente, con los hallazgos de la psicología empírica del conocimiento- que los conductistas conocen como el resto de los mortales, esto es, construyendo los conocimientos? Pues si se concede lo primero, habrá que concluir que los psicólogos conductistas no fueron más que meros propagandistas de un modelo de ciencia y de método científico (que no fueron más que epistemólogos defensores de una epistemología incorrecta), mas si se concede, sin embargo, que fueron psicólogos, psicólogos científicos en algún sentido efectivo, no parece que el concepto de paradigma, al menos tal y como se nos exhibe, sirva para entender tal posibilidad.

He aquí de nuevo, como se ve, el supuesto idealista de que la ciencia es una realización cuya factura depende de la representación que cada cual pueda tener de ella. En este sentido, me parece interesante señalar que, sobre la base de esta representación más bien idealista (utópica, diria) de la práctica científica, se viene ofreciendo no pocas visiones más bien deformadas de la propia historia del conductismo. Por citar un caso que en cierto modo ya es casi un clásico: Brian D. Mackenzie, en su célebre estudio $E l$ conductismo y los límites del método cientifico, de 1977 , nos muestra, me parece, la significativa situación en la que su análisis acierta, a la vez que yerra, en relación con su crítica del método científico. Pues, ciertamente, es correcto entender que el método científico, como artefacto separado, apriorístico (cualquiera que sea, por lo demás, la factura con la que nos imaginemos a dicho método) resulta a la postre ineficaz, estéril, para el desarrollo de la efectiva construcción científica. Pero lo ingenuo es, asimismo, sobreentender que la práctica de la investigación experimental de los conductistas vino regulada por el método que se desprende del modelo positivista lógico de ciencia, y que los límites (sin duda, efectivos) que semejante metodología impone al desarrollo del conocimiento vienen a coincidir (a ser los mismos) con los límites de la investigación experimental conductista. De nuevo, el libro de Mackenzie resulta ser más una crítica (acertada) a la epistemología del positivismo lógico que una crítica (pues en este caso desenfoca el objetivo) de la práctica científica conductista. Por lo demás, el hecho cierto de que los propios conductistas entendieran que habría de ser la posesión del método derivable del modelo lógico positivista de ciencia lo que les permitiría poner en marcha a la ciencia de la conducta (o desarrollarla elevándola hacia un plano teórico, como Koch nos recuerda que fue la ambición de la segunda generación conductista ${ }^{30}$ ), no significa sino que ellos mismos estaban, también, presos de una falsa conciencia epistemológica, que sus propias representaciones epistemológicas oscurecian, más que clarificaban, su propia práctica - situación ésta que no queda críticamente desvelada por la epistemología y la historiografia de corte kuhniano-; sin prejuicio de que, por cierto, estas autorrepresentaciones deformadas que con no poca frecuencia incorporan los gremios científicos a su práctica cumplan efectivas funciones como reforzador ideológico del paradigma en sentido sociológico.

Por citar, por fin, un último ejemplo, tambièn recogido de la bibliografía anglosajona. El historiador de la psicología Allan R. Buss ha escrito un sugerente artículo, La estructura de las Revoluciones Psicologicas, en 1976 , en donde pretende mostrarnos cuál sería el patrón o estructura que subyace a los distintos paradigmas, y a los cambios de paradigmas, en la psicología, con el objetivo de detectar en dichos patrones alguna característica específica de la ciencia psicológica. Según Buss, sería la relación sujeto-objeto, entendida de modos diversos por los distintos paradigmas psicológicos, la estructura que caracterizaría específicamente a dichos paradigmas. Se refiere este autor, en particular, a la concepción que del objeto de conocimiento psicológico se posea en cada paradigma, si como un objeto simplemente o como un sujeto en cierto modo semejante al propio sujeto de conocimiento. Cada paradigma introduciría según esto un distinto tipo de relación entre el sujeto y el objeto de conocimiento. De este modo, los paradigmas correspondientes al estructuralismo, a la psicología humanista y la psicología cognitiva se caracterizarían porque conciben a sus objetos como siendo, a su vez, sujetos, esto es, y dicho en sus propios términos, porque reconocerian en su objeto de conocimiento "la realidad de las construcciones personales»: el conductismo y el psicoanálisis, por otro lado, serían paradigmas que conciben a sus objetos de conocimiento como no siendo sujetos, de modo que ahora el carácter constructivo que antes era reconocido también para el objeto es reservado solamente para el 
sujeto de conocimiento, para el psicólogo; así pues, estos paradigmas se caracterizarian, en vez de como los otros, que reconocían la realidad de los constructos personales, por atenerse solamente a la "persona como constructo reals ${ }^{31}$.

Ciertamente, estas consideraciones sobre las relaciones entre el sujeto y el objeto de conocimiento $y$, en particular, entre el primero como un efectivo de constructor de objetos que pueden ser, ellos mismos, a su vez, sujetos constructores es sumamente sugerente. $Y$ es sugerente, en concreto, la idea de intentar detectar en dicha relación un cierto patrón o estructura (epistemológica, a la postre) que fuera común y característica de las distintas construcciones psicológicas. Con todo, lo cierto es que, planteado el asunto de este modo, no pasa de ser, de nuevo, un conjunto de reflexiones filosóficas sobre distintos modelos filosóficos posibles de acción humana, lo que nos sitúa otra vez ante la historia de la psicología como una historia de distintos puntos de vista filosóficos. Así pues, lo realmente interesante sería encontrarnos con esta reaparición del sujeto constructor en el seno, no ya de un modelo filosófico previo, sino de los ejemplares experimentales mismos construidos por la ciencia psicológica.

Pues bien, en lo que sigue voy a intentar mostrar de qué modo aparecen en el seno de lo que podríamos llamar los ejemplares experimentales psicológicos sujetos en cierto modo semejantes a los propios sujetos que construyen el ejemplar. Naturalmente, para ello necesito esbozar antes mi propia concepción de lo que me parece que constituye la estructura interna de los artefactos experimentales científicos como parte interna componente de la propia racionalidad. Dicho de otro modo, necesito desarrollar, aunque sea brevemente, mi crítica a la concepción epistemológica de factura kuhniana que he venido considerando $o$, si se quiere, desarrollar aquello que, según he dicho, ya está apuntado por el propio Kuhn, pero ignorado por la historiografía de la psicologia que pretende seguir sus pasos. Veamos.

\section{SOBRE LA ESTRUCTURA DEL ARTEFACTO EXPERIMENTAL Y SU LUGAR EN LA CIENCIA}

1. Las ideas que ahora expondré sobre el artefacto experimental pueden considerarse como un desarrollo crítico de lo que podemos llamar, me parece, la concepción epistemológica dominante del experimento, en la cual incluyo, por descontado, al positivismo lógico, pero también, por lo que hasta el presente he venido diciendo, a la tradición kuhniana.

Según esta perspectiva que he llamado dominante, el experimento no es concebido como parte interna de la prueba, la explicación o el argumento científico, sino simplemente como una instancia eventualmente facilitadora de dicho argumento o explicación, la cual se resolvería por completo en el seno del lenguaje. Semejante facilitación experimental se llevaría a cabo, como viene a ser reconocido por todos, del siguiente modo: trátase de poner en acción un proceso observable consistente (en su caso ideal más simple) en una secuencia empirica entre variables al objeto de poder observarlas y manipularlas o modificarlas a voluntad. De este modo, modificando sistemáticamente los valores de la parte inicial del proceso $o$ variable independiente, y manteniendo constantes los demás posibles factores del contorno experimental que pudieran afectar a los resultados obtenibles, se obtienen modificaciones correlativas en la parte final de la secuencia o variable dependiente, de modo que quepa registrar las regularidades empiricas así obtenidas y formular las correspondientes relaciones funcionales (o leyes empíricas). Desde luego que, en principio al menos, no tengo un punto que objetar a esta caracterización de la actividad experimental; esto es, pienso que es así como, de hecho, manejan los científicos sus variables experimentales (asumiendo, por descontado, que he presentado aquí un modelo ideal muy simple).

Ahora bien, la cuestión es la del sentido y papel -epistemológicos- que se confieren a semejante situación experimental. Pues en la perspectiva dominante se presupone que los datos y relaciones empíricas obtenidas en aquella situación están ya, en aquello que de racional tenga su obtención, precontenidos en algún lenguaje, de modo que aquéllos no serían sino simples ejemplificaciones de los contenidos 
lingüísticos organizados por su parte en el interior de una construcción puramente proposicional. En el positivismo lógico, en particular, dichas secuencias experimentalmente obtenidas serían concebidas como los ejemplos empíricos contingentes en la explicación y/o en la predicción y/o en la contrastación de hipótesis teóricas, bien entendido que la naturaleza racional de la prueba científica residiría en la estructura lógico-formal (deductiva) de la explicación, la predicción y/o la contrastación. Dicho de otro modo, los acontecimien-

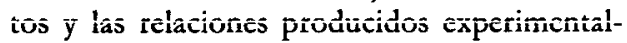
mente son relevantes por lo que respecta a la racionalidad tan sólo en cuanto que se los supone ya precontenidos en un lenguaje observacional, esto es, en cuanto que enunciados deducibles lógicamente como consecuencias de otros enunciados (hipotéticos, teóricos). Se trata, pues, de sobreentender que la racionalidad de la construcción científica reside tan sólo en la construcción proposicional -en la construcción de estructuras o racimos lógico-deductivos- y no en la construcción misma de las secuencias experimentales -en la puesta práctica en acción de relaciones secuenciales experimentales-, de modo que si los datos -o acontecimientos - y relaciones empíricas introducidas de la mano de la actividad experimental han de constar a la postre, de algún modo, como información empírica que dote de contenido empírico al cuerpo lingüístico lógico, esta necesidad (insoslayable, pues de no hacernos cargo de ella no cabría distinguir entre un mero cálculo axiomático y un sistema hipotético-deductivo de la ciencia empírica), se resuelve, en el positivismo lógiço, por el simple expediente de presuponer una suerte de adecuación (diríamos, o isomorfismo) entre la estructura de las secuencias empíricas introducidas experimentalmente y la estructura de los enunciados (de observación) lógicamente deducidos como consecuencia de las hipótesis teóricas. Esto es, sólo en la medida en que la estructura de las secuencias empíricas se adecue a la previa estructura lógica de ciertos enunciados, los enunciados de observación lógicamente deducibles de los enunciados teóricos, será como aquellas secuencias empíricas podrán suministrar su información al cuerpo proposicional previo, el cual someterá a las unidades de información que se supone exhiben aquellas secuencias a un metabolismo puramente lógico (a transformaciones tautológicas). Asi pues, la única racionalidad de los enunciados de observación reside en su pro- piedad lógica de ser lógicamente deducibles de otros enunciados (los teóticos), lo cual pide, como digo, asumir o presuponer una cierta estructura isomorfa entre las secuencias empiricas y los enunciados de observación si es que se ha de entender de alguna manera la presencia de la experiencia en el lenguaje de las ciencias. De este modo, la actividad práctica experimental misma mediante la que se producen, de hecho, aquellas secuencias empíricas queda obviada, y estrictamente excluida, de la construcción racional. Mas, para excluir a la situación práctico-experimental del interior de la construcción racional de los conocimientos empiricos se ha tenido que presuponer, como digo, una de las más genuinas concepciones metafísicas que subyace en el fondo de toda la epistemología lógica positivista: la que sobreentiende la presencia (diríase trascendental) de una suerte de armonía o isomorfismo preestablecidos entre la estructura lógica del lenguaje y la estructura de la experiencia como acto práctico, esto es, de las secuencias empíricas resultantes de su producción experimental.

En la perspectiva kuhniana, los términos lingüísticos -y también los observacionalesaparecen semántica o teóricamente cargados, como si las presencias perceptuales de la experiencia empírica viniesen, de antemano, inevitablemente significadas por ciertos contenidos semánticos previos. Como se sabe, toda la llamada nueva filosofía de la ciencia gira en torno a esta tesis del carácter teóricamente cargado de las observaciones científicas. Sin duda que yo no rechazo esta última tesis. Pero se trata, de nuevo, de saber si los acontecimientos y relaciones empíricos experimentalmente producidos resultan ser simples ejemplificaciones de aquellos términos lingüísticos o si, por el contrario, su proceso de producción experimental juega algún papel en la determinación de aquellas gestalten conceptuales. Por así decirlo, la cuestión es si los ejemplares experimentales kuhnianos son simples ejemplificaciones de los conceptos o si son más bien éstos, en las ciencias, ejemplificaciones de aquéllos. Merece la pena señalar a este respecto que toda esta nueva filosofía de la ciencia se halla sumida, según me parece, en una suérte de insuperable callejón sin salida: pues en la medida en que la construcción de las "cargas» semánticas desde las que se significa los acontecimientos empíricos queda resuelta, de nuevo, en el interior del lenguaje (como una situación pragmática, de hecho, en último 
término inanalizable), obviándose, por tanto, la situación experimental, ocurre que la experiencia empírica resulta a la postre irrelevante como instancia de contraste e incomprensible como efectiva fuente de información, pues cualquier situación empírica puede ser siempre re-interpretada en el seno del juego semántico de cada marco teórico. La idea, tan cara a estas corrientes, de que en la ciencia tienen lugar algún conjunto de presupuestos metafisicos (o weltauschaugen) es simplemente una implicación directa de esta supuesta posibilidad de que, en principio, cualquier situación empirica sea reinterpretable desde dentro de algún marco semántico previo. Las ciencias resultan ser, de este modo, algo así como simples campos semánticos de juego (que admitirían, en principio, indefinidas posibilidades de juego) estipulados por cada marco de presuposiciones metafísicas determinado y en donde la experiencia sólo sería la ocasión para desarrollar (o jugar) dicho juego. Ocasión, en efecto, porque cada instancia empírica siempre puede ser reintepretada desde cada marco teórico - metafísico- previo, o sea, puede ser evadido su posible carácter de instancia de contraste. (No hay que extrañarse, pues, de las posiciones cada vez más radicales al respecto de un Feyerabend, por ejemplo: son simples consecuencias del marco de presupuestos filosóficos de esta nueva epistemología ${ }^{32}$.) Mientras que en el positivismo lógico el contacto del lenguaje con la experiencia quedaba asegurado (se intentaba al menos que lo estuviese) en base a la presuposición de una estructura isomorfa entre el lenguaje y la experiencia, presuposición que resultaba necesariamente implicada habida cuenta de la no consideración epistemológica del contexto práctico-experimental, en esta nueva filosofia de la ciencia, la inicialmente pretendida asimilación epistemológica de la experiencia en el lenguaje resulta, a la postre, en todo lo contrario: en una desconexión radical entre lenguaje y experiencia, implicada asimismo por la no consideración del posible papel epistemológico de la actividad práctica experimental. Si en el positivismo lógico la concepción metafísica que subyacía era la de la armonia preestablecida entre lenguaje y experiencia, en estas nuevas corrientes epistemológicas la posición metafísica que subyace es l̀a del ocasionalismo, de la experiencia en relación con el lenguaje. A fin de cuentas, en ninguno de los dos casos la experiencia queda epistemológicamente racionalizada (salvo por expedientes metafísicos), esto es, no resulta com- prensible el modo como la experiencia pueda jugar un efectivo - y decisivo- papel en relación con la razón científica. Sostengo que esto es así debido a que en ningún caso queda epistemológicamente problematizada la cuestión de la experiencia como acto práctico, es decir, el contexto experimental.

Pues bien, me parece que para abandonar la perspectiva que he llamado proposicionalista e intentar pensar el modo como la prueba científica pasa por el interior del artefacto experimental, debemos empezar por considerar cuál es el tipo de argumento, razonamiento, explicación o prueba (como quiera decirse) que tiene lugar en las ciencias. Este es, según propongo, el llamado razonamiento apagógico, que ya fuera tenido en cuenta en repetidas ocasiones por la tradición filosófica: por Aristóteles ${ }^{33}$ y por Kant ${ }^{34}$, por ejemplo; y, más recientemente, por autores como Peirce y el propio Hanson ${ }^{35}$, uno de los iniciales creadores de la nueva filosofía de la ciencia. Algunas reflexiones, en efecto, sobre la naturaleza de este tipo de razonamiento pueden conducirnos a esbozar siquiera la concepción que defiendo.

En la Crítica de la Razón Pura, Kant nos ofreció una formulación sin duda ejemplar del razonamiento apagógico, por lo que se me permitirá que la traiga a colación. "Cuando los fundamentos - nos decía Kant- de los que se pretende derivar cierto conocimiento son demasiado numerosos o están excesivamente velados, se ensaya la posibilidad de llegar a tal conocimiento a través de sus consecuencias. Sería el modus ponens, esto es, inferir la verdad de un conocimiento partiendo de la verdad de sus consecuencias, lo cual sólo es permisible cuando son verdaderas todas sus consecuencias... Ahora bien, este procedimiento es impracticable, pues el ver todas las consecuencias de cualquier proposición que adoptemos es algo que excede nuestras capacidades. Este tipo de inferencia es, no obstante, empleado... cuando sólo se trata de demostrar algo como hipótesis, admitiéndose entonces la conclusión en virtud de la analogía siguiente: si todas las consecuencias ensayados concuerdan con un fundamento supuesto, todas las demás consecuencias posibles tienen que concordar igualmente con él» ${ }^{36}$. En efecto: el argumento apagógico es el que procede basando la validez de las premisas en la verdad misma de las conclusiones. Pues bien, me parece que esta característica del razonamiento apagógico es 
epistemológicamente decisiva, precisamente por lo que respecta a los conocimientos empíricos al menos en los siguientes sentidos: En primer lugar porque, por descontado, se reconoce el carácter siempre provisional (hipotético) (diriamos contingente, corregible $\mathrm{o}$ mejorable por la experiencia) de los conocimientos empiricos, a diferencia del carácter necesario (o apodíctico) de que gozan las construcciones puramente lógico-formales (deductivas). Si Kant despreció en buena medida el razonamiento apagógico y buscó una estructura trascendental que aseguruase la sintesis "a priori” de los juicios empíricos, fue precisamente por este carácter contingente de dicho razonamiento y porque el filósofo alemán buscaba la manera de dotar al conocimiento empírico de las ciencias de una suerte de necesidad semejante al del conocimiento puramente formal. Ahora bien, esta primera característica nos conduce a esta segunda si cabe más importante: pues, en efecto, si no compartimos la pretensión de una síntesis «a priori», el carácter bipotético de la inferencia apagógica nos muestra su decisiva naturaleza no reductible al razonamiento puramente lógico-formal deductivo, precisamente en cuanto que situación específica del carácter empirico del conocimiento alcanzado mediante dicha inferencia. Pues, en efecto, proceder basando la validez de las premisas en la verdad de las conclusiones resulta, de entrada, improcedente desde el punto de vista lógico-formal (deductivo), puesto que la inferencia deductiva discurre de las premisas a las conclusiones de un esquema deductivo en el que el camino de las conclusiones a las premisas supondría incurrir en la falacia deductiva de la afirmación del consecuente. Por otro lado, a su vez, esta inferencia que va desde las conclusiones a las premisas no puede consistir en la simple inducción o mera generalización empírica, en la "inductio per enumerationen simplicen" de Bacon, en cuanto que suponemos que, en los conocimientos científicos al menos, la hipótesis resultante de la inferencia apagógica ha de ser una hipótesis auténticamente explicativa de las regularidades o secuencias empíricas que caen bajo su dominio y no un mero registro notarial de las mismas; esto es que, como suele decirse, cada hipótesis, en conjunción con ciertas condiciones empiricas iniciales, permita la deducción de más consecuencias empíricas que las que se derivan de aquellas condiciones iniciales solas. Asi pues, la situación que, según propongo, caracteriza específicamente al razonamiento apagógico es tal que las hipó- tesis o premisas a las que lleva no pueden ser $n i$ el resultado de la simple inducción - habida cuenta de que, como digo, ellas han de ser genuinamente explicativas--, ni tampoco dicho razonamiento puede consistir en la deducción lógica - debido a que el camino apagógico discurre de las conclusiones a las premisas o hipótesis que las expliquen-. La cuestión es, pues, que tanto la deducción como la inducción, precisamente como modelos lógicos (supuesto, por lo demás, que la inducción se aviniese a ser considerada una inferencia lógico-formal, cosa que autores comn, por ejemplo, Popper negarian), no acaban de suministrar una explicación suficiente del proceso epistemológico - la inferencia apagógica- en la que hacemos residir lo específico de los conocimientos científicos. $\mathrm{O}$, dicho de otro modo, la inferencia apagógica excede $a$, o - diríamos- contiene algo más y/o distinto que el puro razonamiento lógico-formal deductivo (también inductivo) en algún sentido epistemológicamente decisivo (un sentido que, como ahora se verá, tiene que ver con la práctica no proposicional, y más en particular con la práctica experimental). Cuando se habla, pues, como es frecuente, de que las teorias científicas consisten en estructuras -proposicionales- hipotético-deductivas (o que el método de la ciencia es el hipotético-deductivo), es de todo punto importante subrayar que si bien con la expresión «deductivo" hacemos relación a la susceptibilidad de que las hipótesis ya obtenidas sean encajables en una estructura lógica deductiva (lo cual, por descontado, no niego), lo cierto es que la expresión "bipotéticoy nos remite precisamente al proceso mismo de construcción de las hipótesis que excede, que se sale fuera (por así decirlo) de la pura relación lógica formal de deductibilidad: nos remite al "camino» apagógico de construcción de las hipótesis como el momento epistemológico, no susceptible de explicación lógico-formal, esencial de la construcción científica.

El positivismo lógico, como es sabido, expulsó afuera del ámbito de la racionalidad al proceso de construcción de hipótesis, desde el momento en que su posición filosófica (epistemológica) formalista (logiscista) exigía considerar impermeable a la razón este proceso que, como he dicho, no resulta encajable en molde lógico formal alguno. Todo lo que de racional el positivismo lógico encontró en las hipótesis residía en lo que podemos llamar su virtualidad lógico-formal deductiva de permi- 
tir la deducción a partir de ellas de consecuencias observacionales. La racionalidad les vendría, pues, a las hipótesis, de su costado lógico deductivo posterior a su construcción, no habiendo nada de racional en dicho momento de la construcción misma, el cual, por tanto, fue pensado en términos puramente psicológicos (el proceso psicológico de «idear la conjeturay) y alojado en el extrarracional contexto de descubrimiento ${ }^{37}$. Dentro de la nueva filosofía de la ciencia ha sido Hanson (autor al que hasta el momento, vengo siguiendo muy de cerca en este análisis) quien, con toda seguridad, más se ha esforzado por alcanzar una comprensión epistemológica racional de este proceso mediante su noción de patrones de retroducción. Con todo, la férrea compartimentación epistemológica lógico-positivista entre el contexto de justificación y el contexto de descubrimiento (que, como ya dije, nos obliga a pensar los procesos dados en el contexto de descubrimiento, cuando deparamos la atención en ellos, en términos extrarracionales, habida cuenta de su identificación entre racionalidad y contexto lógico de justificación) se deja notar también, me parece, en el propio Hanson, pues su patrones de retroducción - de razonamiento apagógico, en efecto- no acaban, me parece, de ser sino una componenda a medias entre los aspectos psicológicos y los aspectos lógicos del proceso de la construcción y la posterior contrastación de hipótesis (una especie de proceso psicológico de ensayo $y$ error que va seleccionando - reforzando, podríamos decir en términos del condicionamiento operante- negativamente las hipótesis erróneas a través de sus consecuencias deducibles observacionales falsas).

En definitiva, me parece que la cuestión radica en dar con la estructura epistemológica misma de la retroducción o inferencia apagógica, bien entendido que dicha estructura no es, exactamente, un esquema lógico-formal de inferencia, a la vez que, sin prejuicio de que implique - ¿cómo no? - ciertos procesos psicológicos, se perfile la naturaleza racional de dichos procesos, una naturaleza, de nuevo, que no puede quedar reducida a un patrón proposicional lógico-formal.

Pues bien, sostengo que la racionalidad de la construcción apagógica puede hacerse residir en la estructura misma de los cursos de operaciones que se ponen en juego en los distintos contextos experimentales de las ciencias.
Intentaré explicarme, aunque haya de ser muy brevemente. Repárese, en primer lugär, en que la sola consideración de la estructura hipotético-deductiva de las teorias científicas exige que las hipótesis, si es que éstas han de ser auténticamente explicativas desde el punto de vista del contenido empírico, permitan deducir, en conjunción con ciertas condiciones iniciales, al menos alguna clase de consecuencias observacionales más que las que ya tenemos a partir de las solas condiciones empíricas iniciales. Imagínese el caso, por ejemplo, en el que, en una situación psicológica ideal muy simple, intentamos explicar una secuencia empírica en la que un estímulo observable determinado (A) suscita una respuesta determinada (B) - pongamos, enojarse- postulando un hipotético estado mental - pongamos, un estado emocional de ira- que sólo valiese para explicar dicha secuencia empírica, esto es, de la que sólo dicha secuencia pudiese ser deducida. Naturalmente, a no ser que nuestro hipótetico estado mental nos permita deducir, en conjunción con las condiciones iniciales (A), alguna clase de consecuencias observacionales más que las que empíricamente se siguen de dichas condiciones - digamos, alguna clase distinta de respuestas además de (B)--, estamos en presencia de una pseudoexplicación, de lo que suele llamarse una hipótesis ad boc. Es como si, en el caso del silogismo aristotélico, intentásemos explicar que "este cuervo es negro" (la conclusión) aduciendo que «todos los cuervos son negros» (la premisa mayor). Por el contrario, todo lo que dicho silogismo nos permite es argumentar que si utodos los cuervos son negros» (premisa mayor) y "esta cosa es un cuervo" (premisa menor), entonces "esta cosa (este cuervo) es negro» (conclusión). Asi pues, una generalización empírica (un enunciado cuya forma lógica sea universal y cuyos términos sean observacionales) no puede considerarse auténticamente explicativo de cada una de las instancias particulares de observación que él abarca (de los enunciados singulares de observación que comprende), del mismo modo que cualesquiera enunciados universales o hipóteticos situados en un nivel más elevado en el esquema deductivo no pueden explicarnos a aquellas generalizaciones empíricas, a no ser, de nuevo, que nos permitan deducir más consecuencias empíricas de las contenidas en la generalización en cuestión. Ahora bien, quiere esto decir que lo mismo vale entender que el resultado universal de la inducción no es explicativo de sus instancias 
particulares como que el resultado particular de la deducción a partir de universales no es empiricamente explicativo de dichas instancias particulares, sino sólo lógicamente argumentativo, a no ser que, nuevamente, el canal lógico deductivo se fragmente o multiplique, por asi decirlo, en múltiples canales, como corresponde a la multiplicidad de las conclusiones. En efecto, el hecho particular de que «este cuervo sea negro" no queda explicado aduciendo que "todos los cuervos son negros»; esto es: el enunciado universal «todos los cuervos son negros", no explica, por lo que respecta al contenido empírico, que "esta cosa - que es un cuervo- sea negra", sino que sólo nos suministra un argumento lógico - deductivo-, salvo que, de hecho, dispongamos (en la premisa mayor) de algún conocimiento más sobre «esta cosa» (sobre el término medio) que el que nos ofrece la premisa menor, o sea, que «esta cosa es negra», conocimiento excedente éste que, si se trata de una ciencia empírica, sólo puede haber sido obtenido, a su vez, de algún modo a través de la experiencia (ya no de manera puramente lógica deductiva). Recuérdese que - significativamente- Aristóteles resolvió entender que la premisa mayor del silogismo contenia un conocimiento de tipo distinto, en cuanto que lo sería de principios esenciales, del conocimiento argumentativo, de modo que aquél asegurase el contenido verdadero de éste, $y$, por tanto, de las ciencias, en cuanto que éstas habrian de ser conocimientos argumentativos, de las conclusiones. Esto hace, por supuesto, que el modelo de ciencia de Aristóteles sea rigurosamente metafísico, en donde el contenido cognoscitivo. que discurre a través del canal argumentativo deductivo del silogismo quede garantizado por un conocimiento previo de principios esenciales, y en donde, por tanto, no hay, ni puede haber avance, modificación o desarrollo alguno del conocimiento. Sin embargo, si no aceptamos este principialismo, como parece necesario si es que hemos de entender a las ciencias como auténticos conocimientos empiricos se ha reconocer que (expresado ahora en términos actuales, no aristotélicos) los enunciados universales o hipótesis (teorias) explican en la ciencia empirica, y no sólo permiten establecer argumentos lógicos, en la medida en que ellos contienen, en cada caso, mayor información, sobre cada clase de secuencias empíricas que explican que la contenida por dichas secuencias empiricas, un excedente de información (o "ssurplus meaning", como clásicamente fue llamado ${ }^{38}$ ) que se manifiesta lógicamente en la posibilidad de deducir, o predecir, a partir de la hipótesis en conjunción con las condiciones iniciales más clases de consecuencias observacionales que las que tenemos a partir de las condiciones empíricas iniciales solas, y el cual excedente, como decía, no puede ya ser (al menos en último término) resultado de la pura deducción lógica, sino que ha de ser obtenido de algún modo con base en la experiencia. Naturalmente, este modo empirico de alcanzar el conocimiento que nos permite explicar más conocininicintú es en lo que consiste la construcción apagógica o retroductiva: aquel tipo de construcción mediante la que la pura deductibilidad lógica puede dejar de ser solamente argumentativa y devenir en empiricamente explicativa.

El problema, pues, reside en la retroalimentación de los principios a partir de las conclusiones, y es esta retroalimentación de información la que tiene lugar, como he señalado, a través de la estructura misma de los cursos operatorios experimentales mediante los que de hecho se introducen en las ciencias las secuencias empíricas o relaciones funcionales. En efecto, cada secuencia o relación funcional experimental viene introducida en las ciencias de la mano de algún curso de operaciones experimentales. La cuestión es, ahora, que aquello en lo que consiste la construcción de las hipótesis tiene lugar, a su vez, a través del establecimiento de nuevas operaciones, así como de sus correspondientes relaciones funcionales, nuevas relaciones éstas que, a la vez que pueden llegar a explicar a las secuencias anteriores, forman ellas mismas parte imprescindible del establecimiento del significado de las variables o términos de aquellas otras secuencias anteriores. Las construcciones cientificas, en efecto, irían estableciendo una serie de "círculos» o "bucles" entre una multiplicidad de relaciones empíricas, de suerte que a la vez que unas secuencias van determinando el significado de los términos mismos de otras, van posibilitando su propia explicación. Lo que propongo es, pues, la efectiva presencia de una lógica que podríamos llamar material, no formal, esto es, de una lógica operatoria que constituiría la nervatura última de las construcciones científicas - su nervatura apagógica, digamos-, mediante la que se irian componiendo unas operaciones con otras (así como sus resultados, esto es, unas relaciones empíricas funcionales con otras) en un proceso tal que (por esquematizarlo en dos palabras, y de 


\section{Estudios}

un modo idealmente muy simple), dada una multiplicidad de operaciones $-y$, por tanto, una multiplicidad de secuencias empíricas-al menos parte de las conclusiones (o sea, de los términos o variables consecuentes o finales de las relaciones funcionales) pueden ser (re)tomados a su vez como premisas (o sea, como partes iniciales) de nuevos cursos operatorios y de sus correspondientes relaciones funcionales, de las cuales secuencias parte al menos produzcan conclusiones con las que ya contábamos en la secuencias anteriores, además de otras partes terminales de las secuencias aún no obtenidas. Las construcciones científicas consisten en estos nudos circulares o retroactivos establecidos operatoriamente entre una multiplicidad de relaciones funcionales experimentales, así como, por descontado, en las «redes» con las que estos nudos pueden ir entre sí anudándose. Es de este modo, me parece, como las ideas mismas de "explicación" y de "significado" - de los términos de una proposición- se nos aparecen, si las consideramos como disociadas o mutuamente externas, como puras abstracciones (lógico-formal, la una; y semántica, la otra) desenfocadas por lo que respecta a su pertinencia epistemológica para dar cuenta de las efectivas construcciones científicas; a la vez que si nos situamos desde el punto de vista de la construcción científica que propongo, ambos aspectos, el de la explicación y el del significado, aparecen como momentos conjugados internos a un mismo proceso: el de la construcción, como digo, de estos nudos retroactivos establecidos operatoriamente entre una multiplicidad de secuencias empíricas. Pues, en efecto, el peso de la tradición epistemológica dominante nos tiene acostumbrados a pensar como disociados el momento de la obtención de generalizaciones empiricas del supuestamente ulterior y/o distinto apartado de la explicación de las mismas; disociación ésta que resulta solidaria de la compartimentación o disociación entre los aspectos lógicos y los psicológicos de la empresa científica: de este modo, se suele pensar que una generalización empírica puede obtenerse, en primer lugar y de manera aislada, para pasar luego a idear o suponer la conjetura que la explicaria, de suerte que la validez de dicha conjetura quedaría sujeta a su contrastación mediante sus consecuencias observacionales lógicamente deducidas. Sin embargo, la cuestión es que si los términos de una generalización empírica cualquiera poseen ya algún significado, esto no puede ser debido en modo alguno a la sola obtención de dicha generalización empírica aislada: no sólo ocurre que la inducción sería lógicamente insostenible; es que es también prácticamente imposible si sólo contásemos con una clase de operación experimental - y/o de secuencia empirica - aislada. El significado de los términos de cualquier clase de generalización empírica reposa, como digo, en la red de relaciones retroactivas (relaciones en primer lugar físicas, experimentales) establecidas operatoriamente entre una multiplicidad de secuencias o relaciones funcionales sobre un material empirico determinado. Mas, por lo mismo, la obtención de una clase de generalización empírica determinada implica ya al menos un cierto grado de explicación de la misma, es decir, la posibilidad de diversos enunciados que expresen las distintas secuencias empíricas obtenidas puedan anudarse en una red lógica argumentativa, esto es, deductiva, más o menos compleja (y cristalizada) en cada caso. Por así decirlo, los contenidos conceptuales de los términos de una generalización empírica han de comprender ciertos fragmentos semánticos susceptibles de aparecer en otros enunciados explicativos de aquella generalización empírica. Sin duda, pues, que lleva toda la razón la nueva filosofía de la ciencia cuando nos avisa de la carga teórica o conceptual desde la que significamos a los perceptos u objetos empíricos. La más sencilla de las generalizaciones empíricas comprende términos - lingüisticos - que significan a sus referentes observacionales conceptualmente, esto es, "como - siendo- tales o cuales cosas" (en términos de "ver como», tal como se ha expresado, entre otros, el propio Hanson ${ }^{39}$. $Y$, sin duda, que, como asimismo, Hanson señalara esta identificación conceptual de los objetos empíricos consistente en "ver (los) como - si fueran tales o cuales cosas-", no es algo previo o independiente, sino el resultado del "ver que», o sea, del cuerpo de enunciados en donde estos términos aparecen. Como Hanson nos dijera, en efecto, el significado de los términos de un enunciado depende del propio enunciado en el que el término aparece (como dice Hanson: de una claúsula oracional susceptible de ser precedida por la expresión "ver que» ${ }^{40}$ ), es decir, de la red de relaciones que un cuerpo coherente de enunciados establecen entre sus diversos términos. Lo cual equivale a decir, sin duda, que identificar -o enclasar conceptualmente-- a un objeto consiste en poseer el conocimiento de un conjunto de comportamientos legales del mismo, o sea, 
conocer un conjunto de relaciones entre dicho objeto y otros objetos ${ }^{41}$. Así pues, podría decirse que el significado con el que identificamos una cosa depende de la explicación que de ella seamos capaces de dar. Ahora bien, si no queremos, de nuevo, reducir la explicación a una estructura puramente lógico-formal (a una argumentación); o - dicho de otro modo- si no queremos reducir la red de relaciones semánticas dadas en un cuerpo de enunciados a meras definiciones implícitas acompañadas de un cálculo deductivo (con lo que habriamos de retroceder a la afanosa búsqueda lógico-positivista de reglas de correspondencia que interpretasen empíricamente los cálculos axiomáticos - búsqueda infructuosa de la que ya dije que presuponia una metafísica armonía preestablecida entre la estructura lógica del lenguaje y la estructura de la experiencia-); y si no queremos, por otro lado, conformarnos con tener que rellenar «a priori» los postulados de un cuerpo proposicional con contenidos semánticos principialistas - justamente: las $W e l$ tauschauungen a las que recurren muchos epistemólogos de la nueva filosofía de la ciencia-, como manera de dotar de un contenido semántico a los lenguajes y evadir así la situación de definición implícita puramente sintáctica (con lo que, como también señalé, arribamos ahora a una desconexión radical entre experiencia y lenguaje a la que subyace un ocasionalismo metafísico); si queremos, en definitiva, extraer y desarrollar el sentido crítico que anida en la aproximación de Hanson a la idea de que la explicación da la clave del significado, hemos de percibir, me parece, de qué modo el trasunto práctico (por así llamarle) que subyace a estas redes de enunciados desde los que se significa o identifica, a la vez que se explica, a los objetos de la experiencia, reside en el sistema de las relaciones entre las cosas mismas que nosotros mismos bemos puesto en acción mediante nuestra intervención experimental operatoria sobre el medio circundante.

Así pues, no parece que ni las relaciones lógicas de derivabilidad, ni la idea de contenido semántico previo sean suficientes, ni pertinentes, para comprender lo que podemos llamar el modo o proceso de construcción - de producción- de los conocimientos científicos. El problema, como dije, es el de la retroalimentación de los principios a partir de las conclusiones, y éste un problema que ni puede ser solventado por la derivabilidad deductiva, ni puede ser entendido suponiendo, de ante- mano, unos principios semánticos (que, en cuanto que principios eliminan la posibilidad de la retroalimentación).

Me consta que las ideas que acabo de esbozar suponen una considerable reformulación de los planteamientos epistemológicos tradicionales, lo suficientemente drástica, sin duda, como para requerir una pormenorizada revisión de muchas cuestiones epistemológicas esenciales. No puedo en esta ocasión, desde luego, entrar en esta discusión, tan vasta como necesaria. Me voy a limitar, tan sólo, a apuntar hacia una cuestión que tiene muy directamente que ver con el objetivo que quiero abordar en lo que me resta de esta charla.

Se trata de señalar que la idea de inconmensurabilidad, entre las distintas gestalten conceptuales, o entre los distintos paradigmas como modelos teóricos, tan cara a la historiografía y la epistemología de factura kuhnianas, debe ser críticamente retirada, al menos como cuestión de principio. Mas bien, lo que debe ser discutido es dónde empieza y dónde acaba la inconmensurabilidad en cada caso concreto, en el terreno de cada construcción científica en particular. La cuestión es que la corriente kuhniana nos ofrece un modelo de ciencia como construcción metafísica, enteramente semejante, por ejemplo, al modelo aristotélico (o escolástico medieval, asimismo), en donde los primeros principios toman ahora la figura de las Weltauschaungen, y en donde la experiencia, lejos de ser un componente interno, como acto práctico, de la propia construcción de los resultados cognoscitivos (en el sentido en el que he señalado), acaba reducida a una suerte de instancia pasiva e indefinidamente modelable o sometible a la ontología principialista que en cada caso se defienda. No es de extrañar que estas epistemologías perciban tantas inconmensurabilidades, pues éstas lo son entre los modelos ontológicos previos del campo u objeto, de modo que nos habremos de encontrar con tantas inconmensurabilidades como las que de antemano nuestros presupuestos filosóficos quieran poner. Sin embargo, desde el punto de vista de la construcción operatoria que aquí defiendo, la cuestión de las fracturas $o$ inconmensurabilidades entre unas construcciones y otras es algo que debe ser en cada caso concreto detectado con sumo cuidado, y no presupuesto en modo alguno. Pues ahora las fracturas entre unas construcciones y otras, si son efectivas, deberán pro- 


\section{Estudios}

venir de la no composición, de hecho, de unos nudos de relaciones funcionales con otras, de unos racimos de operaciones con otras. Cada nudo o racimo de construcciones operatorias lo es en la medida en que alcanza algún cierre debido a que ciertos términos pueden ser hechos reingresar al campo de términos ya operados mediante nuevas relaciones retroactivas, a la vez que se demarcan o segregan de otros grupos de construcciones igualmente cerradas. La cuestión es, entonces, que ni tiene sentido distinguir entre diversas ciencias en base a supuestos objetos ontológicamente presupuestos, ni tampoco es pertinente distinguir en el interior de cada ciencia entre supuestos distintos paradigmas en base, de nuevo, a demarcaciones resultantes de maneras ontológicas distintas de pensar los supuestos objetos que unificarían a cada ciencia. En definitiva, me parece que sólo el atento examen epistemológico de cada construcción científica concreta puede percibir el estado, en cada momento del desarrollo histótico, de la «república de las ciencias», esto es, el estado de fracturas y continuidades entre las diversas construcciones que pueblan, siempre de manera «irregular", nunca homogénea, el espacio de las producciones científicas.

Pues bien, creo que esta situación es pertinente por lo que respecta a la cuestión que ahora quiero abordar: voy a intentar, en efecto, exponer algunas razones por las que pienso que la psicologia, como ciencia experimental, sí posee un campo autónomo de construcciones científicas.

\section{EL SEGUNDO SISTEMA DE FUNCIONES COMO MARCO DE DETERMINADAS CONSTRUCCIONES PRACTICO-EXPERIMENTALES (LAS PSICOLOGICAS)}

1. Antes que nada, me apresuro a señalar que la caracterización que ahora pueda ofrecer del campo de la psicología científica habrá de ser sumamente abstracta y general, $y$, por fuerza, en buena medida artificiosa: precisamente porque lo que mis propios presupuestos epistemológicos piden es el análisis detenido de fragmentos muy concretos de construcciones cientificas, mientras que yo ahora voy a intentar el muy arriesgado ensayo de esbozar el perfil de todo un campo científico, el psicológico. Desde luego que, desde el punto de vista epistemológico al menos, lo que en psicologia es urgente discutir es hasta qué punto contamos en esta ciencia con algún puñado de algo que se parezca a unos ejemplares experimentales mínimamente sólidos (o sea, de construcciones experimentalmente explicativas mínimamente trabadas en el sentido en el que vengo apuntando). En este sentido, por cierto, si mis ideas alcanzan algún eco entre ustedes, estas jornadas son una buena ocasión para que los psicólogos cognitivos del procesamiento de la información nos exhiban, más que sus paradigmas metafísicos, el o los ejemplares experimentales con los que cuentan. Por mi parte, voy a acabar esta ponencia con algunas reflexiones más bien generales, pero que espero que tengan alguna relevancia y capacidad de orientación. Lo que me propongo es esbozar algunas de las características decisivas que habría de reunir -0 , mejor, que de hecho reúne- lo que podemos llamar el artefacto experimental psicológico como lugar, precisamente en torno al que se organiza la escala o el campo autónomo de la psicología, sin prejuicio de que dicha estructura general sea modulada de múltiples maneras distintas en el muy irregular y heterogéneo panorama que hasta el presente nos ofrecen las construcciones psicológicas. Ciertamente, la perspectiva en la que me sitúo es sumamente general $y$, por esto, no poco artificiosa, en la medida en que no entraré, en esta ocasión, en el análisis detallado de alguna construcción psicológica concreta. Creo, no obstante, que dicha perspectiva podrá ser relevante si es capaz de detectar lo que podemos llamar el perfil epistemológico general de las distintas construcciones psicológicas, no ya como un marco sobreimpuesto filosóficamente a partir de alguna preconcepción sobre lo que debiera ser el objeto de la psicología, sino más bien como la estructura general que de hecho vienen a recorrer las distintas construcciones psicológicas. Veamos.

La característica más general y básica que me parece que cabe encontrar en cualquier construcción experimental psicológica es, a la par, tan simple como, según creo, decisiva. Se trata de establecer los cursos de operaciones experimentales sobre el entorno ambiental externo al organismo de modo que se preserve siempre alguna distancia física espacial entre el medio experimentalmente intervenido y el pro- 


\section{Estudios}

pio cuerpo del organismo o, más específicamente, sus ejecuciones o movimientos de su musculatura de relación.

Aunque esta caracteristica puede parecer, de entrada, tan simple como irrelevante, sostengo sin embargo que ella tiene notables virtualidades epistemológicas que ofrecer. Intentaré explicarlo.

En primer lugar, es menester reconocer que todas las ciencias comprenden un plano fisicalista en el que se nos dan el tejido de operaciones físicas realizadas sobre cosas físicas, corpóreas, que establecen relaciones asimismo físicas entre dichas cosas. El reconocimiento de este plano fisicalista tiene que ver no con ningún prejuicio acerca de la supuesta necesidad de que los conceptos científicos hayan de referirse necesariamente a cosas físicas (como quería el fisicalismo del positivismo lógico), sino con el reconocimiento de que la empresa científica, en cuanto que actividad práctica, está de hecho sujeta a la propia manipulación corporal de las cosas ejecutadas en último término por y desde el cuerpo humano. En este sentido, la psicología cientifica debe tener también - $\mathrm{O}$, mejor, de hecho tiene- su propio plano fisicalista operatorio como cualquier otra ciencia. $Y$ es, de hecho, precisamente a partir de ciertas características específicas de su sistema operatorio fisicalista (de lo específico, digamos de aquello que, como ciencia, comparte con cualesquiera otras ciencias), desde este estrato operatorio más básico, desde donde cabe detectar lo que va a constituir sus peculiares características. Para explicar estas peculiaridades que, como digo, residen ya en el estrato operatorio fisicalista más básico de las construcciones psicológicas, será conveniente decir antes un par de palabras sobre el sujeto operatorio de las ciencias en general.

El sujeto científico, en cuanto que sujeto epistémico, puede ser considerado básicamente, como digo, como un sujeto operatorio que ejecuta operaciones con términos físicos de un material empírico y corpóreo circundante. Ahora bien, podemos considerar que las operaciones pueden reducirse, sin perjuicio de su complejidad, como a sus elementos últimos, a las de separar y aproximar los términos operados (como señala, por ejemplo, Gustavo Bueno ${ }^{42}$, y como ya nos enseñaran, clásicamente, filósofos como Bacon y Locke ${ }^{43}$ ). Ahora bien, tanto la aproximación como la separación presuponen necesariamente la presencia de un tipo determinado de relaciones para que dicha aproximación y separación puedan ser entendidas efectivamente como operaciones - subjetivas - y no ya como meras relaciones objetivas entre las cosas mismas: se trata de la "presencia a distancia» entre los términos que se aproximan o separan, la cual sólo puede ser puesta del lado del sujeto epistémico como condición del carácter operatorio de las aproximaciones y separaciones que ejecuta. En efecto, la operación de aproximar lo que está físicamente distante supone la co-presencia a distancia -en el sujeto operatorio- de lo que está físicamente distante, y la operación de separar constituye a su vez el desarrollo de la presencia distante. Asi pues, es de todo interés distinguir entre estos dos tipos de relaciones esencialmente distintas: las que podemos llamar relaciones por contigüidad, que son las que se dan entre las cosas físicas mismas, y las relaciones a distancia, cuya idea implica de inmediato un modo de co-presencia de lo que está físicamente distante como una relación ya no contigua, físico-contigua, sino de otro tipo. Dicho en términos psicológicos, se trataría de la presencia experiencial de las cosas de la experiencia (de los fenómenos como presencias mentales, experienciales, subjetivas). Sin duda que lo pertinente desde el punto de vista epistemológico consiste en hacer abstracción de las experiencias psicológicas individuales concretas y en perfilar la idea de nexo a distancia como una estructura objetivo-ideal (epistémica) característica de las operaciones, si bien no es menos cierto que no es posible pensar en dichas relaciones a distancia como entidades o aconteceres concretos si no las pensamos como experiencias individuales de sujetos particulares.

Pues bien, la cuestión es que así como dentro de los resultados de los campos de las ciencias físico-biológicas desaparece la presencia del sujeto epistémico que los ha construido, esto es, de las operaciones y los nexos a distancia, ofreciéndosenos los términos del campo trabados por nexos contiguos, en el campo de las construcciones psicológicas van a reaparecer, por efecto de las propias caracteristicas del artefacto experimental puesto en juego en estas construcciones, aquellos rasgos del sujeto epistemológico (o sea, las operaciones y los nexos a distancia) si bien ahora bajo lo que podemos llamar su figura psicológica, 


\section{Estudios}

esto es, como conductas y como fenómenos mentales. Como antes dije, cada secuencia empírica experimentalmente establecida sólo puede establecerse (como generadora, al menos, de algún significado) por la mediación de nuevas secuencias empíricas que, en parte, explican a la vez que constituyen la condición del establecimiento de la secuencia anterior. De este modo, en las ciencias que genéricamente he llamado físico-biológicas, cada secuencia empírica se constituye y perfila, al menos parte de su significado, en la medida en que viene acompañada de otras secuencias que tienden a resolver las relaciones entre las piezas terminales de la secuencia anterior en términos de nexos por contigüidad, que tienden, por asi decirlo, a aproximar hasta juntar las piezas terminales. Considerando, en particular, a la fisiología como el campo de construcciones científicas lindero con la psicología y que, desde siempre, se ha cernido como el primer candidato para absorber y reducir el campo psicológico, resultan de todo interés algunas observaciones. Como nos pone de manifiesto la historia de esta ciencia, una vez descubierta la irritabilidad del tejido vivo y apuntada, por tanto, la más elemental de las reacciones entre el estímulo y la reacción (esbozado, diríamos, el primer tanteo de secuencia empírica), no tardó en descubrirse la posibilidad de separación entre el lugar corporal de la estimulación y el lugar de la reacción en el propio cuerpo (una distancia o separación físico-orgánica, entre diversos lugares del propio cuerpo del organismo). Los esfuerzos de la investigación experimental fisiológica se orientaron inmediatamente a rellenar - por así decirlo- el espacio orgánico interno entre ambas piezas terminales en términos de nexos contiguos neurofisiológicos, esto es, en términos del concepto de arco reflejo. La fisiología y su desarrollo nos ofrecen, ciertamente, una espléndida muestra del carácter quirúrgico de las operaciones experimentales, de lo que podríamos llamar cirugia experimental como patrón de actividad operatoria epistémica. En cada caso es menester abrir, cortar, extirpar, remover piezas fisiológicas, esto es, analizar experimentalmente el tejido orgánico que media entre las piezas terminales de una reacción (de un virtual reflejo) precisamente para restablecer los canales de relación por contigüidad entre las mismas y para poder, por tanto, conceptualizar como una cierta unidad funcional a cada reflejo a la vez que, por lo mismo, explicarlo. Pues bien, también la psicología nos ofrece, según creo, una no menos interesante muestra de análisis experimental de su propio medio, el que talla a su propia escala (analógicamente dicho y, en su sentido epistémico, de cirugia experimental a su propia escala). En psicología - por así decirlo - retrocedemos no ya sólo desde el lugar del tejido orgánico en donde ocurre la reacción hacia otras partes del cuerpo donde tiene lugar la estimulación, sino que nos salimos afuera del cuerpo y establecemos nuestro sistema de operaciones en el medio ambiente a distancia del organismo. Sin duda, el material fisicalista sobre el que ahora operamos viene dado por las piezas del medio ambiente que ulteriormente serán conceptualizadas como estimulos - como estímulos psicológicos-, así como el material fisicalista que modificamos o controlamos a distancia viene constituido por ciertos movimientos o ejecuciones de la musculatura de relación del organismo. Ulteriormente, en efecto, porque en tanto que piezas físicas dadas en un plano fisicalista no son todavía estímulos ni respuestas psicológicas, sino el material en principio no formalizado (conceptualmente enclasado) sobre el que ejecutamos nuestras operaciones. Ahora bien, sori estas mismas operaciones, o mejor, el tipo particular de sistema de operaciones puesto en juego, el canal epistémico a través del cual se organiza la escala psicológica, merced al que se tallan los conceptos de estímulos y de respuestas psicológicas. Cada operación experimental, en psicología, es siempre establecida afuera del organismo - más en particular, preservando alguna distancia física entre el material directamente intervenido y las ejecuciones de la musculatura de relación-, de modo que la conceptualización de cada clase de operaciones es siempre alcanzada por la mediación de nuevas operaciones igualmente establecidas a distancia de las ejecuciones de relación. Pues bien, es este sistema de operaciones (por lo demás semejantes a los de cualesquiera otras ciencias, es decir, es este conjunto de nudos retroductivos entre relaciones funcionales estblecidas entre acontecimientos ambientales y modificaciones de las virtuales respuestas) establecidas siempre a distancia del organismo, el que confiere la figura conceptual de estímulos psicológicos y de conductas -o respuestas psicológicas - a los materiales objeto de intervención experimental. Repárese en que esta característica de preservar la distancia entre el medio y la conducta del organismo acarrea algunas características no menos importantes. Particularmente, estas 
dos: el organismo experimental (animal o humano) se encuentra intacto y desembarazado, es decir, no sujeto a ninguna constricción física (contigua), al menos por lo que respecta a su conducta, lo que quiere decir, en segundo lugar, que dispone de un espacio físico experimental donde poder desplegar sus ejecuciones, bien locomotrices, bien manipulativas. En efecto, las ejecuciones locomotrices (en la que se fijó, clásicamente, Tolman y Lewis, entre otros), o las manipulativas (a las que han prestado su atención clásicos como Throndike, Koehler, Skinner o Piaget) tienen que ver, justamente, con la conducta propositiva $y$, asimismo, con lo que ya Tolman llamara conducta dócil, es decir, con la conducta que puede ser modificada por la manipulación ambiental: con el contexto del aprendizaje, como más adelante volveré a señalar. La cuestión es que el artefacto experimental psicológico construye unas peculiares condiciones en donde se produce un significativo isomorfismo (hasta cierto grado en función de cada especie experimental) entre el sujeto epistémico, los psicólogos y el organismo experimental. Por exponerlo muy brevemente ( $y$ de un modo muy general e idealmente simple): por un lado tenemos ciertos acontecimientos o modificaciones ambientales que se correlacionan (experimentalmente, por descontado) con ciertas ejecuciones locomotrices y/o manipulativas del organismo. Dichos acontecimientos están intervenidos operatoriamente por el psicólogo, lo que supone la manipulación en último término contigua de los mismos (sin perjuicio de que puedan mediar múltiples "aparatos» que no son, a su vez, sino efectivos operadores) a la vez que la presencia a distancia de los mismos como fenómenos para el sujeto investigador.

Por otro lado, las modificaciones en las ejecuciones del organismo constituyen la manipulación por parte de éste de al menos parte de aquellos acontecimientos ambientales dispuestos por el experimentador, una manipulación, asimismo, contigua con dichos acontecimientos (sea la palanca que la rata manipula en la caja de Skinner, o los palos que el chimpancé Sultan encajaba, o el propio suelo del laberinto que las ratas de Tolman recorrían). Estas ejecuciones, a su vez, son controladas por los mismos acontecimientos ambientales dispuestos por el experimentador (entre ellos, aquellos que el organismo manipula), de modo que es semejante control el que resulta establecido experimentalmente a partir de las operaciones del sujeto investigador. La cuestión es que no se trata de un control que suponga constricción física - contigua- alguna sobre las ejecuciones del organismo que modifica (induce, controla), sino de un control de otro tipo: un control que tiene lugar a través de la propia presencia a distancia con respecto al organismo de los acontecimientos experimentales que él manipula. El isomorfismo, pues, viene a consistir en que las piezas del medio experimental que el investigador manipula forman parte, a su vez, del medio ambiente del propio organismo sobre las que también éste ejecuta alguna manipulación. De ambos lados, se requiere una manipulación contigua con dichas piezas del medio (experimental para el investigador y ambiental para el organismo) a la vez que una organización por nexos a distancia (fenoménica) de dichas piezas: aquella organización que confiere carácter operatorio a la intervención experimental y que confiere su carácter conductual a las ejecuciones de la musculatura de relación del organismo. En efecto, la conducta, sin prejuicio de ser una ejecución física (física-orgánica), es una actividad mental, esto es, mentalmente (distalmente, como ahora diré) organizada. Ahora bien, de lo que se trata es de que, como ya he dicho, dicha organización a distancia, o mental, de la conducta por parte del propio organismo debe aparecer como un resultado experimentalmente establecido a través de la intervención operatoria del sujeto investigador. Esto es, la cuestión es que a partir del control experimental que el investigador obtiene sobre la conducta a través de su manipulación de las variables ambientales, resulte como un hecho efectivamente probado, construido, aquella organización mental de la conducta por parte del sujeto experimental, del organismo. Pues bien, la obtención de semejante resultado queda asegurada (posibilitada) por la característica que he señalado, a saber: por el hecho de quedar preservada la distancia fisica entre todas las variables directamente operadas - por contigüidad - y la conducta del organismo. Como ya antes vimos, las explicaciones (a la vez que las significaciones) se construyen en las ciencias cuando se establece una red de relaciones entre una multiplicidad de secuencias funcionales tal que al menos parte de las conclusiones (o piezas terminales) de ciertas relaciones funcionales son tomadas como antecedentes (o momentos iniciales) de otras relaciones funcionales que 
conducen por su parte a nuevas conclusiones de las cuales con algunas al menos ya contábamos. Por descontado, las explicaciones psicológicas han de construirse como en cualesquiera otras ciencias: estableciendo operatoriamente semejantes bucles retroactivos entre una multiplicidad de relaciones funcionales. Así, en efecto, podemos considerar que, en psicología, un determinado acontecimiento terminal o consecuente (pongamos, una modificación en la variable de respuesta) obtenido a partir de cierta operación experimental sobre un acontecimiento inicial o antecedente (una variable ambiental) puede formar parte, a su vez, como momento inicial o antecedente, de una nueva secuencia cuyo resultado o consecuencia sea una modificación en un acontecimiento ambiental, esto es, en una pieza que por su parte puede ser operatoriamente intervenida por el experimentador como nueva variable antecedente de una secuencia en donde, de nuevo, se nos da al menos algún valor de aquella respuesta. Así, por ejemplo, en un diseño de condicionamiento operante (simplificado) una cierta tasa de respuestas es obtenida a partir de un determinado programa de reforzamiento, mas de suerte que la ejecución de cada respuesta involucra una manipulación de cierta variable ambiental (manipular de un modo determinado la palanca de la caja), tal que dicha variable puede a su vez resultar un antecedente ambiental -como estímulo discriminativo- que influye en las modificaciones de la tasa de conducta. Una primera relación funcional es aquí la establecida entre el programa de reforzamiento (o sea, entre cierto valor de la variable ambiental resultante de ciertas operaciones experimentales - sin prejuicio de que semejantes operaciones puedan involucrar la construcción de un dispensador automático de refuerzos) y la correlativa modificación en la tasa de operantes (o sea, una modificación en la variable de respuesta). Mas, a su vez, esta respuesta actúa como antecedente en una secuencia en la que el resultado terminal consiste en una cierta operación sobre un acontecimiento ambiental (la manipulación de la palanca). La palanca cumple por su parte una función de estímulo discriminativo, esto es, de una variable ambiental que puede ser modificada mediante nuevas operaciones experimentales de modo que se obtengan modificaciones en la variable de la tasa de respuestas (por descontado, el hecho de que ciertos dispositivos luminosos puedan ejercer la función de estímulos discriminativos no es sino una facilitación experimental de la operación de modificar los valores del estímulo discriminativo). De hecho, es la variable utasa de conducta» aquella que anuda las distintas relaciones funcionales obtenibles en una caja de Skinner entre las distintas variables (no es de extrañar, desde luego, que Skinner haya insistido en el carácter decisivo de su variable independiente básica - la tasa de respuestasen el análisis experimental de la conducta). Pues bien, lo específico de las construcciones psicológicas se nos muestra, ahora; en el hecho de que en el seno de cada nudo o sistema de relaciones funcionales puestas en juego en cada construcción, aquellas relaciones establecidas entre alguna variable ambiental (como antecedente) y alguna variable de respuestas (como consecuente) a partir de algún curso de operaciones experimentales, se preserva, como digo, alguna distancia física entre ambos tipos de variables, a la vez que dichas relaciones funcionales van siempre acompañadas o anudadas con otras en las que son las ejecuciones musculares del organismo aquellas que - por así decirlo- «borran" o hacen desaparecer dicha distancia al entrar en contacto contiguo con al menos parte de las variables de ambiente dispuestas por el diseño experimental, es decir, en donde son ciertas ejecuciones musculares las que se relacionan ahora (como antecedentes) con al menos parte de las variables de ambiente (como consecuentes) que formaban parte inicial o antecedente del otro grupo de relacionales funcionales, o sea, las establecidas a partir del contacto operacional contiguo del experimentador con ellas. Así pues, semejantes retroacciones construidas entre ambos tipos de secuencias funcionales conducen al resultado de que las variables o términos - en principio fisicalistas- correspondientes tanto al ambiente como a la respuesta muscular quedan utallados» o conceptualmente enclasados en términos de relaciones distales, o sea, de manera que las respuestas musculares aparecen como efectiva conducta - psicológica - en cuanto que distalmente organizada (mentalmente organizada). De este modo, aquellos fenómenos de los que el experimentador parte (o sea, las piezas ambientales en cuanto que percibidas como co-presencias a distancia y objeto de intervención operatoria) re-aparecen de nuevo bajo su misma figura de fenómenos con respecto al sujeto experimental ( $y$ en consecuencia, sus movimientos musculares como conducta). La cuestión es, pues, que a partir del manejo operato- 
rio experimental que el psicólogo realiza con las piezas ambientales (las cuales aparecen inicialmente como fenómenos para el psicólogo) se obtienen ciertos significados desde los que se enclasa o significa a las propias piezas manejadas, asimismo, en términos de fenómenos (relaciones distales) con respecto al sujeto experimental, debido a que se han establecido relaciones entre dichas piezas ambientales y ciertos movimientos del organismo a través de la mediación de esas otras secuencias o relaciones en las que es el organismo el que nos devuelve - poí así decinlo- la misma escaia de relaciones entre las cosas ambientales desde la que nosotros, como experimentadores, las manipulamos. En definitiva, las relaciones funcionales que la psicología obtiene, lo son entre lo que podemos denominar - utilizando la terminología que la propia psicología ha acuñado- estímulos $\longrightarrow$ "presencias»- distales $\mathrm{y}$ conductas molares - sencillamente, entre estímulos y respuestas psicológicos-. En efecto, aquello que - por volver a nuestro ejemplo anterior - exhibe cierto orden experimental, por lo que se refiere a la respuesta, en un diseño de condicionamiento operante (aquello cuya tasa de respuestas exhibe correlaciones significativas y ordenadas con ciertas situaciones ambientales) es el "acto de apretar la palanca». Como el propio Skinner ha señalado, es «apretar la palanca» aquello que funciona experimentalmente como una unidad. Se trata, por descontado, de una unidad molar, que sólo arbitraria o artificialmente podemos intentar descomponer en supuestas unidades «moleculares», en hipotéticos nexos proximales -o contiguos - entre supuestas unidades físicas -fisiológicas- discretas de estímulo y de respuesta. Como ahora señalaré, la crítica más contundente que, sin duda, debe hacerse a la pretensión conductista de descomponer la conducta en cadenas de supuestas unidades atómicas fisicalistas conectables por nexos contiguos es la de señalar su carácter puramente intencional, pero no efectivo, o sea, efectivamente construible de modo experimental. En efecto, como ahora indicaré, es la propia práctica experimental de los psicólogos conductistas la que puede volverse como argumento crítico de sus pretensiones puramente filosóficas.

2. Pues bien, utilizo el término segundo sistema de funciones para referirme a los contenidos que resultan de las construcciones experimentales psicológicas. Se trata, por descontado, de una caracterización epistemológica de este tipo de contenidos en cuanto que construidos, de hecho, a través de un cierto tipo de práctica científica y experimental.

En este sentido, no será ocioso insistir, en primer lugar, en que lo que pretendo es detectar o recoger esta característica consistente en que lo que podemos llamar los bechos mentales - como la forma de organización de la conducta- aparecen, de hecho, como resultados de una determinada construcción experimental. No se trata, pues, de prescribir ninguna concepciứn filousujíca de io mentai como modelo del que debiera hacerse cargo la ciencia psicológica. Como ya he dicho, no creo que la psicologia - ni ciencia alguna- pueda hacerse a partir de concepción o modelo filosófico alguno de su campo u objeto (a partir de alguna filosofia de la mente, en el caso de lá psicologia). Asi pues, lo que defiendo contiene ciertas virtualidades críticas en diversos sentidos. En primer lugar, permite la crítica de ciertas autorrepresentaciones epistemológicas que con harta frecuencia los propios científicos (los psicólogos, en nuestro caso) incorporan a su propia práctica científica. Lo peculiar de estas autorrepresentaciones a las que me refiero consiste en que conciben a la propia ciencia como susceptible de ser realizada desde el modelo de ciencia que contiene dichas autorrepresentaciones, un modelo que nos ofrece a la ciencia como realizable desde cierta preconcepción filosófica del campo o supuesto objeto de conocimiento de dicha ciencia (en conjunción, a veces, con ciertas prescripciones metodológicas). De entrada, pues, la posición que defiendo resulta crítica de estas concepciones epistemológicas idealistas relativas al proceder de la construcción científica que tantos científicos asumen ( $y$ en donde, como ya hemos visto, cabe incluir por igual tanto a la "concepción heredada» como a la corriente kuhniana, así como a no poco de lo que solemos llamar la nueva filosofía de la ciencia). Mas, en segundo lugar, mis concepciones son críticas, asimismo, del contenido filosófico mismo que aparece en algunas de estas autorrepresentaciones epistemológicas por lo que se refiere a su concepción del campo u objeto de conocimiento. Me refiero, en particular, a las posiciones filosóficas reduccionistas de lo mental a alguna dimensión entendida en términos fisicalistas. En efecto, mucho de lo que solemos tomar por psicología científica no es sino filosofia de la mente acoplada al supuesto epistemológico idealista 
de que la ciencia (la psicología) se construye a partir de algún modelo filosófico previo del campo. En este sentido, aquellas filosofias reduccionistas de lo mental a lo físico que con tanta frecuencia los propios psicólogos han asumido (como supuesta guía de su práctica científica) pueden ser efectivamente criticadas (a veces frente a sus propios defensores, los psicólogos) por la vía de constatar la efectiva presencia de los términos mentales como resultado interno de las propias construcciones científicas y experimentales psicológicas (como digo, de las construcciones de los propios defensores de aquellas filosofías reduccionistas). No se trata, pues, de oponer, al menos de entrada, un modelo o concepción filosófica de la mente frente a estos otros modelos filosóficos reduccionistas. Se trata, antes bien, de acuerdo con mi planteamiento de una filosofía y una epistemología de la praxis, de criticar a semejantes reduccionismos tomando como argumento - por así decirlo- el becho práctico, o pragmático, de la efectiva construcción científica de lo mental (supuesto, por descontado, el análisis epistemológico de esa práctica). En el ambiente cultural y epistemológico anglosajón ha habido - $y$ hay - fundamentalmente dos tipos de concepciones reduccionistas que merece la pena considerar, no sólo por su relevancia en el ámbito filosófico (en la filosofía de la mente), sino, asimismo, por la notable influencia que sobre los propios psicólogos dichas filosofias han tenido, habida cuenta - como digo- del carácter idealista de las epistemologías que estos psicólogos suelen asumir. Una es la que entiende que los fenómenos mentales pueden ser reducidos a (anulados en) funciones neurofisiológicas (cerebrales, suele suponerse), y otra es aquella que reduce los'fenómenos mentales a hechos (o disposiciones) de conducta, entendiendo a su vez dicha conducta en términos de cadenas fisicalistas (orgánicas) de unidades discretas de estímulo y de respuesta asociables por nexos contiguos o proximales. Frente a la reducción que podemos llamar neurologista y frente a la conductista se alza $\mathrm{mi}$ defensa de un segundo sistema de funciones como efectiva construcción experimental.

Se comprenderá ahora, según espero, a qué pretendo hacer relación que mi expresión «segundo sistema de funciones». Se trata de defender la efectiva presencia en el campo de las construcciones psicológicas de ciertos términos concebidos (significados, enclasados) como funciones (como funciones son, por ejemplo, las que aparecen en las ciencias biológicas y muy en particular en las construcciones fisiológicas), a la vez que como funciones distintas de las funciones biológicas y fisiológicas. Las funciones psicológicas serían funciones, en efecto, en cuanto, que como cualquier otra clase de funciones, son concebidas como - por decirlo muy brevemente- actos uitiles. $O$, dicho de otro modo, en cuanto que son efectivamente tratadas como funciones, o sea, en cuanto que la psicología construye (como ocurre con amplios fragmentos de las ciencias biológicas y de la fisiología en particular) explicaciones funcionales. Una explicación funcional es aquella que explica el aspecto de actividad de una función en términos del aspecto de utilidad de la misma. En biologia (por decirlo en términos idealmente muy generales y más bien simples) una explicación funcional es aquella que explica alguna actividad (de un tejido, un órgano o un conjunto concertado de órganos) desencadenada en relación con alguna condición que puede ser tomada como ambiental con respecto a la actividad de aquel tejido anatómico (un ambiente intraorgánico en muchos casos), en términos de la utilidad, el papel y/o el valor de aquella actividad, bien sea en relación con el mantenimiento y/o el ulterior funcionamiento de la misma estructura anatómica o de cualesquiera otras del organismo. Pues bien, estas características estructurales de la explicación funcional aparecen, asimismo, en psicología, si bien aqui se trata de otras funciones netamente distintas: pues mientras que la explicación funcional biológica liga los términos de la explicación por contigüidad, la explicación psicológica se construye precisamente cuando (y sólo cuando, diríamos) los conecta - como vengo diciendo-a distancia. Ciñiéndonos, en particular a la fisiología (cuyas funciones son las que nos interesa muy especialmente distinguir de las psicológicas), aqui se trata de conectar los términos que aparecen en el medio ambiente por nexos contiguos con el propio tejido donde se produce la reacción (la actividad), de suerte que la unidad funcional de cada circuito (piénsese en un arco reflejo), esto es, el establecimiento del valor de utilidad de la actividad se alcanza a su vez cuando se conectz por contigüidad la actividad en cuestión con aquella parte del medio ambiente (que puede ser el propio tejido u otro) sobre la que actúa o influye dicha reacción. Por el contrario, en psicología una explicación se construye cuan- 
do se relaciona $\longrightarrow$ anuda - una relación a distancia entre el término ambiental y la actividad con alguna otra relación en donde la actividad alcanza a entrar en contacto contiguo con el término ambiental operado a distancia de aquella actividad.

Se comprende ahora, me parece, el profundo significado (epistemológico) que tiene el hecho de que así como en fisiología los términos de una construcción siempre nos remiten a nuevos términos en el interior del organismo, en psicología, sin embargo, los términos de cada construcción nos remiten siempre afuera del organismo, hacia nuevos términos del ambiente extraorgánico con los que anudar la construcción. En fisiología, por ejemplo, aunque un término inicial ambiental esté situado en el medio ambiente no orgánico se conecta a dicho término con términos que llegan a actuar por contacto con algún tejido periférico - sea, por ejemplo, un receptor-, de modo que es este contacto contiguo lo que constituye el estimulo fisiologico $\mathrm{y}$, de igual modo, el papel de utilidad de alguna actividad que confiere unidad funcional a algún circuito fisiológico se establece cuando dicha utilidad es evaluada en base a la conexión contigua entre dicha actividad y algún otro lugar intraorgánico, esto es, cuando el propio establecimiento de la utilidad nos remite a tejidos y/o ulteriores funciones de tejidos intraorgánicos. Es, sencillamente, la propia periferia del cuerpo aquello que, remitiéndonos siempre hacia adentro - hacia el interior orgánico-, viene a coincidir - por asi decirlo- con los propios límites del cierre de relaciones que operatoriamente establece la fisiologia, y lo que demarca por lo mismo del campo de relaciones y operaciones de la psicología. En psicología, en efecto, no sólo partimos de términos ambientales operados a distancia de las actividades (virtualmente conductales) del organismo, esto es, sobre el medio ambiente extraorgánico, sino que la unidad funcional de semejantes actividades (aquello que, precisamente, las concebitá como conductas, como funciones conductuales) se alcanza cuando componemos aquellas iniciales relaciones con las relaciones que esta actividad de organismo establece con términos del ambiente que, de nuevo, están afuera del organismo, con términos del medio ambiente extraorgánico. No es casual, por descontado, que al soporte muscular de las relaciones del organismo con el medio ambiente externo lo llamemos "musculatura de relación", pues ésta es la musculatura con la que el organismo establece sus relaciones psicológicas, a diferencia de la musculatura (generalmente de fibra lisa en vez de estriada), mediante la que se producen las relaciones intraorgánicas, las fisiológicas. El cierre que limita las posibles redes de relaciones establecidas por la intervención psicológica se establece, pues, por afuera del organismo, de modo que, en este sentido, lo mental - es decir, las relaciones distales que la psicología construye - se presenta -desde el punto de vista de su localización epistemológica, al menos-, nunca dentro, sino afuera del organismo, de su piel.

Por lo demás, las explicaciones psicológicas toman una figura muy distinta de las fisiológicas (y las biológicas en general), desde el momento en que la presencia del aspecto de utilidad implica siempre algún hecho mental (esto es, subjetivo, en vez de puramente objetivo, como acontece en las explicaciones biológicas funcionales): no sólo la propia organización distal de la conducta es, funcionalmente, útil con respecto al desempeño de la propia conducta, sino que la ejecución de ésta resulta útil a su vez en relación con alguna presencia distal: una conducta operante puede ser útil, por ejemplo, con respecto a un estado mental de impulso y, a su vez, un estado mental de atención puede ser útil con respecto al desempeño de dicha operante. Lo mental aparece, pues, en el lugar de intersección de los diversos momentos que componen el circuito de una explicación funcional completa, esto es, de la construcción de alguna unidad funcional psicológica, sin prejuicio, desde luego, de que cada construcción de este tipo se establezca mediante nudos de una multiplicidad de operaciones experimentales, y sin prejuicio, asimismo, de que cada construcción arroje nuevos términos susceptibles de remitir a nuevas construcciones. Por lo demás, sería de todo interés aquí analizar no pocas situaciones específicas - que pueden darse, y que se dan de hecho, en el camino de la investigación psicológica - de muy distinta índole. Así, por ejemplo, un estado de impulso no deja de ser una presencia mental aun cuando la localización física del estimulo originador sea intraotgánica: el estimulo fisiológico se establecería aqui, de nuevo, por contacto contiguo entre la modificación intraorgánica en algún órgano o tejido y la excitación del canal aferente intraorgánico (interoceptivo) de que se trate, mientras que el impulso psicológico aparece 
como una "toma de noticia» o presencia distal, como lo pueda ser un estímulo psicológico del medio externo. De hecho, la construcción psicológica de un impulso (así como de cualquier otra situación que involucre alguna fuente de estimulación no externa), se establece no sólo a partir de operaciones sobre el medio ambiente externo (a distancia de la conducta, de nuevo), sino que se completa cuando se considera la relación entre la conducta y la modificación que ésta ejecuta sobre el medio ambiente externo (la obtención del refuerzo, por ejemplo, o sea de la variable cuya manipulación experimental -privación - indujo el estado de impulso). Siempre en psicología, como digo, la construcción nos remite y se establece con términos que ocurren por fuera de la piel del organismo, aunque pueda estar involucrado algún hecho intraorgánico, del mismo modo a como las construcciones fisiológicas se establecen entre términos de la piel para dentro, aunque puedan, asimismo, estar implicados hechos ambientales externos (como en la fisiología de la percepción, por ejemplo).

Una consideración atenta, en efecto, de estas características epistemológicas que aquí sólo he esbozado nos posibilitarían desarrollar análisis muy detallados de diversas situaciones que de hecho se dan en las construcciones psicológicas, así como perfilar algunas otras características generales y decisivas que, necesariamente, reúnen estas construcciones en cuanto que dadas en su escala psicológica. No puedo, por descontado, entrar ahora en la consideración de estos pormenores, si bien, a título ilustrativo, me limitaré a apuntar estas dos características esenciales: el ámbito de la propositividad, así como el del aprendizaje, constituyen por fuerza los contextos mismos de las construcciones psicológicas.

En efecto, la propositividad aparece -en sus términos más generales- desde el momento en que toda relación establecida entre alguna variable ambiental y alguna variable de respuesta debe contar necesariamente con otras relaciones en donde es la propia conducta la que -como decía- nos devuelve la misma escala de las percepciones del medio desde las que nosotros lo manipulamos, de suerte que nunca intervenimos directamente sobre dicba conducta, esto es, manipulamos por contigüidad sus propias ejecuciones para inducirla (pues ésta sería una constricción fisica que, inmediatamente, nos saca fuera de la escala psicológica): la necesaria presencia de esta suerte de iniciativa, o despliegue espontáneo (no inducido por contacto contiguo operatorio) de la conducta que establece secuencias con términos ambientales imprescindibles, como digo, para obtener construcciones psicológicas nos sitúa inevitablemente en el ámbito de la propositividad (inevitablemente, en efecto; esto es, lo reconozcan o no sus propios constructores posiblemente sujetos a autorrepresentaciones metacientificas empeñadas en desterrar ciertos conceptos de la psicologia). Repárese, por ejemplo, en la necesaria condición de esperar a que el organismo emita espontáneamente - esto es, nunca elicitada de manera refleja- sus primeros tanteos operantes en un diseño de condicionamiento instrumental: he aquí un principio de propositividad. Las explicaciones funcionales psicológicas son propositivas, en definitiva, por la propia fuerza de las características epistemológicas de sus construcciones.

Por lo que respecta al aprendizaje, éste no es simplemente un posible tema más, entre otros, de los que puede ocuparse, o no, la psicología. Constituye, por el contrario, de nuevo, acaso el contexto determinante mismo de toda la psicologia, habida cuenta de ciertas condiciones imprescindibles que establece todo artefacto experimental psicológico. En efecto, la necesidad de retroalimentar los principios siempre con nuevas conclusiones, se traduce, en psicología, en la necesidad de contar siempre con nuevas operaciones ejecutadas sobre el ambiente que establezcan aquellas modificaciones ambientales que modifiquen la conducta. La modificabilidad de la conducta, esto es, lo que ya Tolman llamara conducta dócil, constituye la posibilidad misma para proseguir el curso. de las construcciones psicológicas. Es, en este sentido, en el que el aprendizaje constituye el contexto determinante mismo de la posibilidad de las construcciones científicas psicológicas. Como ya Skinner reconociera, por lo demás, el ámbito de la conducta dócil y propositiva de Tolman coincide con el ámbito de su conducta operante. Es, en efecto, el ámbito de la conducta propositiva y aprendible el que dibuja el espacio de la conducta psicológica: de la conducta cuyo soporte muscular viene dado por la musculatura locomotriz y/o manipulativa, como ya dije.

Así, pues, éstas que llamo las funciones psicológicas vienen constituidas esencialmente por la conducta: son los actos de conducta las funciones 


\section{Estudios}

o actos útiles de los que se ocupa - que construye- la psicología. Naturalmente, el hecho de que semejantes funciones psicológicas, o conductuales, no sean el resultado de ninguna predelimitación teórico-ontológica previa, sino una interna construcción científica del modo como vengo señalando, nos ofrece el argumento práctico, como decía, más relevante para rebatir esas construcciones filosóficas reduccionistas tan falsas como artificiales (artificiales en cuanto que pretenden hacerse valer como guía hipotética de la ciencia psicológica).

En primer lugar, sin ninguna duda, en relación con el reduccionismo que he llamado neurologista (o «cerebralista», podríamos decir). Las auténticas funciones neurocerebrales, así como cualesquiera otras funciones neurofisiológicas, son las que resultan construidas internamente a su escala fisiológica, una escala de construcción ésta que, como hemos visto, se cierra o limita desde la periferia del cuerpo hacia dentro, y cuya frontera - por así decirlo- es el lindero que la demarca de la escala psicológica, que construye siempre componiendo términos por fuera del organismo. Aquí sí que estamos en presencia, me parece, de una efectiva ruptura, discontinuidad o-como ahora se dice - inconmensurabilidad entre dos escalas cientificas distintas. Efectiva, sin duda, en cuanto que establecida por la mutua segregación de dos redes de términos construidas desde planos (o a escalas) operatorias distintas. La cuestión es que, como ya apunté, aun cuando en ocasiones nos encontremos con algunos hechos susceptibles de aparecer tanto en una construcción fisiológica como en una psicológica, no es el término aislado, sino la red de relaciones que en cada caso compone al término con otros términos, es su determinación por otros términos de una construcción determinada, lo que talla su significado $\mathrm{y}$, por tanto, su pertenencia a una $u$ otra escala (como ahora señalaré en relación con los reflejos condicionados). Así, pues, la mutua irreductibilidad explicativa reside radicalmente en la mutua irreductibilidad constructiva (operatoria) de unos sistemas de términos con otros. Esto es lo que no queda contemplado, ni puede quedar, en las concepciones puramente proposicionalistas de la ciencia, aquellas que tienen a su base, de un modo u otro, lo que podemos llamar la escolástica anglosajona de la filosofía del lenguaje. La reducción de lo mental a lo cerebral suele ser establecida por lo general, en efecto, mediante procedimientos puramente lingüisticos, mediante análisis reductivos de algún lenguaje de términos mentales a algún lenguaje fisicalista (neurológico, que suele ser por lo demás un lenguaje neurológico ficción) llevado a cabo de manera más o menos sofisticada. Se presupone, a su vez, que semejante lenguaje fisicalista puede actuar como la explicación reductiva modelo del lenguaje mental, esto es, como el modelo de explicación científica que la psicología debiera poner en práctica (para alcanzar, por lo que se ve, su estatuto de cientificidad: puics hablar ude fünciones cerebrales produce, al parecer, mayor impresión o apariencia de cientificidad que hablar de hechos mentales): si en el lugar hipotético o teórico de un sistema hipotéticodeductivo, contamos con algún lenguaje fisicalista (neurológico) tal que a él pueda encajarse deductivamente los enunciados de base de términos mentales, parece entonces que hubiéramos alcanzado el ideal de la cientificidad para la psicología. Mas la cuestión es, de nuevo, la validez explicativa -científicamente explicativa- de semejante encaje deductivo. $\mathrm{Y}$ es esta cuestión epistemológica relativa al proceder constructivo de la ciencia lo que siempre queda obviado, ignorado, por los análisis puramente lingüísticos, los cuales se limitan a asegurar - por decirlo así- el encaje deductivo --o reductivo- de una lenguaje (mental) en otro (fisicalista) por el expediente de presuponer siempre, a la postre, el supuesto ontológico que la reducción lingüistica pretende demostrar. Por recordar un ejemplo reciente $y$ muy significativo de este tipo de construcciones de una psicología científica ficción: este es el procedimiento que ejemplarmente sigue Mario Bunge en su programa psicobiológico ${ }^{44}$. Bunge se dedica a construir un conjunto de postulados de lenguaje neurocerebral de los que quepa deducir -entre otros - los enunciados relativos a las experiencias mentales. Sin embargo, es fácil percatarse que este proceder no avanza, en realidad, un punto por lo que respecta a las efectivas explicaciones científicas, en cuanto que percibimos que el encaje deductivo entre el lenguaje mental y el neurocerebral viene, de antemano, asegurado por la presuposición ontológica, sé pide que todo estado mental sea un estado cerebral. Naturalmente, es este presupuesto ontológico apriorista el que dota de contenido semántico a todo el canal deductivo, y el que asegura, de antemano, la identidad semántica entre el lenguaje mental y el cerebral, o sea, el que 
garantiza que la identidad analitica del encaje deductivo entre el nivel teórico y el básico del lenguaje se constituya en vehículo de la identidad semántica entre ambos niveles. De este modo, se da por presupuesto lo que se quería demostrar, o sea, lo que se supone que la ciencia psicológica debería demostrar, probar, explicar. Semejante procedimiento, rigurosamente metafísico, nos recuerda, sin duda, el modelo principialista y metafísico de ciencia de Aristóteles (y de la escolástica medieval), en donde era el conocimiento independiente de los primeros principios el que aseguraba la validez de las demostraciones, del conocimiento alcanzado en las conclusiones. Bunge puede, por este procedimiento, dedicarse a producir tantas ciencias como le venga en gana, como ya hizo - y con no menos ingenio- el estagirita. A la postre son, como digo, los primeros principios ontológicos los que siempre subyacen a los análisis reductivos de unos lenguajes a otros, de modo que el contenido semántico de semejantes reducciones no reside, como suele pretenderse, en las puras técnicas de análisis lingüístico (y/o lógico).

Las conductas dejan, pues, de aparecérsenos como reductibles a funciones neurofisiológicas cuando criticamos cualquier tipo de metafísica que lo pretenda, aparentemente escudada en técnicas de análisis lingüísticos reductivos y/o explicativos, en base al hẹcho pragmático de la mutua irreductibilidad operatoria entre sus distintos campos de términos, entre sus distintas escalas científicas.

Ahora bien, prácticamente lo mismo debe decirse de la pretensión conductista, no menos filosófica y metacientífica, de reducir lo mental a ese concepto de conducta que entiende a ésta como una cadena de unidades fisicalistas discretas conectables $o$ asociables por nexos proximales: precisamente, porque lo que caracteriza a la efectiva conducta construida en la escala psicológica es su organización distal (mental) y construida, entre otros, por los propios psicólogos conductistas. Debido a la notable importancia que en relación con la propia psicología tiene este último extremo, dedicaré lo que me resta de esta charla a realizar un par de observaciones sobre esta cuestión.

3. En el caso del conductismo, en efecto, nos encontramos ya no con las pretensiones de los filósofos por elaborar la guía filosófica de la «buena psicología científica» (pretensión que, por cierto, ha adquirido curiosos ribetes de arrogancia, como cuando Fodor nos decía que bastaria con disponer de una tarde libre para clarificar conceptualmente los problemas de la psicología ${ }^{45}$ ), sino con el caso de profesionales de la psicología que, sin prejuicio de haber hundido sus manos en la práctica experimental, han sido a su vez un caso paradigmático de asunción de todos los tópicos epistemológicos y filosóficos que aqui estoy criticando. Es esta circunstancia la que resulta extraordinariamente significativa y la que hace -me permitiré decirlo-, no poco relevante el tipo de análisis epistemológico que aquí defiendo (cuando se considera, sobre todo, la persistencia con la que se abunda en la bibliografia anglosajona epistemológica y psicológica en tantos tópicos que confunden a utirios y troyanos").

El conductismo asumió -paradigmáticamente, como digo- la concepción idealista de la ciencia que entiende que ésta puede hacerse y desarrollarse a partir de algún modelo filosófico de la misma. En el caso de la segunda generación conductista - los que Koch llamara, en su trabajo clásico de 1964 , los neoconductistas - (todos, por cierto, menos Skinner - como ahora se verá-, o sea, los que Skinner llamara sagazmente conductistas metodológicos $)$, dicho modelo de ciencia fue, como es sabido, el propiciado por el positivismo lógico. En el caso de Watson, o sea, como suele decirse, del conductismo clásico, aunque su modelo epistemológico fuera de factura prepositivista-lógico, una suerte de retazos de positivismo tosco de tipo más bien decimonónico, lo cierto es que prevaleció también el sustrato idealista que caracteriza a todo positivismo. Tratábase de pensar que el método de la ciencia, como una suerte de artefacto previo y separado, daría de sí para devenir en práctica científica, bien fuera el método watsoniano, que exigía simplemente atenerse a los términos empíricos u observables, bien fuera el más sofisticado método de la segunda generación, que tomaba el modelo hipotético-deductivo de factura positivista lógica como esquema lógico capaz de hacer o producir teorías. En ambos casos, además de la ingenuidad epistemológica implicada en semejante concepción del método como hacedor de resultados científicos, se acopló una segunda y no menos acrítica suposición, que consistió en hacer pasar o en adherir inadver- 
tidamente ciertos presupuestos teóricos como parte interna o derivable del propio método.

En el caso de Watson, esta exigencia parece justificada porque, sin duda, la exigencia metodológica de atenerse sólo a los datos observables - públicos - conlleva la eliminación de toda referencia a aspectos no públicos u observables (mentales, por tanto), de modo que la conducta ha de quedar concebida por fuerza en términos exclusivamente físico-fisicalistas. En el caso de los neoconductistas metodológicos, la cuestión es más complicada: porque si bien el aparaato hipotético-deductivo permitia, en principio, la inclusión de términos mentales en el nivel de las hipótesis (puesto que de hecho admite la inclusión de términos no observables), fue el prejucio ontológico fisicalista el que los llevó a pensar que, aun cuando en principio no observables, los términos teóricos debieran contener (en el caso de tomarlos como constructos hipotéti$\cos y$ no como meras variables intervinientes recogiendo la terminología clásica de Mac Corquodale y Meehl ${ }^{46}$ ) referentes fisicalistas, esto es, evadir cualquier terminología mental. Así fue como se produjo la concepción conductista de conducta a la que vengo refiriéndome: cadenas - más o menos complejas, más o menos periféricas o centrales - de unidades neurofisiológicas discretas asociables por nexos proximales o contiguos de estímulos y respuestas. En este sentido debe repararse, por cierto, en que lo mismo da que semejantes cadenas se hipoteticen como teniendo lugar por la periferia o en lugares - neurológicos - más centrales del organismo; dicho de otro modo, la alternativa centralismo-periferialismo, que tantas veces es utilizada como significativa para deslindar la posición conductista de otras (a veces, por los propios cognitivistas para resaltar el carácter centralista del cognitivismo frente al periferialista del conductismo; o por el propio Koch, por ejemplo, para distinguir los neoconductistas de los neo-neoconductistas o tercera generación conductista ${ }^{47}$ ), es irrelevante, al menos para diferenciar con ella la exclusión de la aceptación de lo mental, pues, o bien el "centro" al que nos referimos es mental, y entonces desaparece la idea misma de centralidad porque lo mental es efectivamente construido por fuera del organismo, o bien la coherencia de la idea de lo central es estrictamente fisiológica (una centralidad intraorgánica) y por lo mismo no es mental. Así pues, se tomó un modelo fisiológico (como digo, más o menos central) para concebir desde él a la conducta, porque el prejuicio fisicalista ontológico acoplado al método así lo exigia. $O$, dicho con mayor precisión, se pretendió explicar a partir de semejante modelo de cadenas intraorgánicas E-R a las manifestaciones de la conducta observable del organismo. Se suponía que en el esquema hipotético-deductivo, aquellos modelos de neurofisiología ficción - pues, ¿qué otra cosa eran?- ocuparian el lugar de las hipótesis explicativas, y el lugar de los enunciados observables explicados vendría ocupado por las relaciones observadas y experimentalmente establecidas entre las variables ambientales y las de la conducta que se llamó observable, manifiesta o pública. He aquí, en efecto, el esquema característico de la pretensión conductista: explicar las correlaciones experimentalmente establecidas entre las variables de ambiente y de conducta observable acoplando un aparato hipotético deductivo tal que aquellas correlaciones experimentales quedasen deducidas a partir de las hipótesis relativas a aquellos modelos que pedía el prejuicio ontológico fịsicalista; se suponía, de nuevo, que semejante deducción lógica garantizaba la validez explicativa, esto es, que aseguraba que las correlaciones experimentales quedaban tesueltas en términos de los nexos contiguos que aquellas cadenas hipotéticas postulaban. Pues bien, el carácter artificioso tanto de la naturaleza contigüista y fisicalista de los presupuestos teóricos utilizados, como de la concepción epistemológica que subyacía a la pretensión de utilizar semejantes hipótesis del modo indicado, se manifiesta en la muy significativa circunstancia de que mientras que todos ellos manejaron, de becho, relaciones experimentales entre conductas molares $y$ situaciones ambientales distales, aquellos hipotéticos modelos nunca fueron una efectiva construcción experimental, sino que planearon por encima de los resultados experimentales impermeables a ellos. Significativamente, Heider nos decía, en su trabajo de 1939 Determinantes ambientales de las teorias psicológicas, que el error que suelen cometer los teóricos del E-R consiste en hablar de estímulos y respuestas próximas y, sin saberlo, sustituirlos por las distantes en los argumentos y explicaciones 48 . En efecto, lo que hicieron fue manejar experimentalmente estímulos y conductas distales (diríamos, como no podía ser de otro modo), y empeñarse, a la vez, en acoplar un aparato teórico, como pretendida instancia explicativa, que contenía 
todas esas caracteristicas del modelo -filosófico- conductista de conducta en donde la crítica ha ido a fijar la atención: fisicalismo, asociacionismo (proximal, se entiende), atomismo y otros «ismos" que constituyen, en rigor, el paradigma en el sentido ontológico de Kuhn de la teoría conductista de la conducta, pero no su paradigma experimental, o ejemplar, asimismo, en el sentido de Kuhn.

Por apuntar algunas observaciones, casi de manera telegráfica, sobre esta significativa dualidad entre el paradigma filosófico y los ejemplares experimentales del conductismo: empezando por el propio Watson, la cuestión es que con independencia de su tosca y nada precisa metodología y epistemología positivista, que le llevan, como es sabido, a entender, por ejemplo, como respuesta lo mismo una simple secreción glandular que «dar una conferencia» o "construir un rascacielos» (en realidad, lo que parece que hay que entender aquí es que estas últimas respuestas son descomponibles en unidades simples semejantes a la primera), con independencia, pues, de esta pretensión de concebir a la conducta como descomponible en unidades puramente físicas -fisiológicas- y mínimas, lo cierto es que en sus trabajos psicológicos experimentales (en sus clásicos condicionamientos de fobias infantiles, por ejemplo), Watson se mantiene, inevitablemente, en la escala psicológica de los reflejos condicionados.

Los reflejos condicionados constituyen, en efecto, una muy interesante muestra de construcción lindera con la fisiología si bien interna ya a la escala psicológica. Es del todo punto interesante recordar, a este respecto, el tratamiento que les dio su propio descubridor, el fisiólogo Paulov. Como es sabido, Paulov estaba incurso en una investigación estrictamente fisiológica relativa a ciertas funciones neurofisiológicas digestivas. Y fue en el curso de estas investigaciones donde se encontró con lo que de entrada denominó (acaso con más acierto que el que supuso su posterior retirada del término) «reflejos psíquicos». Es muy ilustrativo, y de un gran significado epistemológico, las diversas fases del tratamiento experimental que Paulov da a esta imprevista situación: en un primer momento, Paulov utiliza procedimientos fisiológicos, los que él conoce, los que forman parte de su tradición científica, de su modo de operar. Como es sabido, logra descomponer experi- mentalmente la secrección refleja del estómago del organismo en contacto con la comida de la secreción refleja del mismo estómago cuando la comida ya no está en contacto con él, sino sólo con su lengua, y obtiene, sumando ambas curvas resultantes, curvas muy próximas a las de la secreción total, las que se obtienen cuando el organismo come y a la vez digiere lo comido. Aqui todavia la metodologia operatoria es característicamente fisiológica: nuestro fisiólogo utiliza la cirugía y fístulas, interviene por contacto contiguo con el cuerpo del organismo: en una parte de la prueba deposita la comida en la lengua del organismo y se la extrae mediante una sonda antes de que llegue al estómago y mide entonces las secreciones del estómago, en otra parte del experimento, introduce directamente mediante una sonda la comida en el estómago y mide las secreciones del mismo. Así pues, aunque cuando Paulov mide la intensidad del reflejo «psíquico" puro se produce una separación espacial entre el lugar de la estimulación -la lengua- y el lugar de la secreción -el estómago-, dicha separación espacial sigue teniendo lugar en el seno del organismo, de modo que la unidad funcional del reflejo puede construirse conectando por contigüidad ambos lugares terminales a través de la mediación de algún centro cerebral. En particular, el estimulo se aplica contiguo con un tejido orgánico - la lengua - $y$, significativamente, mientras Paulov opera de este modo, los parámetros de la medida siguen siendo fisiológicos: intensidades de estímulo y magnitud de la respuesta. Ahora bien, en un segundo momento, Paulov desarrolla un nuevo procedimiento: ahora manipula estímulos a distancia del propio organismo (campanas, luces) y pretende construir alguna asociación experimental estable entre semejantes estímulos - ya distales - y las respuestas reflejas conocidas - contiguas, fisiológicas - a estímulos, asimismo, contiguos, mediante la asociación entre estos dos tipos de estímulos: el que se aplica por contigüidad con la lengua y el nuevo estímulo distal. El nuevo tipo de reflejo que construye es ya muy peculiar: la respuesta es semajante a la de los reflejos fisológicos conocidos, pero su elicitación independiente corre ahora a cargo de un estímulo distal. Lo peculiar es que asi como todavía permanecen las medidas experimentales de factura fisiológica para la respuesta (magnitud, latencia y otras), ahora aparecen nuevos parámetros para el estímulo especificamente distales, que - si se me 
permite decirlo así- saltan a la escala psicológica: la generalización y la discriminación del estímulo constituyen ya un fragmento de construcción psicológica. Paulov está haciendo ya psicología, por mucho que sus planteamientos filosóficos, de factura más bien positivista-materialista decimonónica, le llevaran durante toda su vida a defender una suerte de reducción de la psicología a la fisiología (por lo demás, nunca del todo clara). Lo peculiar de los reflejos condicionados es que comprenden respuestas caracteristicamente fisiológicas ligadas a estímúlos psicológicos, y esto hace de ellos un interesantísimo, y no poco complicado, lugar desde la perspectiva de su análisis epistemológico: no es de extrañar que su descubrimiento tuviese lugat en el seno de una investigación fisiológica como la pauloviana, del tipo de lo que el mismo Paulov llamaba fisiología sintética ${ }^{49}$, o sea, aquella que trabaja con el organismo integro si bien no desembarazado, y en donde, por tanto, la metología operatoria, aunque fisiológica en cuanto que opera por contigüidad con un organismo no desembarazado, permite la ocurrencia, debido a su carácter íntegro, de acontecimientos nuevos no controlados por las manipulaciones fisiológicas experimentales, y difícilmente encajables en el cuerpo de conocimientos y métodos operatorios anteriores: los «reflejos psíquicos» que Paulov tuvo el acierto de categorizar reconstruir y no dejarlos pasar simplemente como un acontecimiento experimental extraño - no identificado-, identificación conceptual ésta que involucró la construcción de un fragmento de conocimiento situado ya en una nueva escala, la psicológica. Así pues, un mismo material puede quedar tallado conceptualmente de modos distintos según la escala de los términos con los que se compone. Las propias reacciones reflejas pueden, pues, sin prejuicio de formar parte de muchas construcciones fisiológicas, ser componentes internos, asimismo, de las construcciones psicológicas: la respuesta condicionada es una respuesta psicológica en razón del nexo -distal- que la relaciona con los estímulos distales-condicionados. Se comprende, por lo demás, que los reflejos condicionados constituyan un ámbito muy especial y complicado donde confluyen las más diversas tecnologías y ciencias: la medicina psicosomática, la psiquiatria córtico-visceral, la modificación de conducta, que laboran todas ellas, cada cual desde su propia escala o perspectiva sobre este material inicialmente desbrozado por Paulov.
Sin prejuzgar, en definitiva, las posibles implicaciones que los condicionamientos de respuestas fóbicas infantiles de Watson tengan en relación con otras aproximaciones - biológicas, fundamentalmente-, lo cierto es que su intervención se sitúa en el plano de la modificación de conducta, que es, por descontado, una tecnología psicológica.

En el caso del neoconductismo metodológico, la situación es, si cabe, aún más ejemplar. Hull y Spence fueron quienes postularon toda una compleja fisiología ficción, organizada según los más estrictos cánones de la metodologia hipotética-deductiva, para dar cuenta en términos de nexos contiguos de los estímulos y respuestas distales a los que, sin embargo, el propio Hull recurre cuando nos aclara el significado auténtico de sus ficciones. Así, por ejemplo, para explicar los hábitos que una rata aprende para salir de un laberinto, recurre, como se sabe, a la hipótesis «reacción fragmentaria y anticipatoria de meta", como supuesto nexo proximal entre estimulos y respuestas fisiológicos que estaria presente en cada situación decisiva del laberinto para explicar la llegada del animal a la meta. Sin embargo, todo lo que Hull nos dice de semejante reacción a la meta es que se define por "anteceder en el mismo lugar del ambiente» y por «estar orientada de la misma con respecto al lugar de partida", o sea, como se ve, mediante términos distales ${ }^{50}$. Curiosamente, con semejante caracterización distal de lo que por su parte el método y sus prejuicios teóricos piden entender en términos proximales, Hull le está dando a Tolman la razón inadvertidamente.

Guthrie, por su parte, es, con toda seguridad, quien nos ha ofrecido el paradigma más ejemplar de concepción conductista de la conducta. Ahora se hace abstracción de todos los problemas teóricos que ocuparon a los conductistas -efectivos problemas teórico-experimentales concretos-, como el de la alternativa entre uno o dos modelos de condicionamiento, o el del papel del refuerzo en el aprendizaje, y se limita a ensayar un modelo de aprendizaje en rigurosos términos de conexiones contiguas entre unidades discretas netamente fisiológicas de estímulo y de respuestas. Significativamente, su intento de explicar en términos de nexos contiguos E-R por un solo ensayo aquello que experimentalmente se manifiesta como un aprendizaje con- 
tinuo y gradual de los que el propio Gutrhie tuviera que llamar actos de conducta correlacionados con lo que, asimismo, acabó llamando patrones de estímulo acaba por complicarse hasta el infinito y ofreciéndonos, como los clásicos epiciclos de Ptolomeo, una perfecta muestra de la posibilidad que ya Popper previera que tiene una teoría para escapar, por medios lógicos, una y otra vez, a su refutación empírica, o lo que Lakatos llamara un programa degenerativo de investigación. Por lo demás, la adecuación entre la situación del modelo teórico de Gutrhie y el modelo epistemológico de Popper es a su vez muy significativa de la incapacidad del formalismo popperiano (y a la postre del de Lakatos también) para dar cuenta de los efectivos procedimientos de construcción científica: los núcleos metafísicos de Lakatos - como las teorías de Popper- (y el modelo de Gutrhie es un caso ejemplar de semejante artifico metafísico) son, por su propia naturaleza puramente proposicional, perfectamente impermeables a la experiencia, debido a que no son resultado interno de una construcción experimental.

Por lo que respecta a Tolman, su caso es no menos significativo. Ahora nos encontramos con una construcción experimental que comprende claramente términos mentales - y cognitivos-, a la que, sin embargo, su autor se - empeña en acoplarle la metodología lógicopositiva (esta vez, por la vía de la versión que dicha epistemologia hizo del operacionalismo) para -digamos- ponerla a salvo de toda sospecha de acientificidad. Por cierto, que la versión del operacionalismo que asumiera el positivismo lógico, y con él el conductismo metodológico, no se corresponde en absoluto con la concepción de las operaciones que aquí he defendido, así como tampoco, como ahora señalaré, con el operacionalismo de Skinner, el cual, como el mío propio, está mucho más cerca del espiritu pragmatista que el operacionalismo tuviera en el propio Brigman que de la versión formalista que de él diera el positivismo lógico. El operacionalismo de Boring, Stevens, Tolman y Prats, el de factura positivista lógica, no tomaba a las operaciones como determinantes internos de la construcción de los conceptos y proposiciones (como aquí he defendido), sino tan sólo como reglas experimentales de correspondencia para re-definir, o reducir, a los términos teóricos previamente construidos en una estructura hipotética deductiva en términos de términos de observación. Por decirlo en dos palabras (lo que, por lo demás exige una consideración muy detallada): se trata, sencillamente, de concebir dos procesos estrictamente inversos por lo que respecta al lugar y papel de las operaciones. Mientras que desde la perspectiva pragmática se defiende la construcción de los propios términos y proposiciones (los teóricos incluidos, por descontado) a partir de las operaciones (desde luego, como se ha dicho, de sistemas de operaciones) desde la versión proposicionalista-logicista se presupone la construcción puramente proposicional de racimos de proposiciones y se defiende después la ulterior reducción de los términos teóricos a significados observacionales por medio de las definiciones operacionales, como una regla más posible de correspondencia.

Asumiendo la versión positivista lógica, los conductistas metodológicos trivializaron las operaciones hasta el punto de dejarlas convertidas en poco más que meras señalizaciones deícticas que unos científicos podían hacer a otros para ponerse de acuerdo en torno a la presencia de algún acontecimiento no observable, como, por ejemplo, una percepción de un organismo en un diseño de discriminación, señalando a los acompañamientos fisiológicos del órgano de la percepción - los ojos, por ejemplo: así es, en efecto, como nos presenta Stevens el operacionalismo en su trabajo clásico de 1939 La Psicología y la Ciencia de la Ciencia. La trivialización de las operaciones es tal que vienen a ser simples sustitutos de las definiciones ostensivas del positivismo lógico, empleadas ahora para llegar a un acuerdo público en torno a algún proceso no observable. Supusieron con esto los conductistas que sería posible recuperar el lenguaje mental para los niveles hipotéticos o teóricos de una estructura deductiva, habida cuenta de que su ulterior definición operacional devolvia a dichos términos su auténtico contenido científico, que es, de nuevo, fisicalista, observacional. Significativamente, mientras que la escuela de Yale no recurrió al expediente operacional, porque postulaba de entrada términos teóricos ya fisicalistas $\longrightarrow$ sea, neurofisiológicos-, aquellos que, como Tolman, utilizaban términos mentales en sus teorías, se veían impelidos a legitimar sus construcciones destruyendo su sentido psicológico mediante la definición operacional. La cuestión es que, de haber sido efectivo semejante expediente operacional (esto es, de no haber sido lo que en realidad fue, 
un artificio puramente intencional), toda la construcción de Tolman perdería su sentido psicológico: pues si términos como «expectativas», «demandas» o «aprendizaje de lugares» tuvieran que ser re-definidos en términos de acontecimientos fisicalistas, toda la construcción de Tolman vería desaparecer su sentido psicológico, de modo que en verdad lo mismo hubiera dado hablar de términos mentales como de cualquier otra cosa, dado que se trataría de meras maneras de bablar. Paradójicamente, de ser efectivo semejante modo de entender a las operaciones, ahora seria Tolman quien le daria inadvertidamente la razón a Hull en su clásica polëmica. $\mathrm{Y}$, sin embargo, hay una poderosa razón para recuperar el sentido epistemológico que tienen las operaciones en Tolman: las operaciones de las que éste nos habla descansan siempre sobre las variables experimentales ambientales a distancia del organismo: de aquí que los términos fisicalistas en los que supuestamente quedan redefinidos los términos teóricos no sean en Tolman términos neurofisiológicos, sino términos ambientales que ocurren por fuera del organismo. Se trata ahora, pues, de re-construir - por así decirlo- la dirección del proceso que Tolman nos ofrece en relación con el papel de las operaciones, y detectar cuántas de ellas son efectivos determinantes de la construcción de no pocos términos teóricos genuinamente psicológicos, mentales.

En realidad, lo mejor que desde el punto de vista psicológico científico los conductistas nos ofrecen está en sus efectivos manejos experimentales de las variables de ambiente y de conducta externas al organismo, que es donde se configura la escala de lo psicológico como construcción experimental, y no en las hipótesis que imaginan estados intraorgánicos, que responden a lo peor de su aportación, o sea, a su filosofía conductista, a sus prejuicios metodológicos y a sus adherencias ontológicas. El periferialismo, de este modo - que tan ingenuamente ha sido criticado por tantos como uno de los defectos del conductismo-, resulta ser aquella característica de la concepción conductista de la conducta que mejor recoge -que no falsea - su propia andadura experimental. Es, sí, de la periferia del organismo para afuera donde se construye la escala de lo psicológico. Y Tolman fue, ciertamente, un psicólogo sumamente sagaz que tuvo, a pesar de sus prejuicios metodológicos conductistas, la perspicacia de no imaginar hipótesis fisiológico-proximales que hubieran desvirtua- do por completo la naturaleza efectivamente distal y molar de sus construcciones.

Pues bien, todo lo que hasta el momento he dicho como crítica a los presupuestos epistemológicos del conductismo metodológico debe ser retirado en el caso de Skinner, pues éste no ha sido jamás un positivista lógico, sino por el contrario el más lúcido de los conductistas - acaso el único- en sus certeras críticas a la metodología del conductismo metodológico de factura positivista lógica. Skinner ha side, por descontado, un conductista, en el sentido de que ha defendido una explícita - y no poco coherente, por cierto- interpretación filosófica de la naturaleza humana, así como de sus resultados experimentales. En este sentido, se le puede agradecer, por lo menos, el habernos explicitado abiertamente los supuestos ontológicos conductistas que en el conductismo metodológico andaban encubiertos bajo un disfraz de metodología científica. Ahora bien, Skinner no ha sostenido en modo alguno esta que bien podriamos llamar su antropologia filosófica conductista como una exigencia derivada de metodología científica alguna. Sencillamente porque nunca Skinner ha defendido metodología alguna en el sentido de algún conjunto de prescripciones previas que hubieran de ser cumplidas para hacer ciencia.

Me permito decir que la verdad es que son tantos y tan profusos los malentendidos que abundan sobre la obra de este autor (el origen de los cuales tiene que ver con el empeño tan extendido de entenderle bajo el prisma del positivismo lógico, y en asimilarle, por tanto, al resto de los conductistas), que me es dificil desenredar en dos palabras la madeja.

Por plantearlo así: Skinner nunca ha partido del supuesto de que fuera menester contar con alguna metodología previa resultado a su vez de algún modelo filosófico de ciencia. Como venimos viendo, ésta es la concepción del positivismo lógico, que involucra una perspectiva de fondo idealista. Para Skinner, por el contrario, cualesquiera conductas humanas, y la ciencia entre ellas, son el resultado de su selección práctica por sus consecuencias. Se trata de la más radical concepción pragmática que quepa imaginar: de toda acción humana $y$, por tanto, también de la ciencia. Así, por ejemplo, en su decisivo artículo $U n$ caso bistórico dentro del método científico, de 1956, Skinner 
nos ofrece una de las críticas más irónicas y mordaces que quepa imaginat de la idea de una metodología separada, y en particular de una metodologia formal hipotética-deductiva (unas cuantas décadas antes que la crítica de Feyerabend al método, por cierto, sólo que aqui con argumentos pragmático-conductuales y no desde el plano después del todo proposicional en el que se mueve el idealismo de Feyerabend). Nos ofrece aquí Skinner, en efecto, una descripción de su proceder o conducta científica en términos de ensayo y error en donde todo, desde los aparatos a las variables relevantes, asi como los conceptos resultantes, van apareciendo o resultando a través de su comportamiento experimental con el medio experimental que su propia conducta va construyendo. La ciencia es para Skinner construcción en el sentido más radicalmente comportamental y manipulativo (en el linaje de las construcciones de cacharros y artefactos de juego que, según nos recuerda en su biografía, tanto le gustaba construir de niño). El modelo de construcción de teorías demandado por el positivismo lógico es el que fue radicalmente criticado por Skinner en su no menos célebre artículo ¿Son necesarias las teorías del aprendizaje?, de 1950. No parece haberse comprendido suficientemente que lo que aquí Skinner se cuestiona es la necesidad o no de esa manera de construir las teorias que reclamaba el conductismo metodológico, y que lo que concluye es que, precisamente en cuanto que construcciones puramente verbales independientes de su construcción experimental son inncesarias (aunque "entretenidas", como reconoce). En ningún momento Skinner niega la posibilidad de alcanzar teorías a partir de la complicación de las operaciones experimentales puestas en juego por el análisis experimental de la conducta, y precisamente porque contempla a las teorias efectivas como un posible desarrollo del análisis experimental indica que aún falta tiempo para ello. $Y$ por lo que respecta a las operaciones, se ha de subrayar que la confusión interpretativa parece subir de punto cuando se empareja el célebre artículo El análisis operacional de los términos psicológicos, de 1945, con el operacionalismo del positivismo lógico. Difícilmente puede encontrarse en toda la bibliografia psicológica y epistemológica producida durante la hegemonía del positivismo lógico una critica tan interesante de la versión del operacionalismo defendida por esta epistemología, del operacionalismo del conductismo metodológi- co, del de "Boring y Stevens", como el propio Skinner dice, asi como una crítica tan sagaz, desarrollada con argumentos pragmáticos, a la idea de que el lenguaje no es por si mismo significativo, a no ser que lo re-formulemos en términos de referentes públicos. Para empezar, el lenguaje subjetivo sí es, de entrada, significativo para Skinner como una cuestión pragmática, esto es, debido al hecho de que la gente de hecho lo utiliza - luego es seleccionado por alguna consecuencia útil- Otra cosa es la naturaleza de sus referentes, y aquí Skinner entiende - llevado por su concepción conductista fisicalista - que dichos referentes son cosas fisicas - estímulos intraorgánicos entendidos como presencias físicas--. Así pues, todo el intento del conductismo metodológico por re-formular el lenguaje privado en términos de referentes públicos carece de interés para Skinner, desde el momento en que las personas han aprendido de hecho a significar sus referentes privados por sus consecuencias útiles (sin prejuicio, como digo, de que Skinner malentienda la naturaleza de dichos referentes privados) en el contexto de una comunidad que ha ido enseñándoles a referirse a tales referentes privados asociando ciertos términos privados con referentes públicos. La reformulación de un lenguaje supuestamente construido por procedimientos formales en términos de referentes públicos ha de aparecérsele a Skinner como inútil y artificiosa desde el momento en que las personas ya han aprendido de antemano pragmáticamente a utilizar términos privados. Desechado el valor epistemológico de semejantes definiciones operacionales, Skinner nos exhibe a las operaciones científicas por la vía de su ejercicio, esto es, contando con las operaciones que en cada análisis experimental concreto introducen ciertas variables y relaciones funcionales.

Así pues, lo radical del conductismo radical skinneriano debe cifrarse en esta perspectiva radicalmente pragmática desde la que su filosofia enfoca toda empresa humana, y la científica en particular, frente a la posición. metodológica desde la que la ciencia era vista en el conductismo que Skinner mismo denominara con este término - metodológico- Esto no impide, por descontado, reconocer que al lado de esta perspectiva radicalmente pragmática Skinner haya defendido lo que podríamos llamar contenidos conductistas, esto es, una concepción fisicalista de toda la realidad. Ahora bien, precisamente sin renegat de su perspectiva 
pragmática (que, como puede apreciarse, yo comparto de muy buen gusto), sino ateniéndose a ella, cabe realizar un análisis epistemológico exento de sus presupuestos contenidos conductistas, en cuanto que fisicalistas, de su propia práctica experimental -del análisis experimental de comportamiento- y tomar estos resultados (como venimos haciendo) como argumento pragmático frente a los propios contendios conductistas (fisicalistas) desde los que (según sostengo, erróneamente), Skinner interpreta dichos resultados de su análisis experimental.

Como es obvio que no dispongo ahora de tiempo para esbozar siquiera el análisis epistemológico del análisis skinneriano de la conducta, me limitaré a apuntar un par de observaciones sobre algunos trabajos muy tempranos de Skinner en donde se nos muestra ya la muy significativa tensión a que me refiero entre la figura epistemológica que toman sus construcciones experimentales y la pretensión conductista de interpretarlas en términos fisicalistas. Me refiero a sus trabajos El concepto de reflejo en la descripción de la conducta, de 1931 , y La naturaleza genérica de los conceptos de estímulo $y$ respuesta, de 1935 . En el primero de ellos nuestro autor pretende perfilar el concepto de reflejo en un punto que podríamos llamar intermedio, o sea, que valiera igualmente para caracterizar al reflejo como pieza fisiológica que como unidad de análisis de la conducta, cuando define al reflejo como una correlación comprobada $u$ observada ante un estímulo y una respuesta: es como si, de este modo, Skinner desease preservar el plano fisicalista para ambos tipos de análisis. Sin embargo, es éste un punto inestable, puramente artificial, que no pertenece en rigor ni a la fisiología ni a la psicología y que inmediatamente se duplica y desglosa en dos sentidos distintos e irreductibles en cuanto que avanzamos un punto en el análisis experimental de cualquiera de los dos campos. Así to reconoce Skinner, cuando señala que la fisiología se interesa por las mediaciones que ocurren en el arco reflejo entre las dos piezas terminales, mientras que la psicología se atiene a lo que ocurre de la piel para afuera del organismo. En efecto, Skinner nos ofrece una muestra de los dos tipos de obtención de distintas clases de legalidades, unas fisiológicas y otras correspondientes al análisis de la conducta, tal que a pesar de la oscuridad conceptual que se deriva de su imposición de una misma terminología para ambos casos, tanto los propios procedimientos experimentales como sus respectivos resultados desbordan aquella homologación terminológica. Así, Skinner apela, para dar cuenta de las legalidades experimentales propias del análisis de la conducta, al establecimiento de terceras variables de ambiente distintas del estímulo que forma parte de una correlación refleja, las variables relativas al impulso, a la emoción y al reforzamiento que resultan de la manipulación del medio ambiente externo y que son las que exhiben curvas o correlaciones ordenadas con la tasa de respuestas de una operante. Aunque todavía aquí Skinner mantiene la oscuridad y ambivalencia conceptual al hablar simultáneamente -0 indistintamente - de las operaciones experimentales mediante las que se introducen estas terceras variables del análisis de la conducta y las operaciones experimentales consistentes en la provocación repetida de ciertos reflejos espinales que establecen las leyes dinámicas o secundarias de los reflejos (la ley de la fase refractaria, la ley de la fatiga, la de la facilitación y la de la inhibición); o sea, aunque todavía pretende amparar bajo una misma terminología (el "reflejo» y la expresión "fuerza de reflejo») a las situaciones experimentales correspondientes a las leyes dinámicas del reflejo (leyes fisiológicas) y a las leyes dinámicas del condicionamiento operante, lo cierto es que la neta diferencia de escala entre ambas clases de leyes nos la exhibe el propio Skinner cuando nos percatamos de que las unidades de medida que especifican a las leyes dinámicas reflejas (fisiológicas) siguen apoyándose en las magnitudes con las que se miden los estímulos y las respuestas reflejas de las leyes primarias, esto es, la intensidad y duración, mientras que la unidad de medida que ubica experimentalmente a la respuesta operante, la tasa de respuestas rompe ya cualquier relación con aquellas unidades de medida reflejas anteriores. Significativamente, mientras que los «cambios concurrentes en la respuestay que tienen lugar en las leyes dinámicas reflejas son medidos en base a las medidas del estimulo y las respuetas de las leyes primarias (de modo que la ufuerza del reflejo» es siempre una medida indirecta en este caso, como el propio Skinner precisa), los cambios dinámicos de la conducta operante adquieren una medida directa, la tasa de respuestas, que no tiene ya nada que ver con aquellas unidades reflejas de medida. En efecto, la definición genérica de las clases de estímulos y respuestas que Skinner busca - expe- 
rimentalmente, de nuevo- en el segundo de los artículos citados, constituyen precisamente las clases psicológicas en las que quedan conceptualizadas las variables de ambiente y respuesta como consecuencia, según nos dice Skinner, de un cierto grado de restricción experimental, un grado donde, precisamente, desaparecen tanto las operaciones como las variables experimentales independientes que habian establecido las leyes dinámicas de tipo reflejo, esto es, las fisiológicas. En realidad, las variables de ambiente del análisis de la conducta no son tales terceras variables, dado que la expresión "tercera" la introducía Skinner en relación con las dos variables correspondientes al estimulo y las respuestas de un reflejo (fisiológico): son, simplemente, las nuevas y distintas variables psicológicas. Unas variạbles cuya definición genérica hace, precisamente, abstracción de las múltiples variaciones fisiológicas de respuesta dentro de una misma clase psicológica de respuesta, porque aquello que, como Skinner dice, procede experimentalmente de manera unitaria con respecto a estas nuevas variables de ambiente es «apretar la palanca» ${ }^{51}$. La clase psicológica concebida como «apretar la palancan es rigurosamente molar, pues hace abstracción de las múltiples posibles variaciones «moleculares» que una situación dada puede contener. Ya es significativo que Skinner no haya puesto nunca hincapié en la idea de nexos proximales o contiguos, sino que todo su énfasis se haya puesto, al defender su interpretación conductista, tan sólo en la naturaleza fisica de los procesos. Es como si Skinner se conformara con subrayar el carácter fisicalista de sus variables, silenciando cuidadosamente el principio de los nexos contiguos, esto es, sin atreverse a sacar las consecuencias derivadas del hecho de que la congruencia de las correlaciones entre sus variables fisicalistas se obtienen manteniéndolas experimentalmente a distancia, pero a la vez atisbando que el principio de los nexos contiguos es enteramente externo e irrelevante a su efectiva construcción experimental. En esto, Skinner, como ya hiciera Tolman, ha hilado fino.

4. Por último, no quisiera terminar sin esbozar, aunque sea muy brevemente, un par de sugerencias sobre la psicología del procesamiento de la información, sobre la que hasta el momento no he dicho nada, y que es el "paradigma» (como gustan de decir no pocos de sus defensores) que nos ha reunido en estas jornadas.
Pues aqui también habria que distinguir entre el paradigma ontológico o filosófico que muchas veces se nos ofrece a título de "primeros principios", de los efectivos ejemplares experimentales con los que hasta el presente contemos. En este sentido, haré dos puntualizaciones.

La primera tiene que ver con ciertas pretensiones filosóficas innatistas que no con poca frecuencia se vislumbran entre algunos psicólogos cognitivos. El innatismo es, sin embargo, impermeable a la propia naturaleza - epistemológica- de la construcción científica psicológica. No se trata, de nuevo, de criticar semejante concepción filosófica -al innatismo- desde alguna otra concepción filosófica, sino de señalar que las construcciones psicológicas experimentales segregan cualquier pretensión innatista de su campo por necesidad. Por necesidad, en efecto, en cuanto que, como dije, la necesidad constructiva de retroalimentar los principios con las conclusiones toma en psicología la forma de contar siempre con conductas dóciles o modificables por nuevos cursos de operaciones experimentales sobre las variables de ambiente: el aprendizaje es el contexto determinante mismo de la psicología científica, lo cual no excluye, por descontado, la posibilidad de la presencia de variables cognitivas en las construcciones psicológicas (o sea, el estudio experimental del aprendizaje de procesos cognitivos, asi como del papel de los procesos cognitivos en el aprendizaje). Lo que sí excluye es la pretensión de construir modelos aprioristicos innatistas que por lo demás nos reintroducen, bajo terminologías tomadas de tecnologías y disciplinas muy actuales, añejas metafísicas de todos conocidas. Ahora bien, las pretensiones innatistas no son arbitrarias dentro de los modelos ontológicos cognitivistas, sino que están estrechamente relacionadas con los modelos heurísticos que estos paradigmas filosóficos toman con la pretensión de hacer ciencia psicológica a partit de ellos. La gramática transformativa y generativa de Chomsky y el funcionamiento de los ordenadores (modelos heurísticos éstos privilegiados de buena parte de la psicología cognitiva) exigen que las «performances» se desarrollen a partir de algún programa previo (sea el programa de un ordenador, sean los universales lingüísticos chomskianos). El problema, cuando se toman estos heurísticos en relación con la psicología, es que la retroalimentación de los principios por las conclusiones que 
exige la construcción científica equivale ahora a la re-programación por medio de la conducta de las variables cognitivas en cada diseño experimental. No niego, en absoluto, pues, la posibilidad de construir variables cognitivas a través de su retroalimentación, como principios o hipótesis teóricas, suministrada por (nuevas) conclusiones, o sea, a partir de (nuevas) modificaciones de conducta en relación con variables ambientales. La cuestión es, sin embargo, que la propia construcción psicológica, por un lado, y la construcción de las gramáticas generativas 0 de los crdeñadores, por otro, se orientan en direcciones diferentes $y$ aun opuestas. Pues mientras que la "performance» de un ordenador o la generación de alguna estructura lingüística concreta nos remite siempre a algún programa previo, de modo que su propia lógica de construcción se orienta en la dirección de la propia lógica formal deductiva, la construcción de la psicología empírica se orienta en la dirección de una construcción no deductiva, sino, como sabemos, retroductiva. El innatismo aparece entonces como una simple metáfora, como el resultado de aplicar a los problemas psicológicos de una manera puramente conceptual - no científico-empirica- el modelo de la lógica deductiva.

Sencillamente, la tecnología de la construcción de ordenadores, así como la gramática generativa, son disciplinas formales (me refiero, por descontado, al ingeniero de programas -o «softwares»-, no al ingeniero de la ferretería de la máquina - de los "hardwares»--, al ingeniero industrial), pero no disciplinas empiricas. Se construye una filosofia, como cualquier otra, cuando semejantes disciplinas formales se toman como heuristicas relativas a la naturaleza humana. Pero son los psicólogos cognitivos, cuando tienen las manos puestas en algún diseño experimental (no cuando hacen propaganda de su metafísica cognitivista), los primeros que saben de las efectivas anomalías experimentales relativas a las conductas de sus sujetos -animales, humanos o no- con las que se topan cuando pretenden dar cuenta de estas conductas desde los modelos informáticos.

Una segunda -y última cuestión-. Como todos sabemos, es ya un tópico contradistinguir a los modelos cognitivistas de los conductistas, en términos de la alternativa "asociacionişmo versus representación", o alguna otra semejante. Lachman, Lachman y Butterfiel, por tomar un ejemplo representativo, nos repiten, en su manual de 1979 sobre Psicologia Cognitiva y Procesamiento de Información el muy extendido tópico: mientras que el conductismo hubiera procedido por asociaciones ciegas, impermeables a las significaciones, el cognitivismo recuperaria las asociaciones significativas ${ }^{52}$. De nuevo, está por ver si semejante polaridad entre asociaciones y representaciones (o asociaciones ciegas frente a asociaciones con contenido significativo o informacional) no es más que un enfrentamiento entre paradigmas filosóficos discĩado ă bố para resaltát la fuerza de la contradistinción. Pues a lo largo de toda esta charla me he esforzado por mostrar que las asociaciones puestas de hecho en práctica por la psicología experimental conductista son las asociaciones que he llamado distales, y no las asociaciones por contigüidad, que son en las que los críticos fijan su atención cuando caracterizan al conductismo -atendiendo a las autorrepresentaciones que los propios conductistas nos ofrecieron, sin duda-. La tradición filosófica nos ha mostrado, al menos desde Aristóteles hasta los asociacionistas británicos, varios tipos de asociación: además de las asociaciones por contigüidad (especial), nos han hablado, por lo menos, de asociaciones por semejanza y de asociaciones temporales. Es obvio que con estas dos últimas con las que tienen que ver las asociaciones distales, que, como me he esforzado por mostrar, son las que de hecho se construyen en los diseños experimentales psicológicos. Así pues, las presencias o "presentaciones" distales son ya, de entrada, aun en sus casos más simples, re-presentaciones, pues la más simple presencia mental es re-presentación. Por descontado que, entre las más simples presencias mentales (con las que trabajó el conductismo, sin duda) y las muy complejas representaciones simbólicas del lenguaje media un trecho muy largo. En absoluto lo niego: cuando los psicólogos cognitivos estudian procesos simbólicos, laboran en mecanismos psicológicos (mentales, por descontado) mucho más complejos que los estudiados por los conductistas. Ahora bien, la distancia que media entre unos y otros procesos es un trecho psicológico. $\mathrm{Y}$ si hemos de recorrer e investigar esta distancia por procedimientos psicológico-experimentales, la perspectiva de la incomensurabilidad entre paradigmas se nos of rèce como impertinente para explicar este recorrido de investigación experimental. 
Por lo demás, si el contenido significativo simbólico va a ser prejuzgado desde modelos informáticos, nos volveremos a topar de bruces con la mutua impermeabilidad o - esta vez sí- inconmensurabilidad efectiva entre la lógica de las construcciones formales y la lógica de las construcciones empiricas y experimentales. Naturalmente, ahora sí que podemos hablar de paradigmas distintos. Sólo que en este caso los "paradigmas" distintos enfrentan a la lógica con la psicología.

\section{Notas}

1 Así se expresa Kuhn, en efecto, en su Postdata, de $1969:$ véase en la pág. 280 de la edición castellana (en Fondo de Cultura Económica) de La estructura de las revoluciones científicas, de 1977.

2 Véase, asimismo, en Kuhn, op. cit. (ed. castellana), en la pág. 280. Estas ideas en donde Kuhn nos desglosa el concepto de paradigma en sus diversos componentes se repiten con un contenido conceptual muy semejante en los tres trabajos mencionados, a saber: su Postdata, de 1969; su Respuesta a mis Críticos, de 1970, y su Segundos pensamientos sobre paradigmas, de 1970. En cada caso citaré algunos de estos trabajos.

3 KUHN: op. cit. (ed. castellana), pág. 280.

4 KuHN: Segundos pensamientos sobre paradigmas, en la pág. i 6 de la edición castellana (Tecnos), de $197^{8}$.

5 KUHN: Postdata, en la pág. 283 de la edición castellana, de 1977.

6 Ibid., págs. 283 y ss.

7 KuHN: Respuesta a mis Criticos, en la pág. 441 de la edición castellana de Critica y desarrollo del conocimiento (Lakatos y Musgrave) (Grijalbo), de 1975 .

8 KUHN: Postdata, en la pág. 280 de la edición castellana.

9 Ibid., pág. 286.

10 Ibid., págs. 286 y 287 .

11 Ibid., pág. 287.

12 Pueden encontrarse estas ideas, con algún desarrollo mayor del que aqui he esbozado, en cualquiera de los tres trabajos que vengo considerando.

13 MASTERman: La naturaleqa de los paradigmas (1970), en la pág. i69 de la edición castellana de Crítica $y$ desarrollo del conocimiento, de 1975 .

14 KuHN: Respuesta a mis Criticos, en la pág. 442 de la edición castellana de Critica y desarrollo del conocimiento, de 1975 .

15 KunN: Posddata, en las págs. 287 y 288 de la edición castellana, de 1977.

16 KUHN: Respuesta a mis Criticos, en las págs. 446 y ss. de la edición castellana de Critica y desarrollo del conocimiento, de 1975 .

17 KuHN:, Postdata, pág. 292 de la edición castellana.

18 Esta circularidad ha sido denunciada, entre otros, por Masterman en op. cit., pág. 173 de la edición castellana de Critica y desarrollo del conocimiento, de 1975.

19 Lenheny: Historia de la psicología (1980), en la pág. 32 de la edición castellana (Debate), de 1982.

20 LeAHEAY: op. cit., en las págs. 268 y ss. de la edición castellana (Debate), de 1982.

21 Ibid., págs. 446 y 447 . En la caracterización de este autor, la lista de «ismos» es la siguiente: «monismo físico", "periferialismo", "emprismo», «asociacionismo", "continuidad filogenética» (entre las diversas especies) y "positivismo». Como se ve, y como suele ser usual, un puñado de notas, metodológicas unas y teóricas las otras, que vendrían a componer el paradigma o modelo previo del conductismo.

22 Ibid., pág. 447 .

23 Ibid., pág. 440 .

24 Ibid., pág. 448 .

25 Ibid., págs. 44 y 45 .

26 Ibid., pág. 44 .

27 Ibid., págs. 45 y ss.

28 Esta caracterización que aquí esbozo lo es de la ponencia que el profesor Ruiz Vargas leyó en el II Congreso de Teoria y Metodologia de las Ciencias, celebrado en Oviedo del 4 al 9 de abril de 1983 , bajo el título de El procesamiento bumano de la información como modelo de conducta.

29 Fuentes ORTEga: "Las aportaciones de la Psicología al II Congreso de Teoría y Metodología de las Ciencias", Estudios de Psicología, núms. 14-15, págs. 195-219, 1983. Aquí puede encontrarse una caracterización y una crítica un poco más detallada de las posiciones epistemológicas que los profesores Ruiz Vargas y Zaccagnini realizaron en este congreso, asi como una presentación crítica general de la polémica epistemológica desarrollada por los psicólogos en el mismo. Por lo demás, me complace indicar que en el texto definitivo del profesor Zaccagnini correspondiente a su conferencia de estas jornadas - texto que Zaccagnini ha tenido la amabilidad de poner a mi disposición antes de que yo concluya la redacción definitiva del presente texto- se hacen algunas puntualizaciones en relación con mi crítica muy relevantes para conocer el alcance y sentido de la misma, asi como de la propia polémica. 


\section{Estudios}

$30 \mathrm{KOCH}$ : Pycbology and emerging conceptions of knowledge as unitary, The University of Chicago Press, Chicago and London, 1964 .

31 Buss: "The Structure of psychological revolutions", Joumal of the History of the Bebavioural Sciences, 14 (1978), págs. $17-64$

32 Por lo demás, no es menos cierto que esta posibilidad de evadir el contraste empirico que siempre tiene una teoria por procedimientos puramente lógicos ya fue explícitamente reconocida por Popper. Como es sabido, frente a esta "estratagema convencionalista» (como Popper la llamara), Popper propone aplicar una decisión metodológica que neutralice a la no menos metodológica decisión que supone la estratagema convencionalista: hacer refutable a la teoria de todos los modos posibles. (Véase, por ejemplo, en Popper, La lógica de la investigación cientifica, en las págs. 78 y ss. de la edición castellana - Tecnos-, de 1971.) Sin duda, que es sumamente significativo que tampoco el isomorfismo entre lenguaje y experiencia implicado por el justificacionismo formalista (o logicista) del neopositivismo (en donde, por descontado, cabe incluir a Popper) acabe por resolver el contacto entre el lenguaje y la experiencia (ni por vías negativas, falsacionistas, como en Popper). Tan significativo, en efecto, que no otra cosa, sino la definitiva bancarrota del positivismo lógico, parece ser el que Popper tenga que recurrir, para bacer valer a las relaciones lógicas como criterio epistemológicn, a la instancia de las decisiones motóúóügicas de naturaieza extralógica (recuérdese la apelación de este autor al "veredicto de un jurado» para hacer comprensibles las decisiones o convenciones que los científicos toman en el curso de una investigación —en las págs. Io4 y ss. de la edición castellana de la Lógica de la Investigación Cientifica-). En efecto: ¿qué es lo que ha añadido de sustancial la nueva filosofia de la ciencia pospopperiana que no estuviese ya contenido en esta suerte de inexorable abandono de la justificación lógica de la razón que implica la apelación de Popper al «veredicto de un jurado»?: no parece exagerado contestar que nada. No sólo Lakatos; también el propio Kuhn, e incluso Feyerabend, están ya epistemológicamente contenidos en este recurso popperiano.

33 ARISTÓTEles: Segundos Analiticos, II, I9.

34 Como ahora señalaré, Kant nos dejó en su Crítica de la Razón Pura una caracterización ejemplar del razonamiento apagógico, si bien no es menos cierto que su autor desestimó en buena medida a este tipo de razonamiento por las razones que también ahora indicaré.

35 Los patrones de retroducción, de Hanson, constituyen, sin duda, un interesante esfuerzo por extraer las posibilidades epistemológicas contenidas en la inferencia apagógica. Peirce, por su parte, también dedicó notable importancia a este tipo de argumento, en coherencia con su perspectiva filosófica pragmática en su Collected Papers, vol. VI.

36 KanT: Crítica de la Razón Pura, pág. 261 de la edición castellana (Alfaguara) de 1978.

37 REICHENBACH: por ejemplo, nos decía en su The rise of scientific Pbilosopby (significativamente, en la obra en donde este autor acuña los términos "contexto de justificación» y "contexto de descubrimiento») «El acto del descubrimiento escapa al análisis lógico; no existen reglas lógicas mediante las cuales pueda constituirse una «máquina descubridora» que asuma las funciones del genio. Mas la tarea del lógico no es dar razón de los descubrimientos científicos; todo lo que le incumbe hacer es analizar la relación existente entre los hechos dados y una teoría que se presente con la pretensión de explicarlos" (Reichenbach, op. cit., I951, c. XIV).

38 ReICHenbaCH: Experience and prediction, 1938, Chicago, Univ. Press.

39 Hanson: Patrones de descubrimiento, 1958, Cambridge, Univ. Press.

40 Hanson: op. cit., eń pág. ros y ss. de la edición castellana (de Alianza) de 1977.

41 Como por lo demás ya advirtiera Popper en La lógica de la investigación científica; véase en pág. 90 de la edición castellana de 1971 .

42 BUENO: «En torno al concepto de Ciencias Humanas. La distinción entre metodologías $\alpha$-operatorias y ß-operatorias». El Basilisco, pág. 27 y ss.

${ }_{43}$ BaCON: por ejemplo, se expresaba así en su Novum Organum I,4: “An opera nil aliud potest homo, quam ut corpora naturalia admoveat et amoveat; reliqua Natura intus transigit». Asi tambièn, por ejemplo, en Locke, An Essay Concernig Human Understanding, lib. II, cap. I 2.

44 BuNGE: The mind-body problem. A Psycbobiological approach. Pergamon, Oxford, 1980.

45 FODOR: Psychological explanation. An introduction to the philosopby of psychology, 1968, Random House. Véase en la pág. I i de la edición castellana (Cátedra) de 1980.

46 MAC COQUODAle y MEEHL: "On a distinction between hypothetical constructs and intervening variables", Psycbological Review, 1948, 55, págs. 95-107.

47 KOCH: op. cit., pág. 17.

48 HEIDER: «Enviromental determinants in psycological theories», Psychological Review, 46, págs. 38 3-410.

49 PAulov: Conferencia sobre la actividad de ias principales glandulas digestivas, I. Conferencia, 1897 . Véase, por ejemplo, lo que nos dice Paulov en la primera de estas conferencias: «Me parece que entre los métodos modernos de la fisiología el método quirúrgico debe reforzar sus posiciones (lo opongo a la vivisección pura). Quiero hablar de la realización de operaciones más o menos complicadas (lo que es un arte), operaciones que tienen como meta, o bien la ablación de órganos, o bien la apertura de una vía de acceso a los fenómenos fisiológicos que se desarrollan invisiblemente en el interior del cuerpo, la supresión de conexiones entre los órganos o, al contrario, el establecimiento de nuevos lazos, etc..., para, finalmente, en tanto que la operación lo permita, curar al animal y devolverlo a su estado normal. La propaganda del procedimiento operatorio me parece muy necesaria, ya que la simple disección del animal en el transcurso de una experiencia aguda, como evidenciamos cada día más, comprende una fuente de errores groseros. 
Este acto de corimoción brutal del organismo va acompañado de multitud de influencias suspensivas sobre las funciones de los distintos órganos. El organismo realiza la conexión más delicada y más racional entre un gran número de partes diferentes y no puede, pues, por su propia naturaleza, permanecer indiferente a los agentes destructores... Si esta circunstancia fue y continúa siendo una traba en la fisiología analítica, constituye un obstáculo insuperable para el desarrollo de la fisiología sintética, que tiene como meta el determinar el curso exacto de los diferentes fenómenos fisiológicos del organismo intacto y normal.» Véase en Paulov, Actitud nerviosa superior, Obras escogidas. Ed. Fontanella, 1982, págs. 72-73.

50 Hull: Principles of behavior, 1943, Appleton, Nueva York.

51 En este trabajo de 1935 dice Skinner lo siguiente: "Supongamos que estamos estudiando un organismo como, por ejemplo, una rata que presiona una palanca. El número de actos distinguibles por parte de la rata que dan lugar al movimiento de la palanca es indefinido y muy amplio. Excepto en ciertos casos extraños, constituyen una clase suficientemente bien definida por la frase "apretar la palanca...". La uniformidad del cambio de tasa excluye cualquier suposición de que estemos ocupándonos de un grupo de reflejos separados y fuerza la conclusión de que "presionar la palanca" es una cosa que procede experimentalmente como algo unitario.» Véase en págs. \& 1 s y \$16 de la edición castellana de Registro Acumulativo (en Fontanella) de i975.

52 Lachman, Lachman y BuTterfield: Cognitive Psychology and Information Processing, An Introduction, 1979, págs. 42 y ss.

\section{Referencias}

Aristóteles: Segundos Analíticos.

BACON, F. (1620): Novum Organum Scientiarum.

BUENO, G. (1972): “En tomo al concepto de "Ciencias Humanas". La distinción entre metodologías $\alpha$-operatorias y $\beta$-operatorias». El Basilisco, núm. 2, mayo-junio, págs. 12-46.

Bunge, M. (1980): The Mind-body problem. $A$ psycbobiological approach. Pergamon, Oxford.

Buss, A. R. (1978): "The structure of psychological revolutions", Journal of the History of the Bebavioaral Sciences, 14, págs. 57-46.

FODOR, J. (1968): Psycbological explanation. An introduction to the philosopby of psychology. Randon House, Inc. (La explicación psicológica. Introducción a la filosofía de la psicologia. Madrid, Cátedra, 1980).

Fuentes ORTEga, J. B. (1983): «Las aportaciones de la Psicología al II Congreso de Teoría y Metodología de las Ciencias». Estudios de Psicologia, núms. 14-1 s, págs. I95-2 I5.

Hanson, N. (1958): Patterns of Discovery. Cambridge University Press, Cambridge (Patrones de Descubrimiento. Madrid, Alianza Ed., 1977).

HeIDER, F. (1939): «Enviromental determinants in psychological theories». Psychol. Review, 46, págs. 383-410.

Hull, C. L. (1943): Principles of bebavior. Appleton, Nueva York.

KANT, I. (1781): Kritik der reinen Vernunft (La Crítica de la razón pura. Madrid, Alfaguara, 1978).

$\mathrm{KOCH}, \mathrm{S}$. (1964): "Psychology end emerging conceptions of knowledge as unitary», en Bebaviorism and pbenomenology (T. W. Wann, ed.), The University of Chicago Press, Chicago and London.

KuHN, T. S. (1962): The Structure of scientific revolutions. University of Chicago Press, Chicago (La Estructura de las revoluciones cientificas. Madrid, F.C.E., 1971 ).

KuHN, T. S. $(1969)$ : Postscript, en The Structure of scientific revolutions, University of Chicago Press, Chicago, $197^{\circ}$ (Postdata, en La estructura de las revoluciones cientificas. Madrid, F.C.E., 1971).

KUHN, T. S. (1 970a): "Reflections on my critics», en Criticism and the growth of knowledge, Lakatos y Musgrave (eds.), Cambridge University Press, Cambridge (Critica y desarrollo del conocimiento. Barcelona, Grijalbo, 1975).

KUHN, T. S. (1970b): “Second thoughts on paradigms», en The Structure of scientific theories, Suppe, F. (ed.), The University of Illinois Press, Urbana (La estructura de las teorias cientificas, Madrid, Ed. Nacional, 1979). ("Segundos pensamientos sobre paradigmas", Madrid, Tecnos, 1978).

LACHMAN, R.; LACHMAN, J. L., y ButTerfiel.D, E. C. (1979): Cognitive Psycbology and information processing. An Introduction. L.E.A. Publis., New Jersey.

LeAhey, T. (1980): A History of Psycbology. Prentice-Hall, Inc. (Historia de la Psicologia. Madrid, Debate, 1982).

LOCKE, J. (1690): An Essay concerning buman understanding.

MAC CoRquodale, K., y MEEHL, P. E. (1948): "On a distinction between hypothetical constructs and intervening vriables). Psycbol. Rev., 55, 95-107.

MaCKENZY, B. D. (1977): Bebaviourism and the limits of scientific metbod. Routledge and Kegan Paul, London and Henley.

Masterman, M. (1970): "The Nature of a Paradigm", en Criticism and the growth of knowledge, Lakatos y Musgrave eds., Cambridge University Press, Cambridge (Critica y desarrollo del conocimiento. Barcelona, Grijalbo, 1975).

Paulov, I. P. (1897): Conferencias sobre la actividad de las principales glandulas digestivas. (PAulov, I. P., Actividad nerviosa superior. Barcelona, Fontanella, 1973). 


\section{Estudios}

POPPER, R. K. (1935): Logik der Forscbung. J. Springer, Wien. (La lógica de la investigación cientifica. Madrid, Tecnos, 1962).

Peirce, C. (1935): Collected Papers, vol. s, Ed. C. Hortshome, P. Weiss, Harvard University Press, Harvard. ReIChENBaCH, H. (1938): Experience and prediction. Chicago University Press, Chicago.

ReICHENBACH, H. (19:1): The rise of scientific pbilosopby. University of California Press, Berkeley and Los Angeles (La filosofia cientifica. Madrid, F.C.E., I953).

Ruiz-VARGAS, J. M.; ZaCCAGNiNI, J. L., y DelClaux, I. (1983): «El procesamiento humano de información como modelo de conductan, II Congreso de Teoria y Metología de las Ciencias, Oviedo, 4-9 de abril, 1983 (Actas en prensa).

Stevens, S. S. (1939): «Psychology and the science of science». Pyycbol. Bulletin, 36, págs. 22 1-263.

SKINNER, B. F. (1931): "The concept of the reflex in the description of behavion). Journal of General Psycbology, 3, págs. 427-458. ("El concepto de reflejo en la descripción de la conducta», en Registro Acumulativo. Barcelona, Fontanella, 1975).

SKINNER, B. F. (1935): «The generic nature of the concepts of stimulus and response». Journal of general Psycology, 1 2, págs. 40-6) ("La naturaleza genérica de los conceptos de estímulo y respuesta", en Registro Acumulativo. Barcelona, Fontanella, 1975).

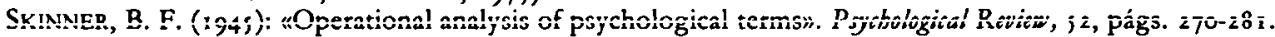
( El análisis operacional de los términos psicológicos», en Registro Acumulativo. Barcelona, Fontanella, 1975).

SKINNER, B. F. (1950): «¿Are theories of learning necessary?». Psycbological Review, 57, págs. 193-216 («¿Son necesarias las teorias del aprendizaje?", en Registro Acumulativo. Barcelona, Fontanella, 1975).

SkinNer, B. F. (1956): "A case history in scientific method». American Psychologist, 25, págs. 47-6s ("Un caso dentro del método científico», en Registro Acumulativo. Barcelona, Fontanella, 1975). 